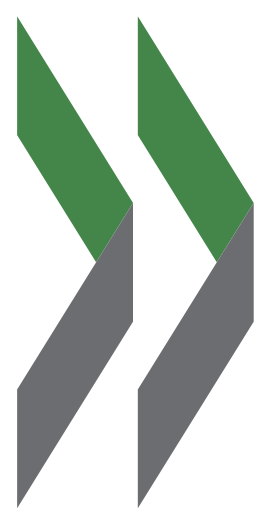

OECD Reviews on Local Job Creation

\title{
Employment and Skills Strategies in Ireland
}
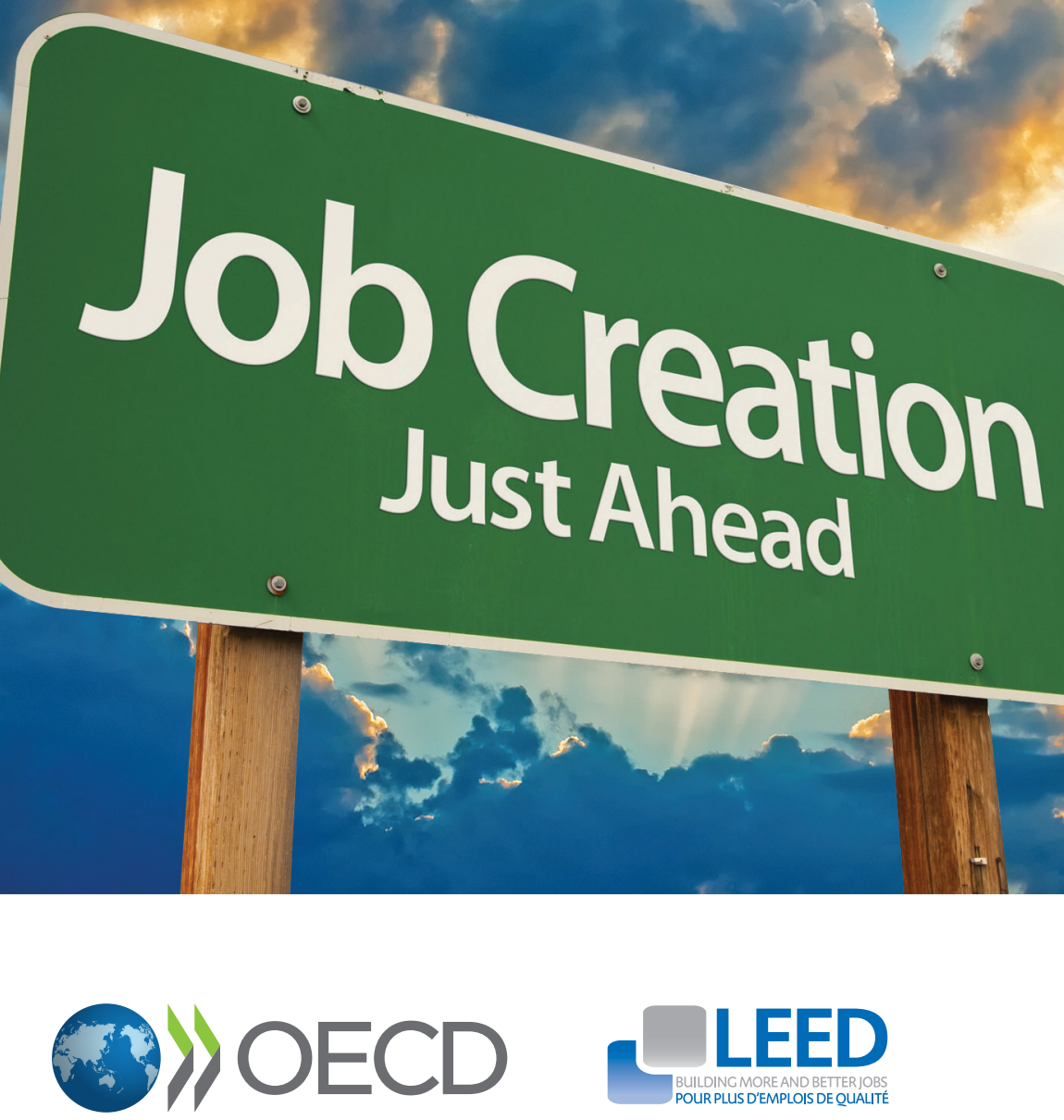

OECD Reviews on Local Job Creation

\section{Employment and Skills Strategies in Ireland}


This work is published on the responsibility of the Secretary-General of the OECD. The opinions expressed and arguments employed herein do not necessarily reflect the official views of the OECD or of the governments of its member countries.

This document and any map included herein are without prejudice to the status of or sovereignty over any territory, to the delimitation of international frontiers and boundaries and to the name of any territory, city or area.

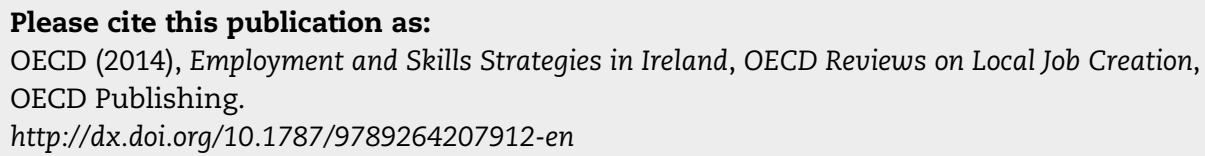

ISBN 978-92-64-20790-5 (print)

ISBN 978-92-64-20791-2 (PDF)

OECD Reviews on Local Job Creation

ISSN 2311-2328 (print)

ISSN 2311-2336 (online)

The statistical data for Israel are supplied by and under the responsibility of the relevant Israeli authorities. The use of such data by the OECD is without prejudice to the status of the Golan Heights, East Jerusalem and Israeli settlements in the West Bank under the terms of international law.

Photo credits: Cover ๑ Andy Dean Photography/Shutterstock.com, ๑ kosmos111/Shutterstock.com.

Corrigenda to OECD publications may be found on line at: www.oecd.org/about/publishing/corrigenda.htm.

(c) OECD 2014

You can copy, download or print OECD content for your own use, and you can include excerpts from OECD publications, databases and multimedia products in your own documents, presentations, blogs, websites and teaching materials, provided that suitable acknowledgment of the source and copyright owner is given. All requests for public or commercial use and translation rights should be submitted to rights@oecd.org. Requests for permission to photocopy portions of this material for public or commercial use shall be addressed directly to the Copyright Clearance Center (CCC) at info@copyright.com or the Centre français d'exploitation du droit de copie (CFC) at contact@cfcopies.com. 


\section{Foreword}

A

cross the OECD, policy-makers are grappling with a critical question: how to create jobs? The recent financial crisis and economic downturn has had serious consequences across most OECD countries, with rising unemployment rates and jobs being lost across many sectors. Indeed, for some countries, the effects the downturn brought with it are continuing, if not amplifying. Shrinking public budgets in some countries also mean that policy makers must now do more with less. In this context, it is necessary to think laterally about how actions in one area, such as employment and training, can have simultaneous benefits in others, such as creating new jobs and better supporting labour market inclusion.

Over recent years, the work of the OECD LEED Programme on Designing Local Skills Strategies, Building Flexibility and Accountability into Local Employment Services, Breaking out of Policy Silos, Leveraging Training and Skills Development in SMEs, and Skills for Competitiveness has demonstrated that local strategies to boost skills and job creation require the participation of many different actors across employment, training, economic development, and social welfare portfolios. Employers, unions and the non-profit sector are also key partners in ensuring that education and training programmes provide the skills needed in the labour markets of today and the future.

The OECD Reviews on Local Job Creation deliver evidence-based and practical recommendations on how to better support employment and economic development at the local level. This report builds on sub-national data analysis and consultations at the national level and with local stakeholders in two case study areas. It provides a comparative framework to understand the role of the local level in contributing more and better quality jobs. The report can help national, regional and local policy makers in Ireland build effective and sustainable partnerships at the local level, which join-up efforts and achieve stronger outcomes across employment, training, and economic development policies. Co-ordinated policies can help workers find suitable jobs, while also stimulating entrepreneurship and productivity, which increases the quality of life and prosperity within a community as well as throughout the country.

I would like to warmly thank the Department of Social Protection, Department of Children and Youth Affairs, Department of the Environment, Community and Local Government, Department of Jobs, Enterprise and Innovation, Department of Education and Skills, and Pobal for their active participation and support of the study.

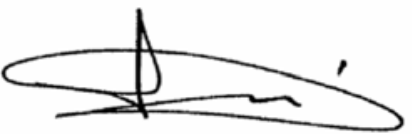

Sergio Arzeni,

Director, OECD Centre for Entrepreneurship,

SMEs and Local Development 


\section{Acknowledgments}

$T_{h}$ his review has been written by the Local Economic and Employment Development (LEED) Programme of the Organisation for Economic Co-operation and Development (OECD) as part of a project undertaken in co-operation with the Department of Social Protection, Department of Children and Youth Affairs, Department of the Environment, Community and Local Government, Department of Jobs, Enterprise and Innovation, Department of Education and Skills, and Pobal. This project is part of the OECD LEED programme of work under the leadership of Sylvain Giguère.

The principal authors are John Sweeney, Senior Social Policy Analyst, National Economic and Social Council; Jonathan Barr, Policy Analyst, OECD and Lucy Pyne, Consultant, OECD. The authors would like to thank Francesca Froy, Senior Policy Analyst, OECD; Ekaterina Travkina, Senior Policy Analyst, OECD; and Debra Mountford Senior Policy Analyst, OECD for their valuable comments on the report. Thanks also go to Michela Meghnagi for her work on the data analysis, as well as Elisa Campestrin, François Iglesias, Malika Taberkane and other colleagues in the OECD LEED Programme for their assistance with this report.

Pobal played a key role in assisting the OECD Secretariat in all aspects of preparing this report, including arranging study visits, providing relevant material, and offering feedback. In particular, thanks go to Denis Leamy, Jerry Murphy, and Emma Rorke. AIRO generously provided the GIS maps included in this report.

The authors would also like to acknowledge the valuable contributions of Thomas Townsend (Visiting Researcher, University of Ottawa), Hilary Steadman (Research Associate, Centre for Economic Performance, London School of Economics), Dermot Stokes (former National Coordinator, Youthreach), and Neil MacCallum (Principal, Neil MacCallum Associates) for their participation on the project study visit and on-going contributions to this report.

Finally, special thanks are given to the national and local representatives who participated in the project interviews and roundtables, and provided documentation and comments critical to the production of the report. 


\section{Table of contents}

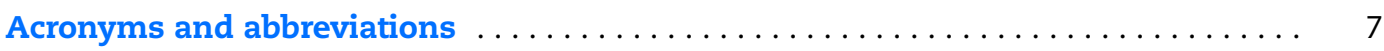

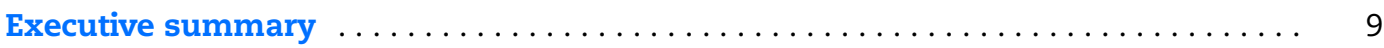

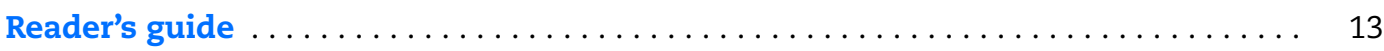

Chapter 1. Policy context for employment and skills in Ireland $\ldots \ldots \ldots \ldots \ldots \ldots \quad 17$

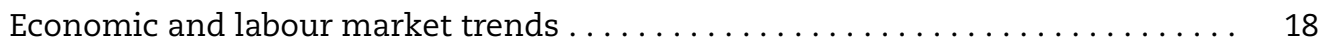

National policy context: A period of on-going reforms $\ldots \ldots \ldots \ldots \ldots \ldots \ldots 20$

Overview of employment policies and programmes $\ldots \ldots \ldots \ldots \ldots \ldots \ldots \ldots 21$

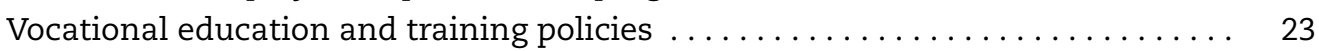

Economic development and regional governance $\ldots \ldots \ldots \ldots \ldots \ldots \ldots \ldots . \ldots \ldots$

Notes. . . . . . . . . . . . . . . . . . . . . . . . . . . . . . . . . . . . . . . . . . . . 30

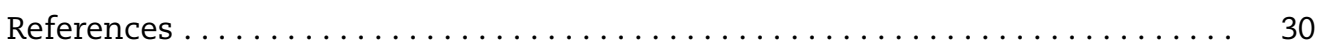

Chapter 2. Overview of the Irish case study areas $\ldots \ldots \ldots \ldots \ldots \ldots \ldots \ldots \ldots \ldots \ldots$

Overview of the Dublin and South East regions $\ldots \ldots \ldots \ldots \ldots \ldots \ldots \ldots \ldots \ldots$

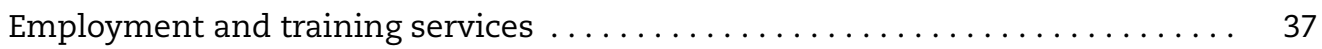

Balance between skills supply and demand at the sub-national level . . . . . . 40

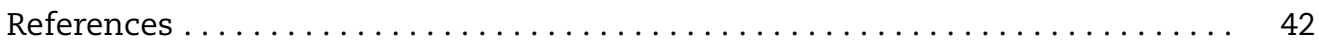

Chapter 3. Local Job Creation dashboard findings in Ireland $\ldots \ldots \ldots \ldots \ldots \ldots .43$

Theme 1: Better aligning policy and programmes to local economic development 45

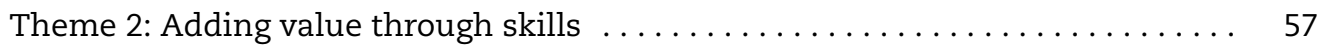

Theme 3: Targeting policy to local employment sectors and investing

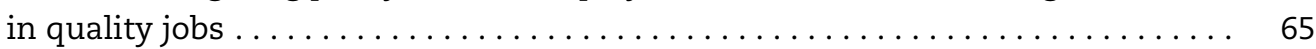

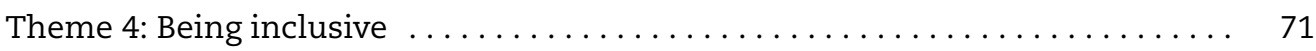

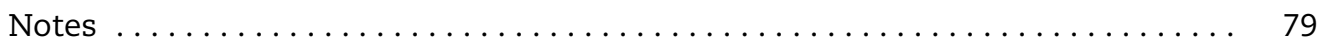

References ........................................ 80

Chapter 4. Towards an action plan for jobs in Ireland: Recommendations

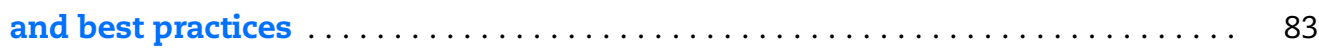

Better aligning programmes and policies to local economic development .... 84

Adding value through skills . ................................ 92

Targeting policy to local employment sectors and investing in quality jobs ... 96

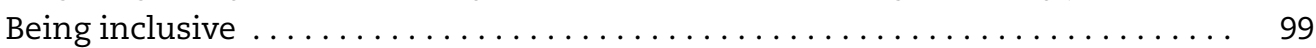

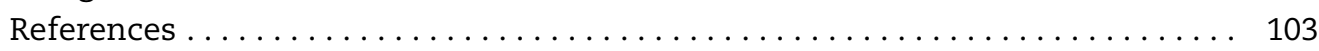

Annex A. Information on interviews and roundtables in Ireland . . . . . . . . . 105

Annex B. Spatial distribution of skills supply and demand in Ireland . . . . . . . . . 108 
Tables

1.1. Employment services: Pre and post-reform $\ldots \ldots \ldots \ldots \ldots \ldots \ldots \ldots \ldots 23$

1.2. Vocational education and training: Pre and post-reforms $\ldots \ldots \ldots \ldots \ldots 25$ Figures

1.1. Sources of economic growth in the Irish economy, 2008-15, \% . . . . . . . 18

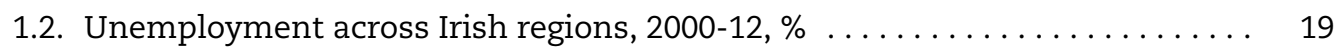

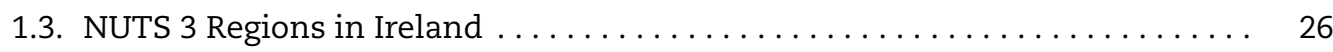

2.1. Maps of the Dublin and South East regions $\ldots \ldots \ldots \ldots \ldots \ldots \ldots \ldots . . \ldots \ldots$

2.2. Employment by broad occupation in Dublin and South East regions, Q1 2012, \% . . . . . . . . . . 35

2.3. Unemployment rate, Dublin region, $2011 \ldots \ldots \ldots \ldots \ldots \ldots \ldots \ldots \ldots \ldots \ldots$

2.4. Unemployment rate, South East region, $2011 \ldots \ldots \ldots \ldots \ldots \ldots \ldots \ldots$

2.5. Understanding the relationship between skills supply and demand ...... 40

2.6. Balancing skills supply and demand in Ireland, $2012 \ldots \ldots \ldots \ldots \ldots \ldots \ldots$

3.1. Overview of results from Local Job Creation dashboard ............. 44

3.2. Dashboard results: Better aligning programmes and policies

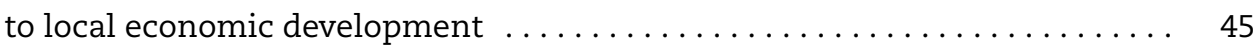

3.3. Employment offices with sufficient, adequate and insufficient capacities, \% 49

3.4. Offices reporting collaboration with other agencies and organisations, $\% \quad \ldots \quad 51$

3.5. Dashboard results: Adding value through skills ............... 57

3.6. Dashboard results: Targeting policy to local employment sectors

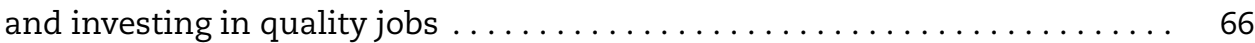

3.7. Dashboard results: Being inclusive $\ldots \ldots \ldots \ldots \ldots \ldots \ldots \ldots \ldots \ldots \ldots \ldots$

B.1. \% of population with post-secondary education, South East region, $2011 \ldots 108$

B.2. \% of population with post-secondary education, Dublin region, 2011 . . . . . 109

B.3. High-medium skill occupations, South East region, $2011 \ldots \ldots \ldots \ldots \ldots \ldots . . . \ldots 110$

B.4. High-medium skill occupations, Dublin region, $2011 \ldots \ldots \ldots \ldots \ldots \ldots$

\section{Follow OECD Publications on:}

http://twitter.com/OECD_Pubs

http://www.facebook.com/OECDPublications

http://www.linkedin.com/groups/OECD-Publications-4645871

http://www.youtube.com/oecdilibrary

http://www.oecd.org/oecddirect/ 


\section{Acronyms and abbreviations}

$\begin{array}{ll}\text { AIRO } & \text { All-Island Research Observatory } \\ \text { ALMP } & \text { Active labour market programmes } \\ \text { BTEI } & \text { Back to Education Initiative } \\ \text { BTWEA } & \text { Back to Work Enterprise Allowance scheme } \\ \text { DECLG } & \text { Department of the Environment, Community and Local Government } \\ \text { DES } & \text { Department of Education and Skills } \\ \text { DJEI } & \text { Department of Jobs, Enterprise and Innovation } \\ \text { DSP } & \text { Department of Social Protection } \\ \text { EGFSN } & \text { Expert Group on Future Skills Needs } \\ \text { FÁS } & \text { National Training and Employment Authority } \\ \text { FETAC } & \text { Further Education and Training Awards Council } \\ \text { GDA } & \text { Greater Dublin Area } \\ \text { IBEC } & \text { Irish Business and Employers Confederation } \\ \text { IDA } & \text { Industrial Development Authority, Ireland } \\ \text { Intreo } & \text { New employment and support service } \\ \text { IRIS } & \text { Irish Reporting and Information System } \\ \text { LCDP } & \text { Local and Community Development Programme } \\ \text { LDC } & \text { Local Development Company } \\ \text { LESN } & \text { Local Employment Service Network } \\ \text { NEAP } & \text { National Employment Action Plan } \\ \text { NFQ } & \text { National Framework of Qualifications } \\ \text { NFTE } & \text { Network for Teaching Entrepreneurship } \\ \text { PES } & \text { Public Employment Service } \\ \text { PLC } & \text { Post-Leaving Certificate } \\ \text { QQI } & \text { Qualifications and Quality Ireland } \\ \text { SCP } & \text { Schools Completion Programme } \\ \text { SEC } & \text { Socio-Economic Committee } \\ \text { SLMRU } & \text { Skills and Labour Market Research Unit } \\ \text { SOLAS } & \text { Further Education and Training Authority } \\ \text { STEA } & \text { Short-term Enterprise Allowance } \\ \text { VEC } & \text { Vocational Education Committee } \\ \text { VET } & \text { Vocational education and training } \\ \text { VTOS } & \text { Vocational Training Opportunities Scheme } \\ \text { WIT } & \text { Waterford Institute of Technology } \\ & \end{array}$





\section{Executive summary}

$S$ imilar to other OECD countries, the recent economic crisis had a significant impact on Ireland and many of the jobs lost during this period have still not been recovered. As articulated in Ireland's Action Plan for Jobs, getting people back to work is a top priority for the government, which has set an ambitious target of 100000 more people in work by 2016 and 2 million people in work by 2020.

The OECD Local Economic and Employment Development (LEED) Programme has developed its reviews on Local Job Creation as an international cross-comparative study examining the contribution of local labour market policy to boosting quality employment and productivity. In Ireland, the review was undertaken time of significant institutional reform. It has looked at the range of institutions and bodies involved in employment and skills policies, focusing on local activities in the Dublin and South East regions.

Local employment and training agencies can play an integral role in creating strategies to boost job creation and increase productivity, but only when effectively integrated with economic development. In Ireland, the reform process represents a unique opportunity to provide local employment and training providers with greater flexibility in the management of their programmes and services within a national accountability framework. This would enable local offices to be more innovative in how they respond to their specific local labour market needs.

Policy co-ordination and integration could be strengthened in Ireland through stronger local partnerships and governance structures. This could lead to more information sharing and the identification of common objectives and strategic initiatives to promote local economic development and growth. Better use of information and data at the sub-national level can help bring local partners together in assessing which labour market interventions are successful. Both youth and adults need information on job opportunities in the local economy and the career progression opportunities available once employed. This requires local labour market intelligence on where new jobs are being offered and articulated career pathways within sectors.

Certain groups in Ireland have been disproportionately impacted by the crisis. A greater focus needs to be placed on youth, as inactivity at a young age has serious repercussions on individuals for the rest of their lives. While the government is advancing the adoption of a Youth Guarantee, action in this area requires a more co-ordinated policy framework, which brings together key government departments and sets out the role of regions and local stakeholders.

Employers have a defining role to play in any local skills system. Ireland has recognised this by introducing a new employer engagement strategy within Intreo, which will be a critical element in creating a more responsive employment service. Education and 
Training Boards will have strong connections with employers to ensure training providers have detailed information on local demand. Furthermore, the apprenticeship system is being reformed to open it up to a broader array of sectors and to more young people - a key ingredient in giving young people the chance to gain work-based training.

Attracting inward investment has long been a successful element of Ireland's economy. However, more attention could be placed on the needs of domestic employers in sectors such as retail, health care, education, and energy. This is particularly the case for small to medium sized employers who provide over half of all private sector jobs in Ireland. Many of these companies are on high growth trajectories, but often face challenges in accessing relevant and responsive training. There is a need to focus more on better utilising the skills of those in work. This includes looking at how the workforce is structured and the relationship between the needs of employers and an individual's skills. In other OECD countries, skills utilisation policies have led to increased productivity and profitability for employers and in the past a number of agencies in Ireland had specific mandates to look at these issues.

Key recommendations

\section{Better aligning programmes and policies to local economic development}

- The reform process underway should be seized as an opportunity to give local employment offices greater flexibility to adapt programmes and policies to local labour market conditions, in particular in selecting target groups and designing programmes.

- Ensure that capacity is adequately supported in the new national and local bodies, including potential outsourced employment agencies.

- Policy co-ordination and integration need to be significantly strengthened between actors at all levels. This can be achieved through stronger partnerships and platforms for local collaboration.

- Increase the availability of data at the sub-national level and use it more effectively in policy making, planning, and evaluation to build a stronger evaluation culture.

\section{Adding value through skills}

- Increase the engagement of employers in employment and training services through stronger partnerships and by giving them greater input into the design and delivery of programmes, including potential new apprenticeship and traineeship models.

- Ensure adequate career guidance and information on pathways is available for both youth and adults, informed by local labour market intelligence.

\section{Targeting policy to local employment sectors and investing in quality jobs}

- Develop policies, which encourage the better utilisation of skills and examine the role that the Education and Training Boards can play in this area.

- Support professional development by putting in place career ladders for lower skilled people to make it easier to move into higher skilled positions. 


\section{Being inclusive}

- Youth need to become a greater policy priority. A national youth employment strategy should be created and conditions should be put in place to support the emergence of integrated place-specific strategies for youth.

- Retain a focus on targeting the most disadvantaged at the local level to prevent longterm unemployment from becoming structural and inter-generational. There is scope to make greater use of public procurement and social enterprise models in this area. 



\section{Reader's guide}

$\mathrm{T}_{\mathrm{h}}$ he Local Job Creation project involves a series of country reviews in Australia, Belgium (Flanders), Canada (Ontario and Quebec), Czech Republic, France, Ireland, Israel, Italy (Autonomous Province of Trento), Korea, Sweden, the United Kingdom and the United States (California and Michigan). The key stages of each review are summarised in Box 1.

\section{Box 1. Summary of the OECD LEED Local Job Creation Project Methodology}

- Analyse available data to understand the key labour market challenges facing the country in the context of the economic recovery and apply an OECD LEED diagnostic tool which seeks to assess the balance between the supply and demand for skills at the local level.

- Map the current policy framework for local job creation in the country.

- Apply the local job creation dashboard, developed by the OECD LEED Programme (Froy et al., 2010) to measure the relative strengths and weaknesses of local employment and training agencies to contribute to job creation.

- Distribute an electronic questionnaire to local employment offices to gather information on how they work with other stakeholders to support local job creation policies.

- Conduct an OECD study visit, where local and national roundtables with a diverse range of stakeholders are held to discuss the results and refine the findings and recommendations.

- Contribute to policy development in the reviewed country by proposing policy options to overcome barriers, illustrated by selected good practice initiatives from other OECD countries.

While the economic crisis is the current focus of policy-makers, there is a need for both short-term and longer-term actions to ensure sustainable economic growth. In response to this issue, the OECD LEED Programme has developed a set of thematic areas on which local stakeholders and employment and training agencies can focus to build sustainable growth at the local level. These include:

1. better aligning policies and programmes to local economic development challenges and opportunities;

2. adding value through skills: Creating an adaptable skilled labour force and supporting employment progression and skills upgrading; 
3. targeting policy to local employment sectors and investing in quality jobs, including gearing education and training to emerging local growth sectors and responding to global trends, while working with employers on skills utilisation and productivity; and,

4. being inclusive to ensure that all actual and potential members of the labour force can contribute to future economic growth.

\section{Local Job Creation dashboard}

As part of the Local Job Creation project, the LEED Programme has drawn on its previous research to develop a set of best practice priorities in each thematic area, which is used to assess local practice through the local job creation dashboard (see Box 2). The dashboard enables national and local policy-makers to gain a stronger overview of the strengths and weaknesses of the current policy framework, whilst better prioritising future actions and resources. A value between 1 (low) to 5 (high) is assigned to each of the four priority areas corresponding to the relative strengths and weaknesses of local policy approaches based on LEED research and best practices in other OECD countries.

\section{Box 2. Local Job Creation dashboard}

\section{Better aligning policies and programmes to local economic development}

1.1. Flexibility in the delivery of employment and vocational training policies.

1.2. Capacities within employment and VET sectors.

1.3. Policy co-ordination, policy integration and co-operation with other sectors.

1.4. Evidence based policy making.

\section{Adding value through skills}

2.1. Flexible training open to all in a broad range of sectors.

2.2. Working with employers on training.

2.3. Matching people to jobs and facilitating progression.

2.4. Joined up approaches to skills.

\section{Targeting policy to local employment sectors and investing in quality jobs}

3.1. Relevance of provision to important local employment sectors and global trends and challenges.

3.2. Working with employers on skills utilisation and productivity.

3.3. Promotion of skills for entrepreneurship.

3.4. Promoting quality jobs through local economic development.

\section{Being inclusive}

4.1. Employment and training programmes geared to local "at-risk" groups.

4.2. Childcare and family friendly policies to support women's participation in employment.

4.3. Tackling youth unemployment.

4.4. Openness to immigration. 


\section{The approach for Ireland}

This study has looked at the range of institutions and bodies involved in workforce and skills development in Ireland. In-depth field work focused on two case study regions: Dublin and the South East. Interviews were conducted with a wide set of stakeholders (see Annex A for a list of those interviewed). An electronic questionnaire was sent to local managers within public employment service offices (the Local Employment Service Offices under the Department of Social Protection) and regional managers in the Local Employment Service (operated by Local Development Companies). It was completed by 46 public employment service offices and 25 Local Employment Services. The questionnaire requested answers based on the current operating context notwithstanding the on-going changes in the operational landscape. In December 2012, two local roundtables were held in each of the case study areas and a national roundtable was held to discuss the findings and recommendations. These meetings brought together a range of national and local stakeholders, including relevant department officials in the fields of employment, economic development, and training; employers; and other local community and social development organisations.

\section{Box 3. Other OECD LEED reviews in Ireland}

In parallel to this review, two additional thematic policy reviews are being carried out by the OECD LEED programme in Ireland - Local Youth Employment Strategies and Delivering Local Development. The Local Strategies for Youth Employment review focuses on how to create the right institutional and policy conditions to promote youth employment at the local level. The Delivering Local Development work examines the local conditions and instruments for policy interventions to achieve successful local economic development in participating countries and localities. This review is assessing the impact of the proposed local government reforms on local economic and community development.

\section{References}

Froy, F., S. Giguère and E. Travkina (2010), Local Job Creation: Project Methodology, OECD Local Economic and Employment Development (LEED), OECD Publishing, Paris. 



\section{Chapter 1}

\section{Policy context for employment and skills in Ireland}

This chapter provides an overview of Ireland's employment and skills system. Ireland's economy was hit by a profound crisis in 2008, after a decade of confident growth, resulting in a contracting economy and high job losses. Rising long-term and youth unemployment have been particularly stubborn. In response to the crisis, significant institutional reforms are underway impacting employment, vocational education and training, and economic development policies. These reforms are a unique opportunity to equip individuals with the necessary skills for long-term labour market success and make services more responsive to the skill needs of the local economy. 


\section{Economic and labour market trends}

The Irish economy was hit by a profound crisis in 2008, after a decade of strong growth which had moved Ireland up to the fourth highest level of GDP per capita in the OECD. Between 2008 and 2010, the economy contracted, strongly impacting all sectors and resulting in severe employment losses. Real GDP growth resumed in 2011 and is forecast to continue rising to 2015 (see Figure 1.1). Net exports have risen since 2008, but their contribution to growth has been almost entirely offset by an on-going contraction in domestic demand. However, domestic demand is improving slowly and is expected to enter positive territory in 2013 - the first time since the recession. Future growth in Ireland will also continue to be impacted by the performance of other countries in the euro area.

\section{Figure 1.1. Sources of economic growth in the Irish economy, 2008-15, \%}

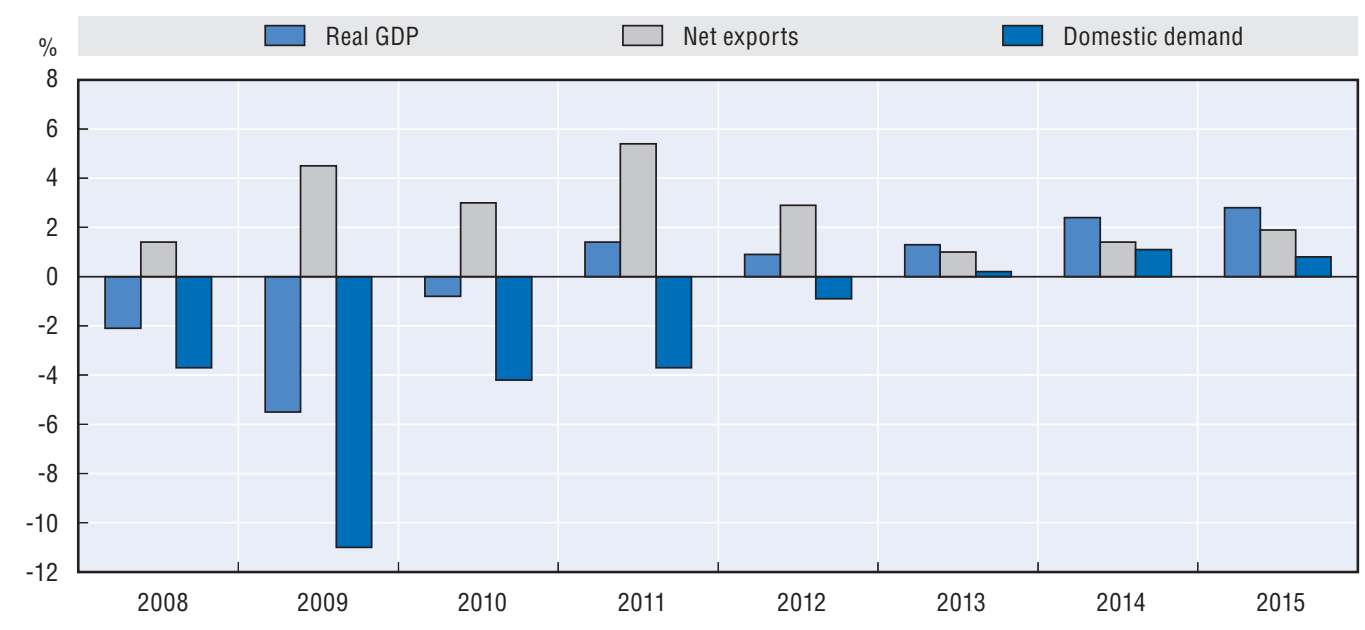

Source: Department of Finance (2013), Irish Stability Programme: April 2013 Update.

During the economic crisis, the employment rate in Ireland decreased from $69 \%$ to $63 \%$, one of the largest falls in the OECD (OECD, 2010). Since 2007, when the peak employment level was reached, the number of jobs has fallen on an annual basis and there has been a cumulative contraction of $15 \%$. This was the result of a sharp contraction in economic activity, particularly in the construction sector, which alone accounted for almost $50 \%$ of the total jobs lost.

Before the crisis the unemployment rate was below 5\%, but since 2008 it has risen rapidly and remained above $14 \%$. Particularly wide differentials in rates of unemployment can be seen by gender, age group (unemployment is two to three times higher for those under 25), nationality (unemployment is six to seven percentage points higher for EU12 nationals than for Irish nationals), and across occupations and skill levels (unemployment for those with the lowest educational qualifications rose by 12 percentage points more than the rate for those with third level qualifications). The long-term unemployment rate 
is above $8 \%$ and has continued to rise even after the aggregate rate stabilised - indeed, in 2012 some $60 \%$ of all the unemployed had been out of work for more than 12 months.

Regional differences can be seen in unemployment rates across Ireland (see Figure 1.2). All regions experienced a steep rise in unemployment between mid-2008 and mid-2009. Since this time, the rise has moderated for some regions, while others continue to experience the impacts of the crisis. In 2012, the Dublin region had the lowest unemployment rate (12\%), while the South East region had the highest in Ireland (18.5\%).

Figure 1.2. Unemployment across Irish regions, $2000-12, \%$

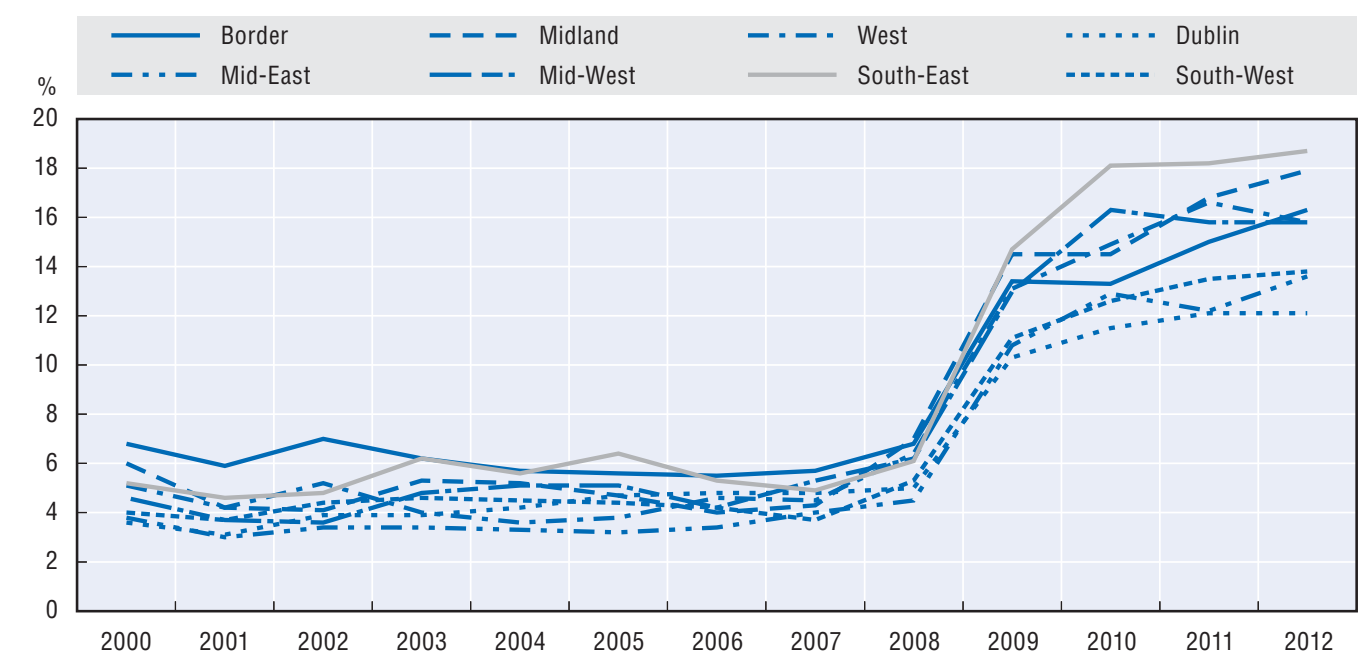

Source: Central Statistics Office Ireland.

\section{Diverging employment tracks: Domestic sector versus exporting sector}

The Irish economy is one of the most open in the world (the value of gross exports in 2012 was equivalent to the country's GDP), with exports concentrated in high-technology manufacturing and knowledge-intensive services. The resilience of demand for much of this output, particularly services, has been a particular strength in the economy's ability to survive a deep and protracted recession. However, the direct employment created by exports is on a modest scale in the context of the country's overall employment needs, and many exporting enterprises recruit employees from abroad to meet their need for high skill workers in particular sectors. The persistent deficit in IT skills at a time of high unemployment is particularly eloquent and it is estimated that some $55 \%$ of the demand for high-level ICT skills is currently met through inward migration (EGFSN, 2012).

Recruitment is continuing to take place in firms serving the domestic market however, much of it is for replacement jobs (which typically outnumber net jobs created by four to one) arising from the high turnover rates that characterise routine service jobs, rather than new jobs. The most recent analysis of gross inflows to employment in 2011 shows that 54\% of individuals went into jobs not requiring advanced qualifications (e.g. into personal and protective service occupations, sales occupations, plant and machinery operation) (DSP, 2012). In the current labour market, there is a large oversupply of labour for these jobs, which is contributing to the discouragement of the long-term unemployed. While those with skills relevant to internationally trading business have better prospects of regaining 
employment, people with relatively low levels of skills, formerly employed in domestic sectors, have lower chances of being re-employed.

\section{Rising youth unemployment}

Young people (age 15-24 years) have experienced a collapse in employment during the recent economic crisis. They took jobs in large numbers during the Celtic Tiger period and the availability of employment at good levels of pay was a strong incentive for some to leave their schooling prematurely. This was particularly the case within the construction sector and for young people in rural areas. Part-time employment became common place in the senior cycle of secondary education and among third level students. Young people tended to be employed in large numbers as shop assistants, bar staff, waiters and in other service sector jobs. When domestic demand collapsed, a high number were left without a job.

Nationally, the youth employment rate fell from over 50\% in 2007 to below $30 \%$ in 2012, one of the largest drops recorded in the EU. The youth unemployment rate more than tripled over the same period, from $9 \%$ to over $30 \%$. Taking into account involuntary parttime work and workers marginally attached to the labour force, the youth unemployment rate is $50 \%$. Compounding this situation, Ireland also has one of the highest levels of young people not in employment, education or training (NEET) in the EU. Many young people have returned to education or are emigrating to other countries for job opportunities. The increase in emigration in Ireland has been almost exclusively concentrated in the 20-24 and 25-34 age groups.

In 2009, benefit payments were reduced for young people. ${ }^{1}$ This lower rate was introduced partly to motivate young claimants to engage in education or training (in which case they receive the full adult rate) and to save money by making parents more responsible for supporting their jobless children. There has been a discernible improvement in the school completion rate and a rise in demand for higher and further education and training places as young people "sit out" the crisis and up-skill/re-skill to improve their chances of finding a job. Ireland has also recently used its 2013 presidency of the EU to advance the adoption of a Youth Guarantee at the European level.

\section{National policy context: A period of on-going reforms}

Significant institutional reforms are underway in Ireland and combined these will have a fundamental impact on policy planning and delivery relating to local job creation (see Box 1.1).

The following section outlines the current policy architecture in each of the three reform areas and the proposed new structures. These reform efforts are on-going and, in some cases, decisions on the redrawn structures have yet to be finalised by the government. 


\section{Box 1.1. Ireland's significant institutional reform effort}

Currently, there are three main reforms happening in Ireland, which will significantly alter the institutional arrangements for employment, vocational education and training, and economic development:

1. Since January 2012, three services-job-matching and job-placement, the administration of benefit, and the design and supervision of active labour market programmes - are being rolled into one integrated service, Intreo, which is designed to adopt a stronger activation approach.

2. The National Training and Employment Authority (FÁS) is being disbanded and replaced by a new body, the Further Education and Training Authority (SOLAS). FÁS's national network of training centres and the country's 33 Vocational Education Committees are being amalgamated into 16 regional Education and Training Boards.

3. Ireland's regional and local government structures are being redrawn, and the city/ county level is being strengthened. The eight Regional Authorities and two higher tier Regional Assemblies are being replaced by three Regional Assemblies through which a slimmed down set of 31 local authorities will work. Local government will assume elements of responsibility for how Ireland's large voluntary and community sector is funded.

\section{Overview of employment policies and programmes}

Employment policy and services in Ireland have been profoundly challenged by the rapid rise in unemployment, the dramatic decline in employment opportunities, and a deep fiscal crisis. The surge in demand for employment related services has created pressures for frontline professionals to reduce the average time they spend with clients on an individual basis with the consequent risk to quality. There is greater heterogeneity among the unemployed; the larger numbers of educated and experienced jobseekers and of nationals from other countries seeking support have necessitated innovation and adaptation in the programmes and supports available.

Until 2012, Ireland's Public Employment Service was the responsibility of the National Training and Employment Authority (FÁS) and that body's parent department, the Department of Jobs, Enterprise and Innovation (DJEI). It was wholly independent of the system of benefit administration operated by the Department of Social Protection (DSP). A "second tier" in public employment services was created in the mid-1990s and is operated by not-for-profit bodies, principally Local Development Companies, under contract from DSP - the Local Employment Service Network (LESN). Local Employment Service offices mainly operate in disadvantaged areas. They source and provide personal development, training, education or placement services as needed. The majority of activity is with clients referred by DSP.

Before the crisis, there were concerns being expressed that the welfare system was overly passive and that receipt of payments needed to be integrated more with the utilisation of active labour market services (e.g. NESC, 2005; DSFA, 2006). In 1998, the National Employment Action Plan (NEAP) was introduced with the goal of integrating the administration of benefit with activation programmes. However, it was found to have had limited effectiveness because of poor co-ordination, where individuals continued to receive benefits even if they did not participate in activation and training programmes (McGuinness et al., 2011). 
An OECD review in Ireland found that some 50\% more staff worked in administering benefits to the unemployed versus placement, referral and counselling services - the reverse of the situation in most OECD countries (Grubb, Singh and Tergeist, 2009). Though this OECD study was done at a time when the national unemployment rate was low, it found that Ireland's public employment services undertook limited engagement with jobseekers and employers. In 2008, it was estimated that $35 \%$ of private sector vacancies were filled through public employment services and that $40 \%$ of unemployed jobseekers did not approach the PES (Fox, 2009).

The Transformation Agenda, set by the Department of Social Protection embraced the principle that the provision of income support to people of working age entails the responsibility of working with them to foster their capacity for self-reliance and reduce their likelihood of depending on social welfare (DSP, 2011). This Agenda committed the department to move from a passive, transaction-focused approach seeking to match payments with entitlements to a proactive, customer-focused approach seeking to improve the social and economic participation of individuals (DSP, 2011). The extent of this development in thinking and service provision played a significant role in the decision to transfer FÁS Employment Services to the Department of Social Protection.

\section{Reform Agenda 1: A new Public Employment Service}

Since January 2012, three types of service - the provision of income supports, job placement and job matching, and the design and supervision of active labour market policies - that had previously been spread across three government departments have been made the responsibility of the Department of Social Protection (DSP) (see Table 1.1). The Department's national network of Social Welfare Offices is being rebranded as a new service, Intreo, and each office is being equipped to operate as a "one stop shop" where unemployed people can get income support, search for work, be referred to the training they need or gain access to direct employment or work experience programmes. The Department has also become the contractor of the Local Employment Service Network. It draws up service level agreements with the Local Development Companies and other bodies that deliver supplementary services under the Local Employment Service Network.

In step with this ability to provide an integrated set of services, and to tailor them around each individual's needs, more pro-active strategies both to engage with claimants and employers are being adopted and implemented.

These reforms are being carried out as part of the Pathways to Work Programme. Its main features include:

- increasing the intensity of engagement with claimants as their unemployment spells lengthen;

- drawing up individually tailored progression plans for the long-term unemployed and monitoring their adherence to them;

- "profiling" new entrants to unemployment to identify who should be treated immediately;

- having recourse to sanctions (reductions in benefit or its suspension) and being able to oblige people to participate in temporary direct employment programmes as necessary;

- developing stronger links with the education/training sector to ensure more courses are relevant to the needs of the unemployed; 
Table 1.1. Employment services: Pre and post-reform

\begin{tabular}{|c|c|c|c|}
\hline & Department of Social Protection & $\begin{array}{l}\text { Department of Health } \\
\text { and Children }\end{array}$ & $\begin{array}{l}\text { Department of Jobs, } \\
\text { Enterprise and Innovation: FÁs }\end{array}$ \\
\hline \multirow{3}{*}{ 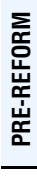 } & Benefit administration & Income support of last resort ${ }^{2}$ & FÁS Employment Services \\
\hline & Welfare to work supports ${ }^{1}$ & & - LES (outsourced) ${ }^{3}$ \\
\hline & & & $\begin{array}{l}\text { FÁS-administered direct employment } \\
\text { programmes }\end{array}$ \\
\hline & & ment of Social Protection: Intreo & \\
\hline \multirow{5}{*}{ 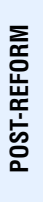 } & & All income support & \\
\hline & & Own employment services & \\
\hline & & - LES (outsourced) & \\
\hline & & Private providers (outsourced) ${ }^{4}$ & \\
\hline & & rience and direct employment progr & \\
\hline \multicolumn{4}{|c|}{$\begin{array}{l}\text { 1. Employment Supports frequently accessed through DSP Facilitators. } \\
\text { 2. Supplementary Welfare delivered by Community Welfare Officers. } \\
\text { 3. Case managers knows as Mediators. } \\
\text { 4. A development which is currently under active consideration. }\end{array}$} \\
\hline \multicolumn{4}{|c|}{$\begin{array}{l}\text { adopting an explicit employer engagement strategy, beginning with developir } \\
\text { databases of local employers in each local office; and }\end{array}$} \\
\hline
\end{tabular}

\section{Vocational education and training policies}

In Ireland, there are two principal providers of vocational education and training: 1) Vocational Education Committees (VECs); and 2) FÁs training centres. 33 Vocational Education Committees operate at the city/county level, and are accountable directly to locally elected councillors (but not to local authorities). Their remit is much wider than vocational education and embraces a significant number of secondary schools, the education of disadvantaged youth and other groups, adult education, and lifelong learning. Their principal vocational programme is the Post-Leaving Certificate (PLCs) programme which provides full-time, mainly one year, courses for young people finishing secondary education and adults returning to education who want preparation for employment without going to third level education (i.e an institute of technology or university). In 2012, some 36500 people participated in the Post-Leaving Certificate programme. A much larger number of vocational education learners (over 150 000) enrol in basic and adult learning courses, the vast majority of which are part-time.

FÁS operates a network of 16 main training centres, runs a national online eCollege for delivering training to unemployed persons, and is responsible for the national apprenticeship scheme, which has 9000 young people spread across its three to four year programmes. In 2012, FÁS trained some 75000 unemployed persons. It contracts out some training to private providers and not-for-profit organisations targeting disadvantaged groups (they accounted for $20 \%$ and $13 \%$ respectively of all FÁS funded training in 2011). FÁS has traditionally collaborated closely with the state's economic development agencies. Until recently, FÁS was funded by the Department of Jobs, Enterprise and Innovation which channelled into it the proceeds of a national training levy taken from employers. There is a strong contrast between the two providers. Vocational Education Committees are quite local, co-ordinated lightly at the national level, and engaged more in the provision of adult education and lifelong learning than in providing specific vocational education. FÁS is a specialist in vocational training and accustomed to engaging with employers and 
monitoring labour market intelligence. It has operated under a high level of national direction.

Progression to higher education (i.e. entering university or an institute of technology) is an important objective of national government policy. There is a national target that the progression rate to higher education should be $72 \%$ by 2020 , up from the current rate of $60 \%$. Participation in secondary education (e.g. high school) has increased during the economic crisis $-90.2 \%$ of young people sat the Leaving Certificate exam in 2011, an increase from $81 \%$ a decade earlier (DES, 2012a). Three key underlying weaknesses have led to major reforms in Ireland's further education and training system:

1. A high status is attached to third level education and there is a strong focus at the secondary level in preparing young people for entry to university. This has contributed to a correspondingly low status for vocationally oriented educational alternatives (e.g. the Post-Leaving Certificate programmes). There has long been consensus on this point and it is reiterated in the recent City and Guilds report on Young people and vocational choices in Ireland (2013).

2. The distinction between vocational education and vocational training, and their provision by providers working within wholly different systems, had become increasingly confusing for young people and their families. This concern has been articulated and acknowledged by government, for example by the Minister for Education in his address to IVEA Congress (DES, 2012b).

3. There is insufficiently detailed direction as to where and how funding for vocational education should be allocated. Indeed, this is one of the underlying diagnoses that has led to the establishment of the Education and Training Boards (Forfás, 2012).

The impact of the recession has altered demand for vocational education and training in Ireland in a number of ways. It has accelerated the restructuring of the economy and the need for skills conversion courses to help people switch from declining sectors/ occupations to those with growth prospects. The surge in unemployment has also led to a large increase in demand for VET, particularly for places in programmes associated with solid employment prospects.

\section{Reform Agenda 2: A re-imagined further education and training sector}

The changes in Ireland's further education and training system are unprecedented since VECs were first established in 1931. A new Further Education and Training Authority (SOLAS) is being established to revitalise the sector and enhance its status (see Table 1.2). SOLAS (which will replace FÁS) is to have overall strategic responsibility for the provision of all publicly funded further education and training in Ireland. It will be responsible for deciding which programmes and courses are provided, adapting existing provision, and introducing new provision as necessary. It will allocate all public funding for further education and training and be responsible for the co-ordination, accountability, quality, and effectiveness of all providers in receipt of public funding.

SOLAS will not deliver any education or training programmes, but conclude Service Level Agreements (SLAs) with 16 regional Education and Training Boards. The current 33 Vocational Education Committees and FÁS training centres and other networks are being amalgamated under the new Education and Training Boards. Each board will represent a catchment area of two to three counties. Each board will comprise 21 members, of which there will be 12 local authority representatives, two staff representatives, two 
Table 1.2. Vocational education and training: Pre and post-reforms

\begin{tabular}{|c|c|c|}
\hline & Department of Jobs, Enterprise and Innovation: FÁS & Department of Education and Skills \\
\hline 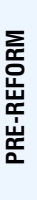 & $\begin{array}{l}\text { FÁS Training Centres } \\
\text { - Training for industry } \\
\text { - External contracting: } \\
\text { Private providers } \\
\text { Community providers }\end{array}$ & $\begin{array}{l}\text { Vocational Education Committees } \\
\text { - Vocational education } \\
\text { - Adult and basic education } \\
\text { - Some second-level schools } \\
\text { - Education of disadvantaged groups in special settings } \\
\text { (e.g. early school leavers, children detention schools, and prisons) }\end{array}$ \\
\hline \multicolumn{3}{|c|}{ Department of Education and Skills: SOLAS } \\
\hline \multicolumn{3}{|c|}{ Education and Training Boards } \\
\hline \multirow{3}{*}{ 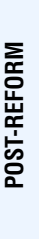 } & \multicolumn{2}{|c|}{$\begin{array}{l}\text { Vocational education and training } \\
\text { own provision; on contract } \\
\text { unemployed; those at-work }\end{array}$} \\
\hline & \multicolumn{2}{|c|}{$\begin{array}{l}\text { Adult and basic education } \\
\text { own provision; on contract }\end{array}$} \\
\hline & \multicolumn{2}{|c|}{$\begin{array}{l}\text { Education of disadvantaged groups } \\
\text { own provision; on contract }\end{array}$} \\
\hline
\end{tabular}

parent representatives and five community representatives - at least one of whom is an employer. The 16 regions in which the board will operate have been chosen primarily on the basis of the scope for achieving operating efficiencies across primary and secondary educational provision.

The bulk of the capacity being inherited by the boards will come from VECs and not from FÁs training centres (four Education and Training Boards will inherit no FÁs training centre at all). They will begin, therefore, with a strong background in providing basic and further education rather than in workforce development. However, the reforms create significant potential to improve workforce development by ending duplication and competition in the previous dual system. It is also a clear remit of SOLAS that vocational education and training programmes should be better aligned with quality employment prospects and that course provision should be adjusted more regularly in response to labour market intelligence, while the strong relationship that SOLAS and the Education and Training Boards are to have with Intreo creates the potential for more of those on the Live Register to find a route to stable employment through training.

\section{Economic development and regional governance}

Ireland created eight Regional Authorities in 1994 (NUTS 3 level), largely for the purpose of applying and accounting for funding from the EU Structural Funds (see Figure 1.3). Their central purpose was to strengthen co-ordination between their constituent local authorities and across other public service providers in their regions. Their most significant power is the statutory responsibility to draw up Regional Planning Guidelines to co-ordinate and align the spatial planning of local authorities with infrastructure investments under the country's National Development Plans and the National Spatial Strategy. The second generation covers 2010-22, and has been more binding on local authorities. The latest Regional Planning Guidelines, benefiting from prior regional competitiveness agendas prepared by Forfás, provide clear accounts of each region's economic structure and how it is expected to develop. A very deliberate hierarchy is intended in Ireland's spatial planning process, with Regional Planning Guidelines setting the key parameters for city/county development plans and the latter, in turn, setting 
parameters for the more than 350 Local Area Plans which frame the context for job creation initiatives by the local community sector.

Regional Authorities have struggled to have real influence on regional economic developments. Their boundaries are not particularly aligned with economic flows, travelto-work areas or public administration boundaries. They lack a direct electoral mandate, strong statute-based powers and the resources to develop specialised competences and expertise, and as a result they have been unable to become strong co-ordinating regional voices (DEHLG, 2008). Lacking in any historic or cultural underpinnings, they have also been unsuccessful in recasting "regional identities" in a country where county allegiance and an historic four-province division remain much more influential. Their Regional Planning Guidelines have proven unable to deal with significant inter-regional issues affecting one or more Regional Authorities. Higher-level frameworks for co-operation were provided by two Regional Assemblies at the NUTS 2 level, but they have been ineffectual in identifying solutions to issues spanning the regions and at distributing responsibility for implementing them.

Figure 1.3. NUTS 3 Regions in Ireland

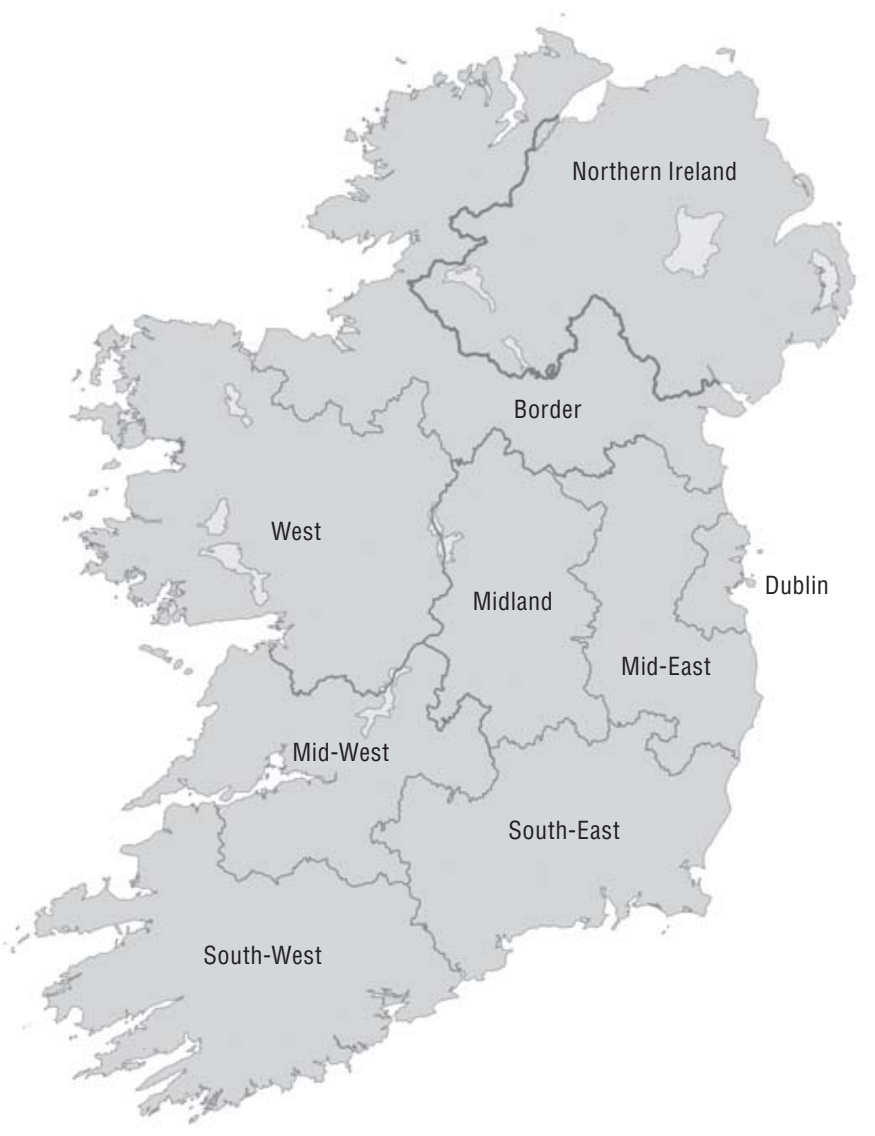

Source: Department of Environment, Communities and Local Government (DECLG) (2010), Implementing the National Spatial Strategy: 2010 Update and Outlook. 


\section{Ireland's economic development agencies}

Ireland has a strong set of national advisory bodies and state agencies delivering services to enterprises that collectively seek to strengthen the multiple factors that underpin the success of its export-led economic model and internationalised economy.

Forfás is the national policy advisory board for enterprise, trade, science, technology and innovation and operates under the Department of Jobs, Enterprise and Innovation. As well as undertaking independent studies and initiatives, it services a set of specialist advisory bodies that monitor the economy's capacity to make maximum use of science, technology and innovation (Advisory Council for Science, Technology and Innovation), the skill needs of internationally trading enterprises (Expert Group on Future Skill Needs EGFSN), and the international competitiveness of Ireland's business environment (the National Competitiveness Council). Forfás has co-operated closely with the regional authorities to inform the economic development chapters in their Regional Planning Guidelines.

IDA Ireland and Enterprise Ireland are particularly sought after as partners by groups working to support economic development and job creation at the regional, city/county and sub-county levels. IDA Ireland has an expertise acquired over decades in attracting inward investment in sectors and companies with strong growth prospects, while also encouraging multinationals already in Ireland to upgrade their operations. Enterprise Ireland works with indigenous companies to encourage those exporting to increase the scale and sophistication of their operations and enter new markets. It also reaches into the large pool of non-exporting domestic companies to identify those with the ambition and capabilities to begin exporting. At the regional level, Shannon Development, the Western Development Commission and Údarás na Gaeltachta also operate as economic development agencies.

\section{Box 1.2. Economic development agencies: A regional focus}

The national development agencies have a strong commitment to the development of local economies. They regard the development of vibrant urban centres as essential for national economic development, which are capable of offering international connections, broad and deep labour market pools, quality infrastructure and amenities, and a range of skilled sub-supply companies and other business advantages that enable internationally trading enterprises to compete successfully. While it is accepted that, ideally, internationally trading companies should be widely distributed geographically and not overly concentrated in a few urban centres, the constraints are also very apparent. Inward investors frequently choose between the Greater Dublin Area and alternative locations overseas and consequently, a failure to bring them to Dublin entails losing the projects altogether. The client companies of Enterprise Ireland are more widely dispersed geographically, but, once they begin to achieve scale and aspire to enter new export markets, the preference of indigenous companies can also be to site expansions in or close to Ireland's larger urban centres. Overall, the economic development agencies are keener to promote "regional thinking" and commit to regional partnerships rather than engage at the county level. 


\section{Local community development}

Ireland has a vibrant local development landscape. Community and voluntary bodies play a large role in working with local residents to tackle unemployment and improve job readiness, as well as having more general community development functions. Although they generally have a small geographical remit, government departments and national agencies are their major conduits of funding and four nationally administered programmes accounted for over $80 \%$ of their core funding in 2008 (DECLG, 2011). ${ }^{2}$ There is an established pattern of central funding and national supervision of projects at the subcounty level, an approach which has developed in response to perceived weaknesses in local government and mainstream public service providers and their lack of responsiveness to particularly disadvantaged communities. Local development groups have grown accustomed to dealing directly with central government and national agencies rather than with local government.

A network of area-based partnerships (not-for-profit companies governed by boards) was created to tackle structural unemployment and social exclusion in disadvantaged urban and remote rural areas in response to the unemployment crisis of the early 1990s. By 2008, there were over 90 such partnerships - subsequently renamed Local Development Companies. These partnerships have retained a high degree of autonomy under Service Level Agreements with the Department of Social Protection. The number of Local Development Companies was reduced through mergers to 51 and they have become larger, mainly county-based entities.

In an OECD review of the Irish partnership model, a number of strengths were highlighted including their practical problem solving approach, the informal alliances and cross-sector networks which they have brokered, and the platform they have given to disadvantaged communities to have a more direct say in policy making (OECD, 2001). However, a number of weaknesses in local development activities came increasingly into focus during the "boom" years, when resources were relatively abundant. These included significant overlap in service provision, with groups in the same locality receiving funding from different sources to provide the same type of service (Department of Finance, 2009; Department of Public Expenditure and Reform, 2011).

The multiplicity of channels and programmes through which national funding reached local groups suggested an inadequacy of local area intelligence at the national level to ensure funding was adequate to need and that it was used efficiently (Department of Finance, 2009). There was no formal mechanism at the national level for gathering and processing what was learned by the differently organised regional and local operations of government departments and national agencies. Furthermore, City/County Development Boards $^{3}$ did not have the impact expected of them, particularly in integrating local services and supporting local economic development (DECLG, 2012a; DECLG, 2012f). Relationships between local government and Local Development Companies have varied, ranging from "collaboration to competition" (Indecon Consultants, 2008).

\section{Reform Agenda 3: New regional frameworks for stronger local authorities and greater role in local economic and community development}

In October 2012, the government announced a profound overhaul of regional and local government in the policy document Putting People First: An Action Programme for Effective Local Government (DECLG, 2012a). It has taken a clear decision to strengthen the city/county 
level of local government, and to fundamentally reshape the regional tier so as to facilitate more effective collaboration between local authorities. The eight Regional Authorities and two Regional Assemblies are to be replaced by three newly constituted Regional Assemblies: an Eastern-Midlands Region will serve 2.2 million people, a Southern Region serving 1.5 million people and a Connaught-Ulster Region serving 0.8 million people. It is considered that these regional boundaries will correspond more closely to travel to work areas but the existing NUTS 2 and 3 classifications will remain.

\section{Box 1.3. What does "local" mean in the Irish context?}

The most popular use of the word "local" in Ireland refers to very small populations. The geographical remit, for example, of many of the groups applying to national bodies for support for local and community development may be a large housing estate, a village or part of a town, with population sizes clustered in the ranges from 200 to 20000 individuals. "Local" is next applied formally to what is the primary unit of local government in Ireland, namely, the city and county level (corresponding to municipalities in other countries), whose administrations are called Local Authorities. There were 34 of these in 2011 with an average population size of approximately 135 000. Finally, "local" also applies to each of Ireland's eight NUTS 3 regions into which the city and county local authorities are grouped. They had an average population size of 573500 in 2011. Ireland's small scale relative to other OECD countries and the traditionally strong attachment of Irish people to place, therefore, combine to give the word "local" unusual plasticity in Ireland.

Through this reform the government is validating that city and county authorities form the core element of local government in Ireland. Complementary changes will take place within them so that they can work more effectively together within the framework of the new assemblies pooling their resources to support wider metropolitan and regional economies. 12 local authorities will work through the Eastern-Midlands Assembly, ten through the Southern Assembly and nine through Connacht-Ulster to provide a coherent framework for economic development and underpin the economic dimension of the National Spatial Strategy. The existing Regional Planning Guidelines are to be "recast" as Regional Spatial and Economic Strategies, ${ }^{4}$ drawn up with inputs from all relevant central government departments and agencies, the state's economic development agencies, and higher education institutions. Their preparation and monitoring will be guided by Regional Strategy Steering Groups. While the decisions taken are clear, much of the detail concerning how the new arrangements are to work remains to be clarified.

Central government involvement in operational details of local services will be reduced and administrative controls and procedures streamlined. Local authorities will have a much stronger capacity for direct co-ordination and they will be involved in a range of new policy areas, working more effectively together within the framework of the new assemblies. In particular, local government will be devolved greater powers allowing it to play a much stronger role in local economic development. Some local authorities are currently very active in facilitating economic development by efficiently carrying out traditional functions that are critical to enterprise and economic activity (e.g. planning, environment, infrastructure) and by serving as contact points with business. However, an extensive examination of the measures that local authorities have at their disposal finds that they are not always fully used (DECLG, 2012b, 2012d). 
The local authority reform agenda is also intended to bring the local development sector and local government closer together through an alignment process. The details of how exactly the process will operate remain unclear, though some decisions have been set out. A five-year City/County Local and Community Plan will be drawn up by each local authority, to be fully integrated with the higher order City/County Development Plan. It will encompass all state-funded local and community development interventions and will set priorities for expenditure on the basis of detailed local needs analyses. A Socio-Economic Committee (SEC) will be established in each local authority, with a proposed membership drawn from the local authority, local and community interests and appropriate state agencies. Committees will develop the plan, receiving critical input from the area's Local Development Companies in doing so, and will also play a key role in decision-making on national and EU funded programmes. ${ }^{5}$

\section{Notes}

1. Lower maximum personal rates of Jobseeker's Allowance/Benefit for young people than for adults were first introduced in 2009 - EUR 100 weekly for 18-21 year olds and EUR 144 for 22-24 year olds in 2013 as against EUR 188 for those aged 25 or over.

2. A snapshot of the local development landscape in 2008 identified 870 small independent organisations operating across the state to deliver a service or fulfil a role in their local community and being supported by public funds to do so (Department of Finance, 2009). It was estimated they received at least EUR $280 \mathrm{~m}$ in core funding in 2008 with a further EUR $100 \mathrm{~m}$ coming from other state sources.

3. 34 City/County Development Boards were established by the government in 2000 as a means to better integrate public and local service delivery. They were made up of representatives from local government, the local development sector, the social partners and state agencies.

4. The current RPGs will be replaced in 2016.

5. A forthcoming OECD report examines the impact of the proposed local government reforms on local economic and community development. See OECD, forthcoming b.

\section{References}

Behan, J. and C. Shally (2010), “Occupational Employment Forecasts 2015: FÁS/ESRI Manpower Forecasting Studies”, Report No.13, www.fas.ie/NR/rdonlyres/FDBB3580-C466-4002-8EE7C289E9E8BAB2/999/OccupationalEmploymentForecastsMarch2010.pdf.

City and Guilds (2013), Young people and vocational choices in Ireland, City and Guilds Centre for Skills Development.

Central Statistics Office, CSO online database, www.cso.ie.

Department of Education and Skills (2012), "Retention Rates of Pupils in Second Level Schools: 2005 and 2006 Entry Cohorts".

Department of Environment, Communities and Local Government (DECLG) (2010), Implementing the National Spatial Strategy: 2010 Update and Outlook, www.environ.ie/en/DevelopmentHousing/ PlanningDevelopment/NationalSpatialStrategy/PublicationsDocuments/FileDownLoad,24144,en.pdf.

DECLG (2012a), Putting People First: Action Programme for Effective Local Government, www.environ.ie/en/ PublicationsDocuments/FileDownLoad,31309,en.pdf.

DECLG (2012b), Local Authority Support to Enterprise and Business: Analysis of Economic Templates, Enterprise Strategy Steering Group of County and City Managers' Association.

DECLG (2012c), Our Sustainable Future: A Framework for Sustainable Development in Ireland.

DECLG (2012d), Supporting Economic Recovery and Jobs - Locally, Sectoral Strategy of the Local Government Sector to Promote Employment and Support Local Enterprise.

DECLG (2012e), Local Area Plans: Public Consultation Draft of Guidelines for Planning Authorities. 
DECLG (2012f), Final Report of the Local Government/Local Development Alignment Steering Group.

DECLG (2011), Interim Report of the Local Government/Local Development Alignment Steering Group, www.environ.ie/en/Community/AlignmentofLocalGoutLocalDev/.

Department of Environment, Heritage and Local Government (DEHLG) (2008), Stronger Local Democracy: Options for Change, Green Paper on Local Government Reform, www.environ.ie/en/LocalGovernment/ PublicationsDocuments/FileDownLoad,17134,en.pdf.

Department of Finance (2013), Irish Stability Programme: April 2013 Update.

Department of Finance (2012), The Irish Economy in Perspective.

Department of Finance (2009), Local Delivery Mechanisms: Briefing paper.

Department of Public Expenditure and Reform (2011), "Rationalising Multiple Sources of Funding to Not-for-Profit Sector", Central Expenditure Evaluation Unit, Cross-Cutting Paper No. 1.

Department of Jobs, Enterprise and Innovation (2012), Action Plan for Jobs.

Department of Social Protection (2012), A Review of Department of Social Protection Employment Support Schemes.

Department of Social Protection (2011), Briefing Material for Minister Joan Burton T.D., July 2011.

Expert Group on Future Skills Needs (2012), The Expert Group on Future Skill Needs Statement of Activity 2011, Forfás, Dublin.

Expert Group on Future Skills Needs (2007), "Tomorrow's Skills: Towards a National Skills Strategy", 5th Report, www.skillsstrategy.ie/pdfs/egfsn070306_skills_strategy_report_webopt.pdf.

Forfás (2013), Regional Labour Markets Bulletin 2012.

Forfás (2012), Guidelines for the Alignment of Further Education Programmes with the Skill Needs of Enterprise.

Forfás (2010), Forfás Regional Competitiveness Agendas: Overview, Findings and Actions.

Forfás (2007), Role of the Institutes of Technology in Enterprise Development: Profiles and Emerging Findings.

Fox, R. (2009), Job Opportunities in the Down-Turn, FÁS.

Grubb, D., S. Singh and P. Tergeist (2009), "Activation Policies in Ireland", OECD Social, Employment and Migration Working Papers, No. 75, OECD Publishing, doi: 10.1787/227626803333.

Indecon International Economic Consultants (2008), Review of County/City Development Board Strategic Reviews and Proposals for Strengthening and Developing the Boards, DECLG.

McGuinness, S. et al. (2011), "Activation in Ireland: An Evaluation of the National Employment Action Plan", Research Series No. 20, Economic and Social Research Institute, Dublin.

National Economic and Social Council (2008), The Irish Economy in the Early 21st Century, No. 117, National Economic and Social Council, Dublin.

National Economic and Social Council (2005), The Developmental Welfare State, National Economic and Social Council (NESC), Dublin.

OECD (2014, forthcoming), “Delivering Local Development: Ireland”, OECD Local Economic and Employment Development (LEED) Working Papers, OECD Publishing, Paris.

OECD (2010), OECD Economic Outlook, Vol. 2010/2, OECD Publishing, doi: 10.1787/eco_outlook-v2010-2-en.

OECD (2001), Local Partnerships for Better Governance, OECD Publishing, doi: 10.1787/9789264189461-en. 



\section{Chapter 2}

\section{Overview of the Irish case study areas}

To better understand the role of the local level in contributing to job creation and productivity, this review examined local activities in two Irish regions: 1) Dublin; and 2) the South-East. This chapter provides a labour market and economic overview of each region as well as the results from an OECD LEED statistical tool which looks at the relationship between skills supply and demand at the subnational level. Both areas have different local economies and labour market characteristics. Dublin is the economic powerhouse of Ireland while the South East region is significantly smaller and more rural. 


\section{Overview of the Dublin and South East regions}

In-depth fieldwork for this study was undertaken in two regions in Ireland: Dublin and the South East region - see Figure 2.1. These two areas were selected after consultation between the OECD and the government based on their urban-rural characteristics.

The Dublin region sits on Ireland's east coast and is home to the country's capital, Dublin. Though overwhelmingly urban, it contains some rural areas. The region contains 1.3 million people, is made up of two counties (Dublin City and Dublin County) and contains four local authorities. A large metropolitan area, the Greater Dublin Area (GDA), has developed around the region with an economic footprint that extends well beyond the administrative boundaries of its local authorities. The economy of the region was the powerhouse during the Celtic Tiger period and is the main transport node in the country, with Dublin's international airport and principal seaport accounting for large shares of passenger and trade flows between the country and overseas.

The South East region is significantly smaller than its Dublin counterpart, with a population of around 500 000. It is made up of five counties (Carlow, Kilkenny, South Tipperary, Waterford and Wexford) and six local authorities. The heart of the region is a triangle formed by Waterford City, Kilkenny City to its north and the almost equidistant Wexford Town to the east. In the National Spatial Strategy, Waterford City is designated a "gateway" (as is Dublin) but is considered to have been the most poorly performing gateway among Ireland's more established cities (Fitzpatrick Associates, 2009). Several labour market catchment areas can be detected within the South East region. A broad northeastern fringe of the region comes within the influence of the Greater Dublin Area. A broad western fringe has a substantial rural population and is made up of North West Kilkenny, South Tipperary and most of County Waterford. Overall, more than $50 \%$ of the South East's total population live in villages of less than 1500 or in the open countryside.

\section{Local labour markets and impact of the crisis}

Dublin and the South East have quite different local economies and underlying labour market characteristics. Not unusual in a metropolitan region, the employment structure in Dublin is skewed towards white collar jobs and heavily dependent on a wide diversity of services, including private and public, high- and low-skilled, those based on international trading enterprises and those serving the local market. In the 1980s, there was a substantial shift away from older manufacturing sector jobs towards the development of a service economy with growing numbers of jobs in high value, knowledge-based services and low-skilled retail and domestic services. This gathered pace as the region's economy nearly doubled in size between the early 1990s and 2007. In 2012, almost a quarter of people in employment in the Dublin region were employed in professional occupations with a further 15\% employed as associate professionals (see Figure 2.2 for a comparison across the two regions). In the South East region, skilled trade occupations account for the highest share of employment at 18\% (SLMRU, 2012). The second largest employment occupation is professional followed by elementary occupations. 
Figure 2.1. Maps of the Dublin and South East regions

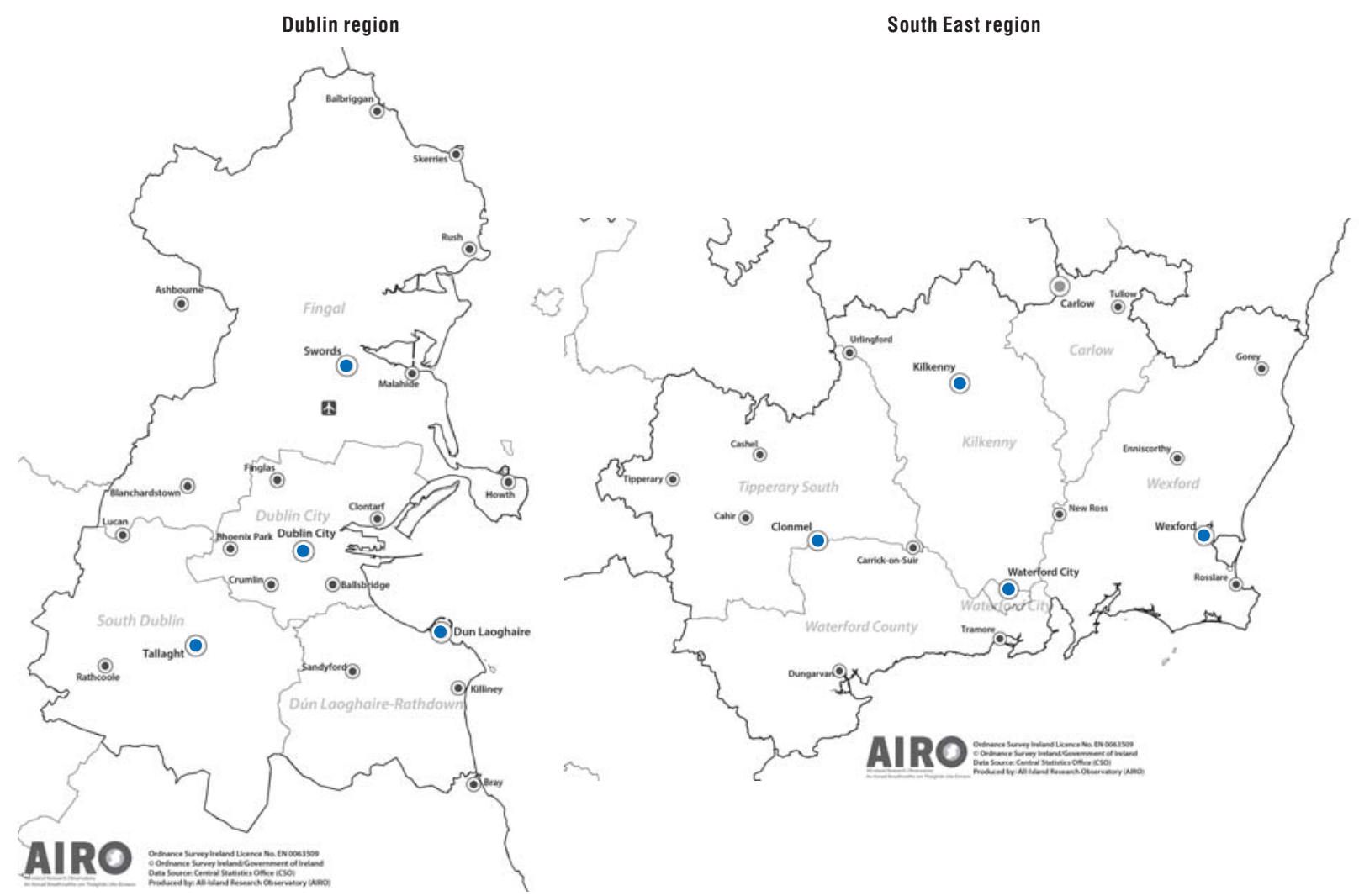

Source: All-Island Research Observatory, 2013. Figure 2.2. Employment by broad occupation in Dublin and South East regions,
Q1 2012,\%

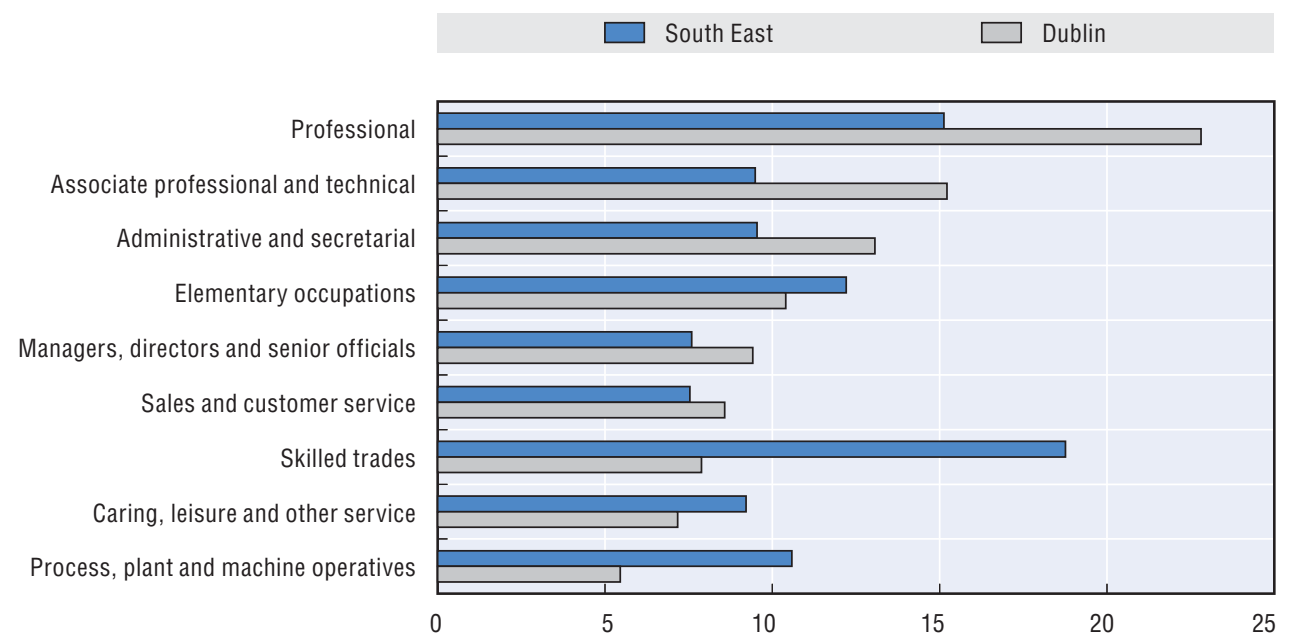

Source: Skills and Labour Market Research Unit (SLMRU) (2012), National Skills Bulletin, July 2012, Dublin.

The dynamics of economic development are delivering more jobs for Dublin than for the South East. For example, of the 167 companies that publicly announced the creation of new jobs with inward investment assistance during 2012, 79 were in Dublin and only seven were in the South East. When the location of the entire stock of inward investment 
assistance is studied, $47 \%$ is found to be in Dublin and only 3\% in Waterford (Williams et al., 2012). Dublin accounted for over $80 \%$ of the locations of inward investors in Financial Services, Entertainment and Media, while Waterford's highest share was in Consumer Goods (9\%). The regional labour market profiles produced by Forfás confirm the greater attractiveness of Dublin to skill-intensive economic activity (Forfás, 2012).

\section{The Dublin Region}

The recession has hit both regions hard and the unemployment rate has soared in both, but by much more in the South East than in Dublin. From being around 5\% in 2007, the unemployment rate peaked at $13.4 \%$ in Dublin. A net 124000 jobs were lost, almost $20 \%$ down on peak employment in 2007. Almost $70 \%$ of these job losses occurred in three sectors that are not particularly characteristic of the region's economic structure Construction, Industry, and the Wholesale and Retail Trade. The most resilient sectors in terms of employment levels were Education, Health and Social Work, and ICT. Figure 2.3 shows the unemployment rate in the Dublin region according to Electoral District. There are large coastal sections which have unemployment under 15\%, except further North into Rush, Skerries and Balbriggan where unemployment falls between 15-25\%. Pockets to the West display higher unemployment rates, around Lucan, Blanchardstown, and Rathcoole, including some distressed pockets with unemployment at over 30\% around Tallaght, Finglas, and Crumlin. It is interesting to note that Dublin City presents a chequered image, with varying unemployment levels side by side (see Figure 2.3). The density of city living makes it possible for contiguous neighbourhoods to have sharply different labour market profiles where communities with high levels of disadvantage border much more affluent communities.

The challenge in raising skill levels and fostering a socially inclusive labour market in the Dublin region is similar to those in other large metropolitan areas. If left unchecked, the rapid development of services tends to polarise the labour market as traditional blue collar jobs in Manufacturing and Port Activities disappear, and the age and skill sets of those losing their jobs make it difficult for them to make the transition to services jobs. There is an ever growing contrast between the salaries and job prospects of graduates and skilled migrants employed in internationally-traded services or the public sector, and lower skilled workers who are competing for a shrinking share of total employment.

\section{The South East Region}

In the South East, the unemployment rate peaked at around 20\%. A net 41000 jobs were lost, a drop of $18 \%$ on the peak employment in 2007 . This high concentration of job loss occurred in the three sectors most characteristic of the region's economic structure. Some $55 \%$ of these job losses occurred in Construction alone, a further $16 \%$ in Manufacturing and $12 \%$ in the Wholesale and Retail Trade. The most resilient sectors in terms of employment levels were in Education, followed by Health and Social Work, with a contribution from a small ICT base. The pattern suggests that the South East's economy is becoming increasingly concentrated on high-end service activities. Figure 2.4 presents the unemployment rate in the region in 2011 according to Electoral District and provides an interesting comparison with Dublin. Generally speaking, jobless rates on the East coast are higher than those inland, with the exception of small pockets of lower unemployment around Wexford. There are large pockets to the West (and South West in particular) with unemployment at under $15 \%$. Waterford presents a mixed distribution with areas of 
Figure 2.3. Unemployment rate, Dublin region, 2011

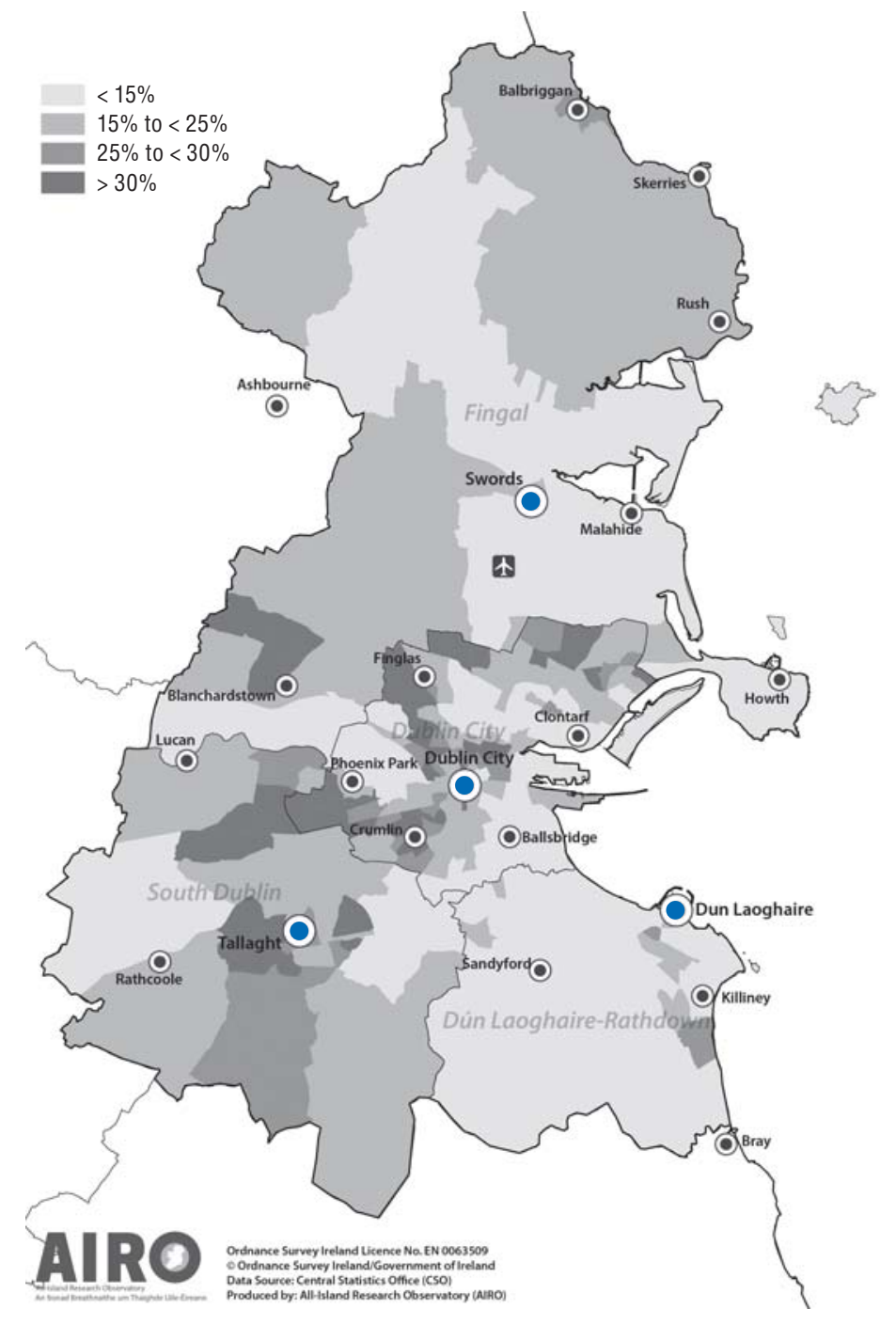

Source: All-Island Research Observatory, 2013.

relatively low unemployment neighbouring areas with unemployment from 25 to $30 \%$. The same applies to Carlow. Clonmel and Kilkenny sit in districts with 15 to $25 \%$ unemployment, but there are pockets with under $15 \%$ unemployment.

In the South East region, a critical challenge is how to retain people in the region where the sectors for which they are trained are developing more rapidly elsewhere. An additional factor is the widely dispersed population where a significant proportion of residents live in rural areas, thereby making it more difficult to provide access to activation services.

\section{Employment and training services}

\section{Employment services}

Employment services in each region are delivered by the same government department - the Department of Social Protection - which is in the process of remodelling public employment services. In addition, the department contracts not-for-profit bodies to 
Figure 2.4. Unemployment rate, South East region, 2011

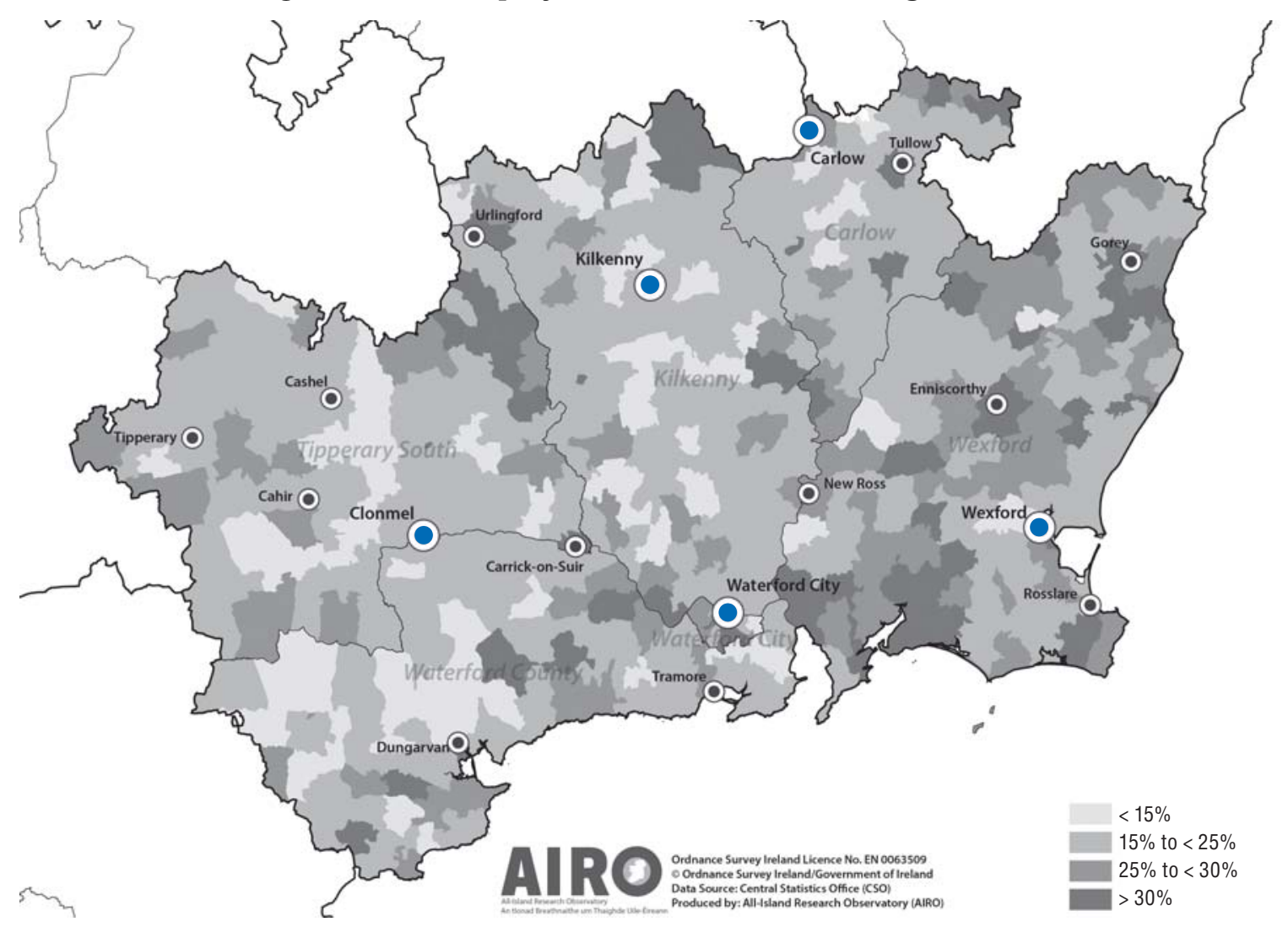

Source: All-Island Research Observatory, 2013.

provide additional services in areas with high concentrations of long-term unemployment, usually in the form of a Local Employment Service.

In the Dublin region, the Department of Social Protection has a network of 17 local offices (grouped into three divisions - Dublin North, Dublin Central, and Dublin South) into which 16 FÁS employment services offices are being amalgamated. In addition, the Department of Social Protection contracts 11 not-for-profit bodies to operate a Local Employment Service in their areas. The single busiest office in mid-2012 had over 12000 monthly claimants (Tallaght) and the next two busiest handled over 9000 each.

In the South East region, the Department has a network of 18 offices (six local and 12 branch offices). Local offices are staffed by its own personnel and based in urban centres and large towns, while branch offices are managed by individuals on contracts for services and are based in smaller towns, many within rural areas. Six employment services offices operated by FÁS in the region are in the process of being absorbed into this network. In addition, there are four not-for-profit bodies under contract to provide employment services. The single busiest office in the region in 2012 (and the busiest in the state) was Waterford City with an average monthly caseload of the order of 12000 ; Wexford Town and Kilkenny City follow with 7000 and 6000 respectively over the year to mid-2012. 


\section{Box 2.1. South East Region Employment Action Plan}

Concerns at the South East's continued high and above average levels of unemployment, and a series of high profile company closures, prompted the development of the South East Region Employment Action Plan (2011). The plan describes how the region has suffered disproportionately as a result of the financial crisis and how its industrial base has not developed strong clusters in specific sectors that can help attract future investments. Prepared by Forfás at the request of the Minister for Jobs, Enterprise and Innovation, it sets out actions to tackle the situation. These include prioritising the region for attracting additional investment in areas such as life sciences, financial services and clean technology, and committing the state economic development agencies to work closely with the region's local authorities and other relevant bodies. It also offers additional enterprise support for new start-ups in the region and promotes the take-up of grants to invest in innovation.

A key feature of the plan is the commitment by the state's enterprise development agencies (Enterprise Ireland, IDA and Science Foundation Ireland) to develop a programme of structured engagement with the key research groups in the ITs within the region to identify potential collaboration opportunities with existing enterprises. The enterprise agencies will stimulate increased linkages between firms to facilitate the forging of relationships through sub-supply and/or collaborative arrangements, including contracted research, outsourced services, materials procurement, and partnerships.

Source: Forfás (2011), South East Region Employment Action Plan: Spotlight on the South East, www.forfas.ie/media/ 021211-South_East_Action_Plan_Publication.pdf.

\section{Education and training}

A major difference between both regions is their endowments of higher education institutions. In 2012, Dublin had over 60000 students distributed across three universities and four Institutes of Technology, whereas the South East had approximately 10000 in two Institutes of Technology. The current principal post-secondary training providers are Vocational Education Committees and FÁS training centres. The Dublin Region has three Vocational Education Committees, which operate some 25 to 30 colleges of further education between them, and five FÁS training centres. They are being brought together under two Education and Training Boards, one for Dublin City and one for County Dublin and Dun Laoghaire.

The South East Region has six Vocational Education Committees, each with its colleges of education and outreach centres for course delivery, and two FÁS training centres. They will become accountable to two Education and Training Boards (one for Waterford and Wexford and one for Kilkenny and Carlow).

It can be noted that in Dublin, there are more areas with a high level of post-secondary education attainment compared to the South East. This may be due to the richer educational endowment, but also the fact that more highly skilled people move to the capital city from other regions to find higher skilled employment (Figures 5.1 and 5.2 in Annex B show the percentage of the population in both regions with post-secondary education by Electoral District). Analysis has also been carried out on the extent of high to medium skill occupations in both regions. In Dublin, there is a clear concentration of high skilled jobs in Dun Laoghaire-Rathdown municipality and also pockets on the outer ring of Dublin City, particularly in Ballsbridge, Clontarf and Howth. 
The distribution of higher skilled jobs generally reflects the broad distribution of high levels of post-secondary education, although it is interesting to note that while there is a high demand for high skilled jobs in the north west of the region, there is a lower level of high skills supply. There is also a correlation in the South East, although this is less noticeable than in Dublin. In particular, there is a high demand for medium-high skills around Kilkenny and its hinterland, where a relatively high supply of skills is found, and also smaller pockets around Dungarvan, Wexford and Waterford (see Figures 5.3 and 5.4 in Annex B for more on the distribution of high to medium skill jobs).

\section{Balance between skills supply and demand at the sub-national level}

The LEED Programme has developed a statistical tool to understand the balance between skills supply and demand within local labour markets (Froy, Giguère and Meghnagi, 2012). In the Irish context, this tool can help to provide policy makers with an understanding of skills mismatches, which may occur at the sub-national level. It can inform place-based policy approaches at the local level.

\section{Figure 2.5. Understanding the relationship between skills supply and demand}

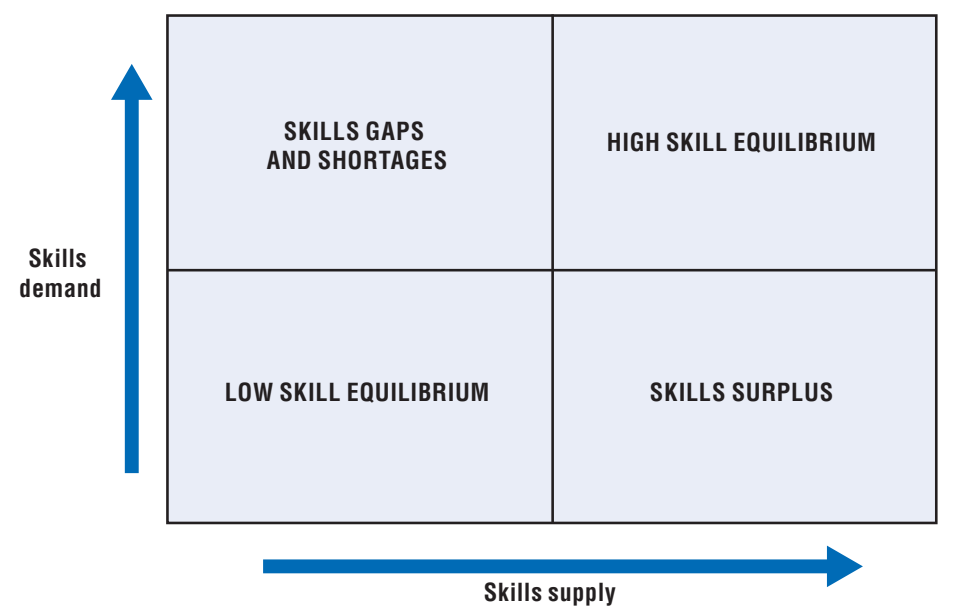

Source: Froy, F. and S. Giguère (2010), "Putting in Place Jobs that Last: A Guide to Rebuilding Quality Employment at Local Level”, OECD Local Economic and Employment Development (LEED) Working Papers, No. 2010/13, OECD Publishing, doi: $10.1787 / 5 \mathrm{~km} 7 \mathrm{jf} 7 \mathrm{qtk9p}-\mathrm{en}$.

Looking at the figure above, in the top-left corner (skills gaps and shortages), demand for high skills is met by a supply of low skills, a situation that results in reported skills gaps and shortages. In the top-right corner, demand for high skills is met by an equal supply of high skills resulting in a high-skill equilibrium. This is the most desired destination of all high performing local economies. At the bottom-left corner the demand for low skills is met by a supply of low skills resulting in a low-skill equilibrium. The challenge facing policymakers is to get the economy moving in a north-easterly direction towards the topright corner. Lastly, in the bottom-right corner, demand for low skills is met by a supply of high skills resulting in an economy where what high skills are available are not utilised. This leads to the out migration of talent, underemployment, skill under-utilisation, and attrition of human capital, all of which signal missed opportunities for creating prosperity.

This typology was applied to the eight regions in Ireland, including the case study regions of Dublin and the South East - see Figure 2.6 below. 


\section{Box 2.2. Explaining the diagnostic tool}

The analysis is carried out at Territorial Level 3 regions (regions with populations ranging between 150 000-800 000). The supply of skills was measured by the percentage of the population with post-secondary education. The demand for skills was measured by the percentage of the population employed in medium-high skilled occupations. Regions are also classified in relation to the average state unemployment rate. The indices are standardised using the inter-decile method and are compared with the national median. Further explanations on the methodology can be found in Froy, Giguère and Meghnagi, 2012.

Source: Froy, F., S. Giguère and M. Meghnagi (2012), "Skills for Competitiveness: A Synthesis Report", OECD Local Economic and Employment Development (LEED) Working Papers, No. 2012/09, OECD Publishing, doi: 10.1787/ 5k98xwskmvr6-en.

Figure 2.6. Balancing skills supply and demand in Ireland, 2012

Unemployment below national average

$\square$ Unemployment above national average

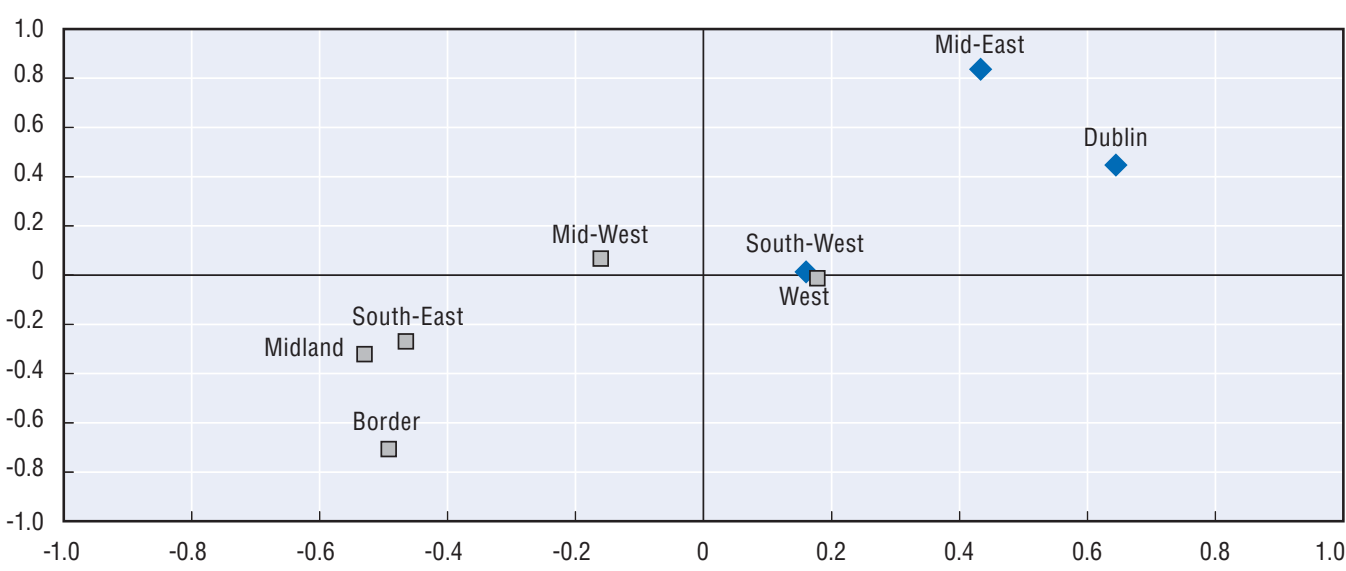

The results from this analysis show variations across the regions. Two regions in Ireland (Mid-East and Dublin) occupy the high skills equilibrium quadrant, while two (South-West and West) are on the axis between the high skills equilibrium and skills surplus quadrants. The remaining regions are in the low skills equilibrium quadrant or in the skills gaps and shortages quadrant. The regions in the high skills equilibrium quadrant also have unemployment rates below the national average, indicating that in a region where there is a relatively high demand for and supply of medium-high skills, there is lower unemployment. Those regions found in the low skills equilibrium quadrant have an unemployment rate above the national average. The two case study regions for this study occupy two different quadrants, which corresponds to their different labour market contexts and rural-urban classifications. Dublin is in the high skills equilibrium quadrant, while the South East region occupies the low skills equilibrium quadrant which suggests there is a concentration of low skilled jobs in the region.

A number of challenges were encountered in trying to gather the relevant data for Ireland at the TL3 level. For the other countries participating in this study, data to apply the diagnostic tool is collected for two different years - generally with a five-year gap to identify trends over time. For Ireland, this was not possible because the classification of 
occupations changed from 2010, which broke the time series and limited the comparability. In addition, no recent data was available on income or gross value added which are used as a proxy for productivity in the computation of the demand index. It is important to note that while this tool shows sub-national variations in the supply and demand of skills, it does not take into account the variations within individual regions themselves. Therefore, this tool is useful when analysed in conjunction with other measurement tools.

\section{References}

EGFSN (2012), The Expert Group on Future Skill Needs Statement of Activity 2011, Forfás, Dublin.

EGFSN (2010), "Future Skill Needs of the Wholesale and Retail Sector", www.skillsireland.ie/media/ EGFSN\%20Wholesale\%20Retail\%200NLINE\%20FINAL.pdf.

Fitzpatrick Associates (2009), Preparation of a Gateway Development Index, Department of Environment, Heritage and Local Government, Dublin.

Forfás (2013), Regional Labour Markets Bulletin 2012, Dublin.

Forfás (2012), Guidelines for the Alignment of Further Education Programmes with the Skill Needs of Enterprise, Dublin.

Forfás (2011), South East Region Employment Action Plan: Spotlight on the South East, www.forfas.ie/media/ 021211-South_East_Action_Plan_Publication.pdf.

Forfás (2010), Forfás Regional Competitiveness Agendas: Overview, Findings and Actions, Dublin.

Forfás (2007), Role of the Institutes of Technology in Enterprise Development: Profiles and Emerging Findings, Dublin.

Froy, F., S. Giguère and M. Meghnagi (2012), “Skills for Competitiveness: A Synthesis Report”, OECD Local Economic and Employment Development (LEED) Working Papers, No. 2012/09, OECD Publishing, doi: 10.1787/5k98xwskmur6-en.

OECD (2006), Competitive Cities in the Global Economy, OECD Publishing, doi: 10.1787/9789264027091-en.

O'Gorman, A. (2008), "A profile of the current City of Waterford VEC adult education programmes, provisions and cohort", www.waterfordvec.ie.

SLMRU (2012), Regional Labour Markets Bulletin 2012, Expert Group on Future Skills Needs, FÁs, Ireland.

Williams, B. et al. (2012), "Synthesis Report - Dublin Ireland's Flagship: Dublin's Role in the Irish and Global Economy 2012", Working Paper Report 4. 


\section{Chapter 3}

\section{Local Job Creation dashboard findings in Ireland}

This chapter highlights findings from the local job creation dashboard in Ireland. The findings are discussed through the four thematic areas of the review: 1) better aligning policies and programmes to local employment development; 2) adding value through skills; 3) targeting policy to local employment sectors and investing in quality jobs; and 4) inclusion. 


\section{Results from the dashboard}

This section of the report presents the key findings from the in-depth fieldwork undertaken in Ireland. In the following section, each of the four priority areas within each theme is presented and discussed sequentially, accompanied by an explanation of the results.

The full results of the Local Job Creation dashboard across Ireland are presented in Figure 3.1 below. Overall it can be seen that Ireland performed most strongly in targeting policy to local employment sectors and investing in quality jobs and inclusion, followed by adding value through skills. Aligning policies and programmes to local economic development was the weakest performing thematic area.

\section{Figure 3.1. Overview of results from Local Job Creation dashboard}

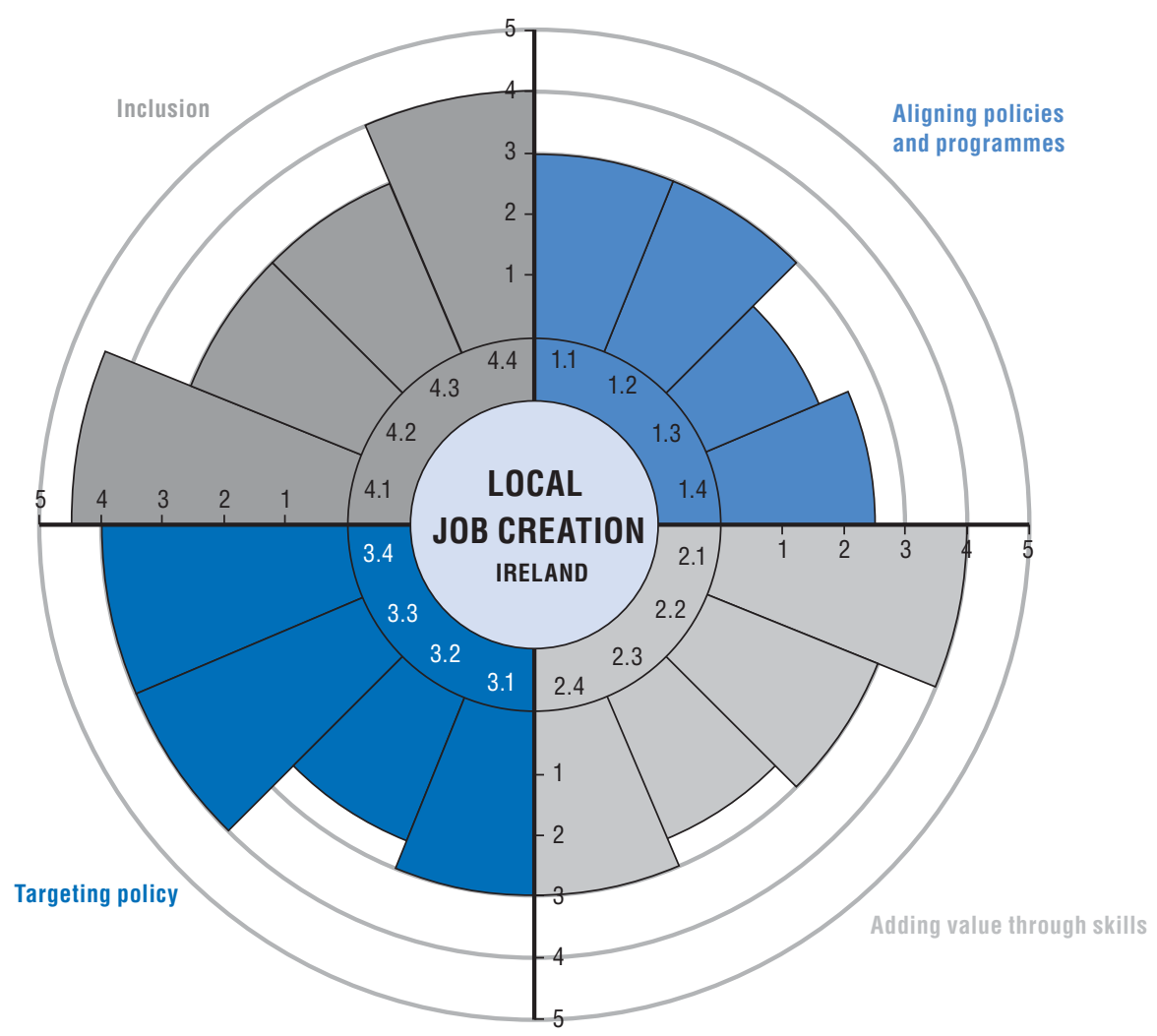




\section{Theme 1: Better aligning policy and programmes to local economic development}

Figure 3.2. Dashboard results: Better aligning programmes and policies to local economic development

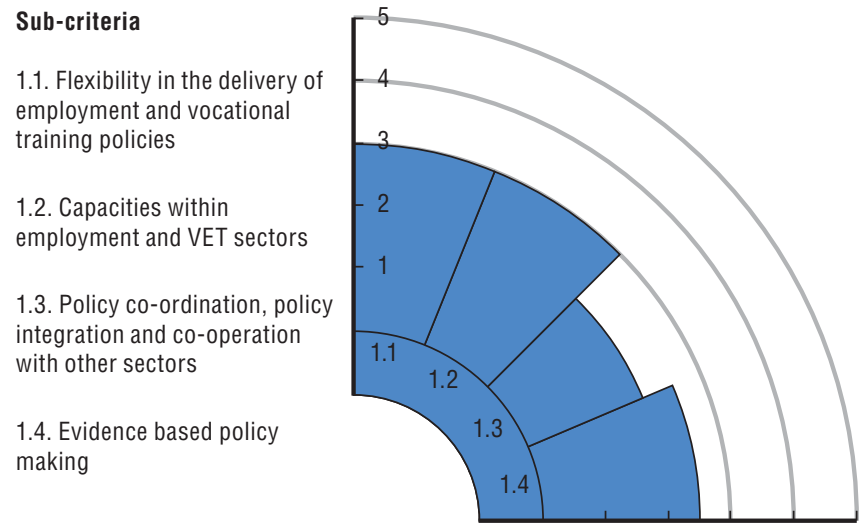

\section{Flexibility in the delivery of employment and vocational training policies}

The OECD defines flexibility as "the possibility to adjust policy at its various design, implementation and delivery stages to make it better adapted to local contexts, actions carried out by other organisations, strategies being pursued, and challenges and opportunities faced" (Giguère and Froy, 2009). Flexibility deals with the latitude that exists in the management of the employment system, rather than the flexibility in the labour market itself. The achievement of local flexibility does not necessarily mean that governments need to politically decentralise (Giguère and Froy, 2009). Governments just need to give sufficient latitude when allocating responsibilities in the fields of designing policies and programmes; managing budgets; setting performance targets; deciding on eligibility; and outsourcing services.

\section{Programme design, target groups and strategic approach}

The local offices of the remodelled employment services under Intreo will operate in the same way across regions and in each local office. Discretion rests with individual case officers in providing information, advice and guidance to individual job seekers. A client focus is the principal source of any regional or local differences in service delivery and depends on "who comes through the door" rather than on programmes or entitlements specific to a region/locality. The supports and measures at the disposal of case officers, designating "at risk" groups, and setting minimum service levels for individuals in these groups are all set nationally. Several national programmes afford case officers additional discretion to tailor and supplement assistance to individual needs. An officer can recommend the use of the Technical Employment Support Grant to tailor training to the precise needs of an individual by purchasing training that cannot be sourced in another way, as long as approved by the regional manager. The Technical Assistance Training Scheme and the Activation and Family Support Programme also allow officers to supplement assistance to individual needs. There have been public consultations to facilitate input from local stakeholders when designing and revising some national employment schemes (e.g. the review of Employment Support Services, the Back to Education Allowance, and the Activation and Family Support Programme). 
The remodelled public employment service has also assumed responsibility for direct employment programmes. These are designed and administered at the national level, but need to be "drawn down" by local development groups. There are no regional quotas for these and their level of use therefore largely reflects the health of the local development sector in an area. While Dublin City and rural areas in the South East have different contexts within which to provide employment services, this is not reflected in how most programmes are designed.

\section{Budget management}

The degree of autonomy which local offices have in budget management has an important impact on their ability to develop and implement active employment measures which are catered to local needs and groups. In Ireland, local offices do not receive flexible budgets for programme delivery because they do not design their own programmes; instead they "draw down" on national programmes. Furthermore, funding is flowed by programme line with limited flexibility for the local level to adjust budgets across programmes based on demand. The Department of Social Protection provides funding to local offices to ensure they have sufficient resources to deliver the activation measures required of them. Budgets are generally allocated according to the number of registered unemployed per county, against which the number of case workers needed is calculated. The OECD LEED electronic questionnaire results identified budget management as an area where both types of offices (e.g. the public employment service offices and the Local Employment Services Network) have limited flexibility.

\section{Performance management}

Flexibility in performance management can enable local offices to have input into how their activities are measured and how the outcomes they are delivering are evaluated. Flexibility in performance management is important, as local offices may be doing innovative activities which are not being captured in indicators set at the national level. In many countries, local employment offices are measured on their performance against targets set at the national or regional level, but in some cases targets are negotiated with local offices before being set.

In Ireland, performance management requirements are set at the national level with limited involvement or negotiation with local employment offices. The principal requirement on the employment service is to work with those referred to it in keeping with the requirements set out in the Pathways to Work programme. This essentially means that each local office is required to interview every person who registers as unemployed and assign them a PEX score (probability of exit), depending on which additional supports are provided and whether they are referred to a national training/employment programme. Local offices are held accountable to this and if they fail to process claims efficiently and

clients do not receive the necessary packages of services, penalties may be imposed and the district manager is likely to intervene.

\section{Outsourcing}

Outsourcing is carried out nationally and local employment offices are not involved in this process. Service level agreements are drawn up by the Department of Social Protection with "implementing bodies", usually the Local Employment Service Network via Local Development Companies, to provide employment supports to specified disadvantaged 
groups in an area. The contracted bodies have autonomy to introduce measures specific to their areas, but have to meet standard minimum service entitlements and outcome objectives for individuals from specified cohorts. The service level agreements specify target groups, the essential services to be supplied in each case ("outputs") and what constitutes the required caseload of a single "mediator" (guidance office). In both the Dublin and South East regional meetings, those operating a local employment service office commented that complying with the specifications of the contract does not guarantee optimal service. This was also expressed in the OECD electronic questionnaire in which a number of respondents commented that the Local Employment Service could offer a more efficient and effective service if it had greater flexibility to operate, particularly in relation to staff deployment, budget operation, and provision of training supports. In particular, the Local Employment Services Network finds that cohorts specified as priorities at the national level do not in fact reflect the individuals with greatest needs in their localities. Additionally, in their experience some of the transformative impacts which interventions have on the unemployed do not classify as outputs because they are not as easy to measure as, for example, entry to a job or progression to a training programme.

As part of the reform process, there is a move by the national government to make greater use of outsourcing to private providers. The expectation is that this will reduce costs, provide more placement officers and improve placement rates, as well as meeting the requirements set by the Troika. There is also scope in this contracting relationship for private agencies to act as prime contractors and to sub-contract out services to not-forprofit bodies, such as the Local Employment Services Network.

\section{Vocational education and training (VET)}

There is a significantly greater degree of flexibility within the vocational education and training system. Both main providers of vocational education and training, Vocational Education Committees (VECs) and FÁS training centres, have a high degree of local input into the decisions as to what courses are delivered and how they should be designed. Vocational education and training actors have more opportunity than their employment service counterparts to adjust programmes to local needs and both providers seek to incorporate significant "bottom up" planning into delivery. There are high expectations in each region regarding how the new institutional architecture and reporting relationships will operate post-reform. Local stakeholders want to ensure that the merging of FÁS training and Vocational Education Committees, and bringing them under the central direction of SOLAS, will not reduce flexibility.

\section{Curriculum design and planning of future VET}

Vocational Education Committees have considerable autonomy at the city/county level. The Department of Education and Skills monitors aggregate budgets tightly, but leaves the composition of course provision largely to the individual VECs. A high local content of course provision is assured by the extent to which their constituent colleges are locally embedded and by the core role of Adult Education Officers. VECs also have broader basic and adult education objectives and are not specifically focused on workforce development. Much of their provision is not informed by labour market intelligence or guided by knowledge of employment outcomes.

In the case of FÁS training, the national level significantly informs and shapes course selection, content and standards, while local flexibility is assured by the strength of its 
regional divisions and the large reliance of its local training centres on contracting external providers. Most FÁS training is explicitly for workforce development and endeavours to be informed by the best available labour market intelligence. Planning for the provision of FÁS training in both regions begins when its individual training centres make proposals on the courses they would like to run. These course proposals are based on:

- How they assess local employers' needs.

- Their own in-house capacity.

- The new programmes that FÁS's central Curriculum Development Unit has developed.

- The courses that can be contracted from third parties.

- Local knowledge of what VECs and other providers will be making available.

At the regional and national levels, these proposals are integrated into a national Annual Service Plan. In a significant new departure in 2011, personnel in each FÁs region were provided with a profile of their region's labour market (its economic structure, employers, and composition of its unemployed) before training centre managers submitted their plans for service provision. This exercise reinforced local management's sense of accountability to local and regional stakeholders.

External contracting by FÁS has become an increasingly important mechanism to make training provision more responsive to skill demands. Private training providers that are on a FÁS contracted training list now account for as much as $20 \%$ of all FÁS funded training, and procedures have been put in place to ensure better quality contracted training by means of a shift away from awarding contracts on the basis of the lowest price to awarding them to the "most economically advantageous tender". Under its interim board pending its dissolution, FÁS external training also incorporated a new bonus for contracted trainers that rewards them for exceptional performance via a "Positive Employment Outcome Payment" for each additional learner placed in employment (this does not include progression to higher levels of education or training).

Both VECs and FÁS are restricted in the numbers of places they can provide in particular schemes (e.g. Vocational Training Opportunities Scheme). There is little flexibility to reallocate places from colleges in areas which are experiencing little or no population growth, to colleges in areas of rapid population expansion. If there is found to be greater/lesser demand for a course, allocation is adjusted at the national level and this is applied evenly across the regions rather than taking into account factors such as local demand or population shifts. Funding for courses depends on whether the course was filled in the previous year rather than on the relevance of the course to the needs of the local labour market. An element of inflexibility can also be attributed to the delivery of courses based on the academic year, which runs from September-May.

\section{Capacities within employment and VET sectors}

In both regions, concerns were expressed relating to the lack of capacities in the face of higher unemployment rates, thus placing greater demand on the employment and training system. Concern was also highlighted regarding the institutional reconfiguration taking place which is merging a range of organisations, each with its own history, procedures and culture, in a short time frame.

In the OECD electronic survey to employment offices (the public employment service and the Local Employment Service Network), respondents were asked if they thought their 
organisation had sufficient capacity to achieve its goals. Within public employment service offices, the largest concern was expressed about the number of employees - 53\% deemed the number of staff to be insufficient. $73 \%$ of respondents within the public employment service responded that financial resources were adequate to fully sufficient. $78 \%$ of these offices responded that employee qualification levels were adequate or fully sufficient.

In contrast, respondents from the Local Employment Services Network responded that financial resources were their biggest concern $-46 \%$ responded that financial resources were insufficient. Over 90\% of respondents from the Local Employment Service Network said that staff qualification levels were adequate to fully sufficient and $71 \%$ of respondents indicated that human resources (e.g. the number of staff) were adequate to fully sufficient (see Figure 3.3).

\section{Figure 3.3. Employment offices with sufficient, adequate and insufficient capacities, \%}

In your opinion, does your organisation have sufficient funds and qualified staff to achieve its goals?

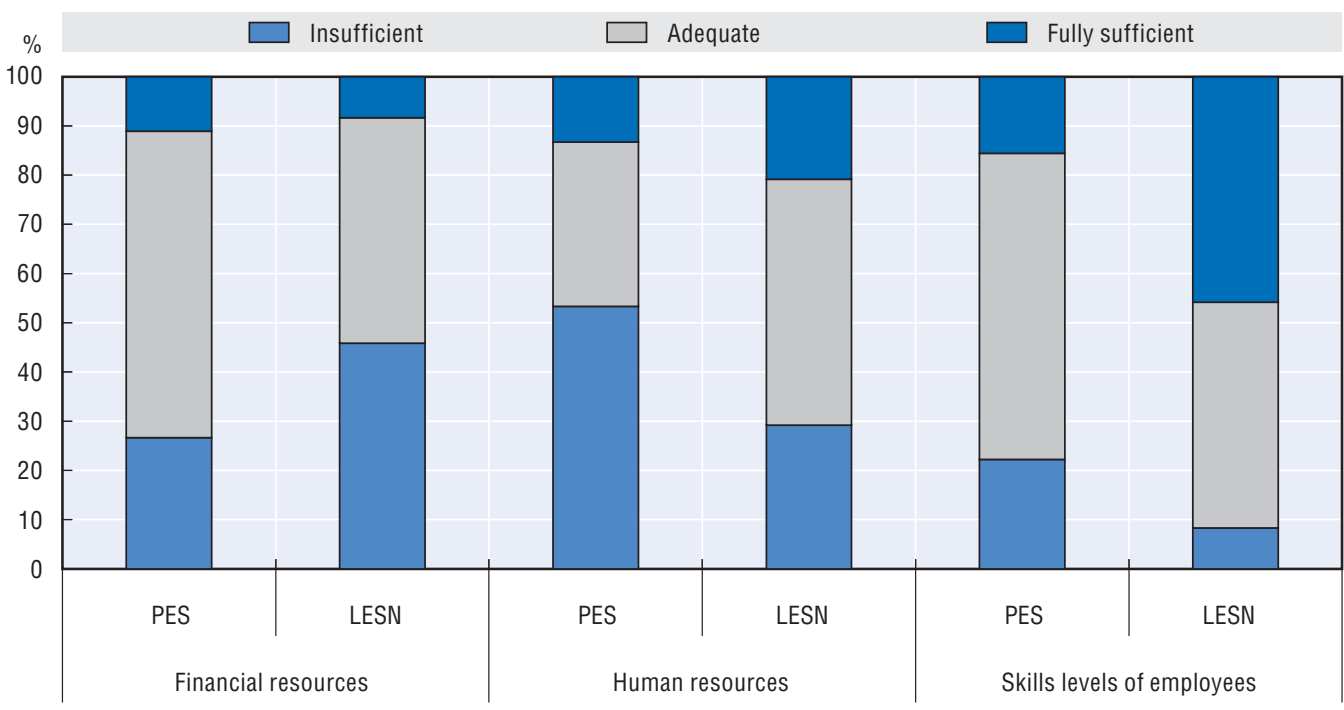

The employment and training system is being affected by the Employment Control Framework under which staff who retire or whose temporary contract expires cannot be replaced. Frequently, it is staff with core experience and skills that leave the organisation, which can create increased workloads for remaining staff. At present, each case load officer oversees approximately 800 jobseekers, which is extremely high by international standards (OECD, 2013e). The Department of Social Protection is aware that despite the absorption of staff from merging bodies, there will still be a significant shortfall in case officers needed at the local level to roll out the Pathways to Work activation programme primarily because the requisite skill sets are difficult to reproduce at short notice. In addition to redeploying staff, it is planning to increase resources by contracting private providers to supplement its own staff resources potential, and to incorporate a significant element of payment-by-results into contracts to boost capacity within a tightly constrained budget. This is expected to reduce case officer ratios to 200 jobseekers per case worker over the next two years. 
Not all of the new bodies will inherit the same previous structures or staff numbers/ skill sets post-reform, creating the risk of uneven service provision. For example, four Education and Training Boards across the country will not inherit any FÁs training Centre. In a related issue, the merging of staff from separate organisations (Department of Social Protection, FÁS employment and Welfare Officers into Intreo and FÁS Training and Vocational Education Committees into Education and Training Boards) means that staff may not have the right skills in their new organisation. For example, merging active labour market programmes and benefit administration functions will create a more integrated service, but it may also mean that case managers previously working in processing payments for the jobless may not have the required knowledge of labour market and training opportunities, interview skills and the welfare supports available to provide a consistent and effective service. Similarly, staff in the new Education and Training Boards may not possess (and may take years to develop) the workforce development focus and labour market expertise of the out-going FÁs training centres.

\section{Policy co-ordination, policy integration, and co-operation with other sectors}

One of the weakest areas in terms of the dashboard findings relates to the limited policy co-ordination, integration and communication between government departments and agencies both at the national level and in their local operations in the employment and training services. This is similar to findings from a previous OECD study, which found that, at the time, the Irish public service was segregated overall, leading to sub-optimal coherence in policy development, implementation and service delivery (OECD, 2008).

There are examples of broad collaboration in each study area, but these tend to be overly reliant on good inter-personal relationships between key personnel, the quality of individual leadership, and/or the stimulus of a specific event, rather than being built on institutional requirements. Indeed, this study has found that the pressure of reduced resources is forcing some public service providers to retrench into policy silos and pull out of partnerships, reducing the extent of collaborative action taken at the local level and making it more difficult for policy co-ordination. This lack of effective co-ordination is compounded by a weak regional tier which has limited impact on policy making.

\section{Collaboration within and between employment and training policy areas at the national, regional and local levels}

Local employment offices were asked in the OECD LEED questionnaire which agencies they collaborate with and the general type of collaboration (e.g. informal versus formal). Public employment service offices responded that they are most likely to co-operate with social welfare organisations, followed by colleges and training institutions, and organisations working with ethnic minorities (see Figure 3.4). This is similar to the findings for the Local Employment Service Network. Public employment service offices and the Local Employment Service Network tend to participate in more informal, on-going collaboration but Local Employment Service Network offices indicated that they are more likely to be involved in "other" types of collaboration, such as sub-contracting relationships, especially with social welfare organisations and local development companies. They are least likely to collaborate with unions or universities, followed by economic development organisations and education policy makers.

The lower levels of collaboration with the education sector indicate limited engagement with both secondary level education and universities which may be a missed 
opportunity. There is also clearly a lack of engagement with broader economic development actors. Respondents were invited to assess the impact of their collaboration with other agencies, and $84 \%$ of public employment service offices and $89 \%$ of the Local Employment Service Network responded that collaboration results in a strong impact on the delivery of services. Respondents were keen to stress the importance of their local links and the value these can bring, particularly the Local Employment Service Network. For example, one respondent indicated "regular contact with other agencies ensures that we are up to date with their policies and procedures and people in other agencies play an instrumental role in assisting us to help clients and to implement initiatives at a local level that will benefit all concerned".

\section{Figure 3.4. Offices reporting collaboration with other agencies and organisations, $\%$}

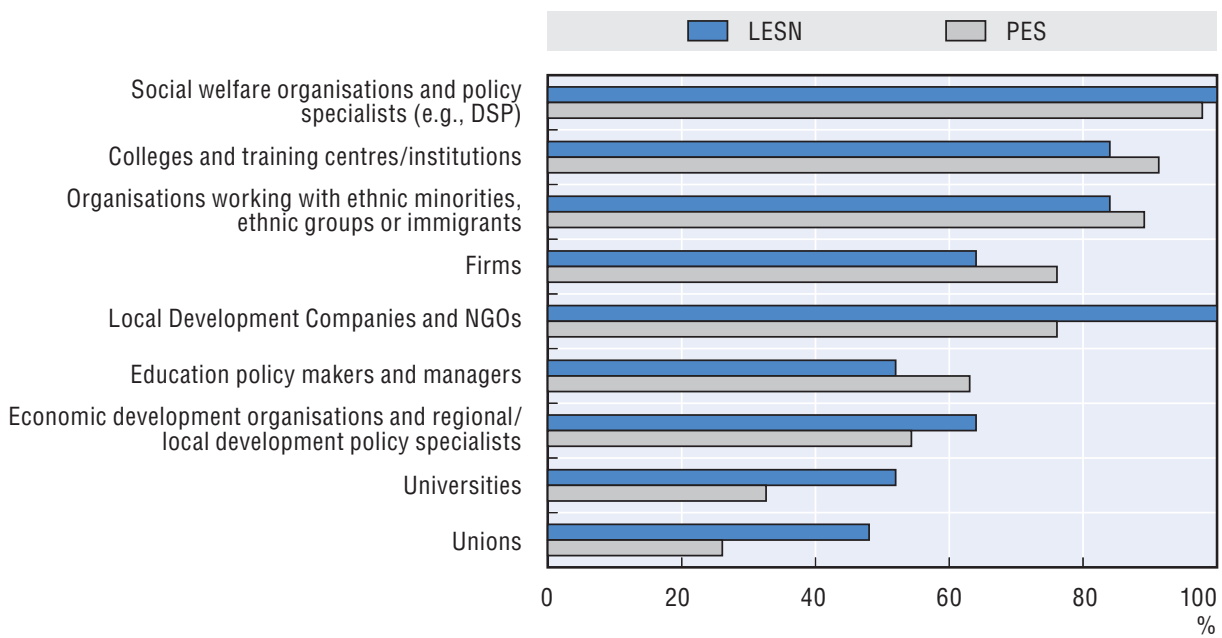

Note: Collaboration consists of four types: i) Informal, on-going collaboration, ii) a formal bilateral partnership, iii) a multi-stakeholder partnership and, iv) a sub-contracting relationship.

It is acknowledged that there is a need for a much greater degree of co-operation between employment services and the vocational education and training system. Prior to the reforms underway, the district managers of the employment service and their equivalents in FÁS and Vocational Education Committees did not have structured communication. As part of the reform process, new procedures for routing people from the Live Register to training courses that enhance their employability are being actively explored and a provisional protocol for how Intreo and current training providers cooperate is already in place. The merging of FÁS Training and Vocational Education Committees into 16 Education and Training Boards is expected to improve collaboration not only within the vocational education and training sector, but to more closely align the training sector with public employment services as Education and Training Boards will work closely with local Intreo offices. At the national level, the legislation establishing SOLAS requires it to develop a strong relationship with Intreo.

In addition, the expectation is that a more unified employment service will be established within the new employment services model. Responsibility for administering benefits, providing employment services, and granting access to employment programmes is being made available at "one-stop" locations, alongside additional advice on a wide 
range of connected issues, such as transport and childcare services, and should strengthen the co-ordination of these services.

Brokers who can facilitate joint action on barriers to labour market integration exist, but they generally operate within their own organisation rather than cutting across providers and offering a holistic service in a wide array of areas such as housing, health, and justice. At the small area level, staff in area-based partnerships and centres for the unemployed advocate on behalf of jobseekers and work closely with other public agencies but they have no ability to provide a joined up service and to accompany a jobseeker through the complex maze of social supports.

\section{Collaboration with area-based partnerships and the private sector}

There is systematic co-ordination between public employment services and the Local Employment Service Network in disadvantaged areas via Service Level Agreements, and public employment services also have a certain level of engagement with area-based partnerships - although each side has considerable autonomy. There has been close working with Local Development Companies to ensure that clients benefit from the expertise and additional services which they can provide, and typically the Department of Social Protection (through local employment service offices) is represented on the Local Development Company boards.

There is a high level of recognition by the public training system of the value of training delivered by the not-for-profit sector. FÁS training, in particular, is a major conduit of public funding to not-for-profit bodies engaged in community-based training and provides funding through three principal initiatives - Specialist Training Centres, Community Training Centres, and Local Training Initiatives. FÁS has promoted good practice within programmes, which SOLAS should seek to develop and strengthen going forward. VECs have been less likely to engage with area-based partnerships. Communication between the private sector and public training providers is sporadic. Under the planned reform of local government, new Socio-Economic Committees (SECs) will be set up in local authorities (a number of pilot SECs are about to be launched) and there is an expectation that these will provide a new space for co-ordinating social inclusion policies and improve on the integration achieved by their predecessor, the County Development Boards.

\section{Collaboration for broader regional and local economic development}

Co-operation between employment services and training provision with economic development agencies and actors at all spatial scales is particularly weak, and mechanisms bringing these actors together are generally non-existent. There is no structured communication between local employment services and bodies promoting regional economic development (e.g. state development agencies, the regional authorities, the local authorities, employer representative bodies, higher education institutions, and area-based partnerships). There is a lack of an authoritative, independent forum in Ireland which speaks on behalf of regional and local economies and there is no authoritative coordination of these players, as a result of which sub-national strategies for employment services and skills development do not exist. While there are numerous boards, partnerships and committees operating at the county and sub-county level, often these lack decision making powers and influence, making the majority of them quite weak. As a result, it is unclear with whom Intreo and SOLAS should co-ordinate actions to address 
regional and local skills needs. The redrawing of the eight regional authorities into three 'super regions' could potentially provide better frameworks for co-operation and better match travel to work areas.

In both case study areas, it was not clear with whom employment services and vocational training providers should engage in order to align their services more closely with local economic development. There is an interesting contrast between how the two regions are proceeding in the search for strategic economic leadership. While large scale brings an institution more resources, opportunities and ambition to focus on research and skills, as evidenced in the Dublin region, it can also entail a greater focus on national and global developments rather than on local employment sectors.

In the South East, bilateral dialogue and communication is less complex than in the Dublin region as there are fewer stakeholders. There are examples of strong joint working, particularly between Waterford Institute of Technology (WIT) and VECs, and indeed their provision is mutually complementary. VECs serve as stepping stones, bringing more local people to the stage where they aspire to and meet the requirements for progressing to the WIT themselves, while the presence of the institute in the region serves to motivate local people to want to access third level education. For example, many of the courses run by the Waterford College of Further Education (a constituent college of the Waterford City VEC) have direct links to courses in WIT. The Institute also exercises a particularly strong leadership role in attracting and supporting internationally-traded companies and graduates. Its quest to acquire university status is one of the most insisted upon policy recommendations among stakeholders across the region. Similarly, the spectrum of activities of Carlow Institute of Technology is credited with enabling its sub-region to benefit to a greater extent from its proximity to the Greater Dublin Area, which is advantageous to local residents in the wider region. Nevertheless, no convincing regional forum has yet developed and indeed, the South East illustrates the difficulties in creating a tailored platform to speak for the regional economy and in "earning" a leadership role among key stakeholders. Faced with the challenges of a large agricultural sector and a vulnerable manufacturing base, the relatively poor performance of its regional gateway, and the need for collaboration between at least four county authorities to support its development, the region has struggled to coalesce around internal leadership.

The key difference in developing strategic leadership and a joint vision for Dublin's economic development is the much larger diversity of organisations and sectors that impact on the performance of Dublin's economy. The Economic Development Unit of Dublin City Council ${ }^{1}$ has invested in supporting a collaborative leadership network across regional leaders in local government, business, and academia - the Creative Dublin Alliance. The Alliance helps to identify, discuss, recommend, and distribute solutions in response to the challenges that Dublin faces as an international city region which is competing with cities globally for mobile talent and enterprises. Membership of the Alliance, however, is high-level and selective. Third level institutions, for example, are represented but not the City of Dublin Vocational Education Committee. The Alliance also remains vulnerable to changes in key personnel and to the emergence of new priorities for individual key players. Box 3.1 gives more information on the Alliance and other Dublin city examples of collaboration. 


\section{Box 3.1. Collaboration for city-level economic development, Dublin region}

The four local authorities in the Dublin region work closely together under the aegis of the Dublin Regional Authority. In 2009, the four authorities collaborated to produce an Economic Development Action Plan for the Dublin City Region and when the local authorities subsequently produced their separate development plans for 2011-17, each engaged with its responsibility and roles in helping to deliver on the 2009 Plan. These documents contain significant elements of analysis and prescriptions as to how the economy and employment are to develop within each council area, including at the level of quite defined small areas. A particular challenge to exercising strategic leadership in the Dublin region is the large number of organisations and sectors that impact on the performance of the city's economy. Several developments are underway in an effort to create more stable and effective coalitions to steer the region's economic development. For example:

- Dublin City Council plays a prominent role in the Creative Dublin Alliance, a network for the Dublin region bringing leaders in local government, business, education, and creative sectors together. It was created in 2009 arising from the need to create strong leadership as a priority. Its purpose is to help identify, discuss, recommend, and distribute solutions in response to the challenges that Dublin faces as an internationally competitive city region, including innovation, entrepreneurship, attracting and retaining talent, and city-region marketing. It is chaired by the Dublin City Council City Manager and includes representatives from other local authorities, IDA Ireland, University College Dublin, Dublin Institute of Technology, Dublin Chamber of Commerce, and Enterprise Ireland as alliance members.

- The Digital Hub is a vibrant cluster of digital content and technology enterprises located in Dublin's south-west inner city. Set up by the Irish government in 2003, it fosters innovation, technological development and creativity. It is home to 66 digital enterprises, ranging from start-ups to well-established businesses. Since the project's inception, 170 companies have progressed through the Hub, including some now wellestablished names. The initiative is managed by the Digital Hub Development Agency, an Irish state agency, and the board includes representatives from a wide range of sectors including education, business, arts, social and urban regeneration interests. The sponsoring partners are the Department of Communications, Energy and Natural Resources, IDA Ireland, Enterprise Ireland, and Dublin City Council.

- Fingal County Council and Dublin City Council have formed a Cleantech Cluster, The Greenway, in collaboration with Dublin City University, the Dublin Institute of Technology, the Dublin Airport Authority, and Ballymun Regeneration Ltd. The Greenway provides a "test-bed platform" for companies seeking to trial and commercialise their technologies on a municipal scale and through it they can work closely with the two largest local authorities in Ireland and other defining stakeholders.

\section{Evidence based policy making}

\section{Use of up-to-date, locally specific data}

Data collection and dissemination on local economies and labour markets is improving in Ireland. The main state agency for data analysis is the Expert Group on Future Skills Needs (EGFSN) which advises the Irish government on current and future skills needs of the economy and on other labour market issues that impact on Ireland's enterprise and employment growth. Established in 1997, the EGFSN reports to the Minister for Jobs, Enterprise and Innovation and the Minister for Education and Skills and is funded by the 
National Training Fund. Forfás provides it with research and secretariat support while the FÁS Skills and Labour Market Research Unit (SLMRU) provides it with data, analysis and research and manages the National Skills Database.

There are a number of main sources for regional and local data collection and analysis. An annual National Skills Bulletin provides estimates of skills shortages across the full range of Standard Occupational Classifications, carried out by the EGFSN. This contains a short section on regional skills profiles but does not provide the same level of detail, and sector specific analyses are likely to be ad hoc. In 2012, the EGFSN also published regional labour market profiles which have significant potential to support regional decision making by education and training providers, as well as career guidance and immigration services. These profiles extract data from the Central Statistics Office, government departments, the state development agencies and other sources to sketch the characteristics of each region's economic structure and workforce. The data and analysis comes from the SLMRU and its National Skills Database. ${ }^{2}$ The Dublin region has actively been trying to improve its evidence base in recent years. The Dublin Regional Authority and DCC Economic Development Unit have enlisted the School of Geography, University College Dublin, to develop a regionally specific profile from national statistical and public administrative sources, and to develop indicators.

While data collection at the sub-national level is improving, and authoritative profiles on local labour markets are beginning to emerge, there is concern in both regions that the capacity to use this data to inform policy making and planning and to evaluate programmes is lagging. Data on their own do not constitute evidence and data systems need to be audited and complemented by qualitative follow-up. Only when framing questions and analyses do data have relevance in confirming or rejecting interpretations of what is happening. There was agreement in both regions and nationally that not enough is known about the outcomes attributable to specific employment and training interventions and that evaluation which is carried out rarely informs service planning.

Relatively few courses, programmes and providers can demonstrate outcomes for participants and there is a particular absence of longitudinal tracking of individuals after course or programme completion. For example, the progression of over half of the 30000 learners who completed the main vocational education programmes (Post Leaving Certificate Programmes) in 2010 was unknown (Forfás, 2012). Likewise, there is no requirement on the 25000 welfare recipients supported by the Back to Education Allowance to notify the Department of Social Protection of results obtained when they complete their courses (DSP, 2012).

In guidelines for the alignment of further education programmes with the skill needs of enterprises, Forfás found that data on retention, dropout, completion rates and outcomes in further education were insufficient to permit proper evaluation and guide the reallocation of resources (Forfás, 2012). An OECD review of Ireland's vocational education and training system similarly emphasised the need to generate and use evidence and research to a much greater degree (Kis, 2010). These examples are symptomatic of a generally weak evaluation culture in Ireland.

There is a strong desire that, post-reform, employment services and vocational training should be guided by the results of research that tracks individuals after interventions. However, there is concern that difficulties in using the unique individual identifier for public services (the PPSN) are slowing progress. Pobal is attempting to apply a 
stronger evaluation approach to the local development sector by introducing the Irish Reporting and Information System (IRIS) but is aware of the work still to be done to improve its core indicators and to advance from recording activities to identifying outcomes. This involves the challenge of improving metrics for capturing the diffuse objective of community development (Box 3.2).

\section{Box 3.2. The Integrated Reporting and Information System}

The Integrated Reporting and Information System (IRIS) is an integrated caseload management tool for the Local and Community Development Programme (LCDP). It was developed by Pobal in 2010 in line with a new LCDP framework and rolled out in 2011 to the 52 Local Development Companies (LDCs) funded under the LCDP. The Department of the Environment, Community and Local Government is the lead government department for the LCDP and covered the costs of developing the data system. Pobal uses the data in IRIS to oversee the implementation of the LCDP and to fulfill its reporting requirements to government. It is also a valuable source of information for analysis and to support research projects. LDCs find IRIS a useful resource as it assists them to fulfill their contractual obligations under the programme and to plan, analyse and track their work.

IRIS contains the objectives, annual work plans, and budgets and expenditure for each LDC, detailed on a quarterly basis. The progress of each activity is tracked, and outputs against targets based on the national programme indicators (e.g. number of beneficiaries participating in labour market training) can be measured. IRIS contains the personal details of over 100000 people and 5000 Local Community Groups which have benefitted from the programme. Each is tracked over the course of their engagement with the LCDP and their progression is recorded. Detailed and summary reports can be generated from the system to provide easy to access information on the status of each LDC in implementing their work plan and meeting their targets for outputs or expenditure.

\section{Collecting data and administering policy for the local travel to work area}

Data collection and evaluation is made harder by the fact that there is no clear fit between administrative boundaries and "travel to work" areas in Ireland. ${ }^{3}$ In the Dublin region, the travel to work area extends far beyond its boundaries and even the larger Greater Dublin Area has failed to reflect the large levels of in-migration. However, under the new regional assembly divisions, the Eastern and Midlands Regional Assembly will better reflect commuting patterns and should provide a new framework within which 12 local authorities can work together. Similarly, the new, much larger Southern Regional Assembly will take in the South East region and provide a better framework within which ten local authorities can co-operate. Currently the South East regional boundary is affected by much commuting to the GDA, while on the region's Western fringe there is some commuting to Limerick and Cork. The merging of Waterford City and County Councils in 2013 can be expected to improve joint data gathering and analysis at a county-wide level, and thus better reflect and respond to employment and travel patterns within the county. 


\section{Theme 2: Adding value through skills}

Figure 3.5. Dashboard results: Adding value through skills

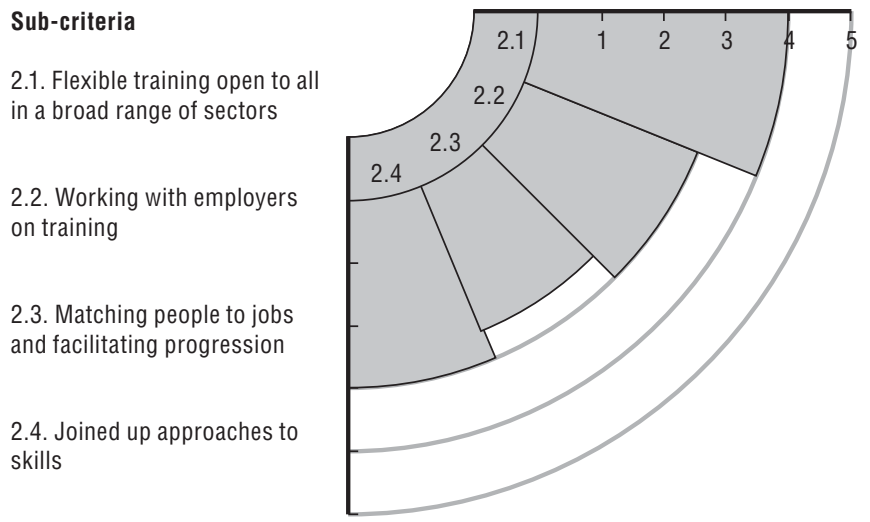

\section{Flexible training open to all in a broad range of sectors}

Most people in both the Dublin and South East regions have access to training in a variety of sectors. Physical access is generally quite good as residents are generally within reach of a site where training is being provided. This is particularly the case for people living in or near urban areas. Residents in disadvantaged areas can be disproportionately affected by the quality of public transport and the availability of childcare. For rural residents, options also depend on car ownership. The fact that access is good in the South East, despite its dispersed pattern of population settlement, reflects the wide outreach of Vocational Education Committees and Local Development Companies. The quality of broadband connections is also a contributing factor to being able to access training, and this is widely available in both case study regions. FÁs provides a national online training service, the E-College, which is designed to provide a flexible response to the skill needs of job ready individuals. It delivered free training courses to an estimated 12000 unemployed people in 2012 (see Box 3.3).

Modularisation has been mainstreamed in how training courses are delivered, however it is not yet available in all vocational education courses - indeed it is not yet an option in Post Leaving Certificate programmes which are the single largest vocational education programmes. There is quite extensive after-hours training, mainly provided by private sector providers, and this can be classroom based, on-line and blended. Generally, private sector providers target specific occupations and their fees reflect the likely earnings to be had in those occupations. For example, one particularly large private sector provider, the Open College, provides more than 70 FETAC Levels 5 and 6 courses in both regions with fees starting at EUR 249 (in 2012). The quality of training in both regions has been significantly enhanced by the fact that most training is certified. Most providers have embraced the National Framework of Qualifications - the single structure for recognising all education and training in Ireland. ${ }^{4}$

Nonetheless, challenges were noted in certain respects in both case study regions. Post Leaving Certificate programmes remain full-time only and all modules must be completed before any accreditation is gained. In addition, all full-time VEC provision is 


\section{Box 3.3. FÁS E-College - flexible response to the skill needs of the job ready}

Online courses in the E-College, set up by FÁS, are designed to be a flexible response to the specific skill needs of job ready individuals who require training with certification to assist them to re-enter the labour market. Online courses are available free of charge to unemployed clients. Courses are also available, for a fee, to employed persons who wish to update their skills. These courses are delivered completely online and technical support is also provided. All FÁS online courses last for 14 weeks, but learners continue to have access to the course and materials for a further ten weeks (i.e. 24 weeks in total). Over 30 courses are available and course categories include Operating Systems, Networking and Technical Support, Software Development/Programming, Office Applications, Web Design/ Multimedia, and Soft Skills.

Unemployed clients will be able to participate in blended learning courses in selected areas in the near future, which provide additional online tutor support and a range of online training with enhanced learner supports including telephone, email, E-tutor and instructor led workshops. Some courses may also include one to one, group mentoring, assignments or project work. Fee paying clients can register and pay online while unemployed clients can register in their local FÁS Employment Services Office.

Source: eCollege Learning Portal (2013), eCollege Learning Portal website, www.ecollege.ie.

based on the academic year, meaning course enrolment is at the beginning of September each year and no teaching occurs during the summer break (it is primarily FÁs training that allows monthly intakes). Demand has grown for courses perceived to be better quality however, core budgets are slow to reflect shifts in learner demand and to update training curricula. A significant degree of provision is based on the capacity and skills of providers and on learners' demands.

Local training curricula are slow to adapt to changing business needs, and trainers often do not have up-to-date skills themselves. However some imaginative ways are being piloted to speed up innovation and implementation by providers (e.g. the MOMENTUM Programme - see Box 3.4). In a clear departure from the more traditional annual adjustment of the budgets of incumbent providers, private, not-for-profit and public providers were invited to propose programmes that demonstrably link specified types of disadvantaged jobseekers with specified areas of employment, and to assume some of the risk if employment outcomes fall below their expectations.

\section{Access to relevant training for workers and the unemployed}

There is a strong and consistent national policy focus on supporting the jobless to improve their employability by engaging in training or returning to education. Indeed, most FÁS training is for those seeking work and a high proportion of training places is reserved particularly for the long-term unemployed. As the priority shifts to the long-term unemployed, FÁS has been reducing its provision for training those already employed. Subsidised training for workers occurs only on a small scale and in quite specific circumstances (e.g. in Skillnets and SKILLVEC). A universal Competency Development Programme drew down significant European Social Funds for training of the lower-skilled in company workforces but was discontinued after 2008 and subsequently, FÁS was directed to concentrate its training on the unemployed in support of Intreo. FÁS is 


\section{Box 3.4. MOMENTUM programmes - more innovative, rapid responses to employers' training needs}

A recent government initiative has been launched which will provide free education and training projects for up to 6500 long-term jobseekers to assist them in gaining in-demand skills and to access work in sectors of the economy where there are job opportunities. The programmes include on-the-job training in the form of work experience modules as well as the development of the workplace skills required to obtain and retain employment. 36 education and training providers from both the private and public sectors will offer 62 individual MOMENTUM programmes in 87 locations across the country. These projects will be in the expanding employment areas of ICT, digital media, healthcare and social services, the green economy, food processing, and sales and marketing. Programmes are based on clusters of occupations in sectors associated with good national employment opportunities. Specific projects will also be available for those under 25 to assist them to enter or return to employment, including "Train To Work Opportunities", "Green Pathways", and a Graduate Activation Programme.

MOMENTUM is an outcomes-based model of education and training. The payment system to providers is outcomes based with part payment reserved for key stages of the programme, including challenging certification, progression and employment outcomes at the end of the programme. The courses are tailored to both the needs of the long-term jobseeker, but also employers who are experiencing skills shortages. MOMENTUM is administered by FÁS and funded by the Department of Education and Skills through the ESF supported Labour Market Education and Training Fund.

Source: FÁS (2012a), "Momentum programme offers 6500 training and education places for jobseekers", 18/12/12, www.fas.ie/en/About+Us/News/momentumskills.htm.

currently spending eight to nine times more on training people for employment than on training people in employment (FÁS, 2012b; FÁs, 2013).

A minimum of $75 \%$ of FÁS training places is currently reserved for those on the Live Register for longer than 12 months. When individuals undertake training, they receive the equivalent of their social welfare payment as a training allowance plus a weekly training bonus. Unemployed participants have access to mainstream training and to the longer, more occupationally-specific programmes, as well as foundation and bridging courses. Unemployed people who return to education (full-time or part-time) can retain their social welfare payment and have their tuition fees paid, although conditions vary from programme to programme. The unemployed are also entitled (as are all students) to apply for a grant on the basis of their household's financial position.

There is an emphasis on assisting learners requiring additional supports to undertake mainstream training through providing bridging or foundation training and approximately 18\% of FÁS training provision in 2013 has been allocated to this type of support (FÁS, 2013). A significant proportion of these supports is directed at early school leavers and disadvantaged adults via the Community Training Centres and community groups. Vocational Education Committees also target early school leavers with remedial skills through Youthreach Centres. In addition, the local development sector acts as a broker between individuals and state services and provides "bridging" courses that bring individuals to a level where they can progress to state training. 
Employer bodies and enterprise agencies have called for the new vocational education and training body (SOLAS) to be given a strong mandate for promoting in-work skills development of the existing workforce in the interests of up-skilling and utilising skills more effectively to raise productivity. During the OECD study visit, some local stakeholders expressed concern that with the disbandment of FÁS, there will no longer be a specialist workforce development agency. The demise of a specialist training agency for the hotels and catering industry (CERT) in 2003 was cited as a precedent, and its effectiveness in upskilling lower skilled workers in the sector has not been emulated by other providers to date.

\section{Training in generic skills}

Within public training provision, there is a certain amount of emphasis on basic skills training. Results from the OECD LEED questionnaire to employment services indicated that literacy and number training are a core component of training funded. However, during the OECD study visit, stakeholders expressed that more could be done with jobseekers to ensure they have the necessary basic level generic skills. Employer groups, in particular, noted that basic skills were frequently lacking in job applicants and that the secondary level education system needs to put more emphasis on these skills. Regarding higher level generic skills, these have been assumed to be primarily the responsibility of mainstream education. However, there is greater recognition of the need for "soft" skills to be developed alongside occupationally specific skills in basic and advanced vocational training.

\section{Working with employers on training}

\section{Employers and publicly funded training}

Employer groups consulted for this study expressed dissatisfaction with the standard and relevance of publicly funded training. Public training curricula offered by VECs and FÁS training were seen as slow to adapt to changing business needs, and trainers often do not have up-to-date skills themselves. Larger employers rely primarily on in-house training/ private trainers to bring new employees (including graduates and people who completed state training) to the required skill levels. In general, employers' interest tends to be more focused on the education system and the supply and quality of higher education level graduates, rather than on public training.

Employers contribute to training via the National Training Fund, administered by the Department of Education and Skills. A small levy (0.7\%) is incorporated into employers' basic social insurance contribution. Employers would like to be more involved in the design and implementation phases of new training programmes so as to ensure the best fit with their requirements, and there is scope in the changing education and training architecture to build in more employer involvement. Intreo is introducing an Employer Engagement Strategy, which will appoint a person in each local office to develop a databank of local employers and actively "market" local jobseekers to them. There will also be private sector business representatives on each of the Education and Training Boards.

In both case study regions, some not-for-profit bodies are working closely with employers in setting up training programmes. The two most successful examples are Skillnets and FIT Ltd, set up to facilitate workplace training and up-skilling. Both FIT and Skillnets are particularly adept at motivating unemployed people to complete training and the initial evidence is that they place sufficiently high proportions of them to ensure a high return on investment (see Box 3.5). 


\section{Box 3.5. Promoting and facilitating workplace training - Skillnets and FIT Ltd.}

Skillnets was established in 1999 to promote and facilitate workplace training and upskilling by SMEs. It is the largest organisation supporting workplace training in Ireland. In 2011, it had 70 operational networks through which it trained over 40000 people for a total expenditure of EUR 25 million. It is a state-funded, enterprise-led body that co-invests with enterprises, particularly SMEs, when they co-operate in networks to identify and deliver training suited to their workforces. A network of SMEs, which are mostly sectoral or regional, is guided by a steering group of the local enterprise representatives. The steering group gives strategic direction and guidance to a network manager who co-ordinates all operational activity leading to the delivery of an agreed training plan with learning interventions suited for the member company workforces. The national programme is coordinated by Skillnets Ltd., who contract with all networks and provide programme support and monitoring to ensure the delivery of agreed quantitative and qualitative target outputs.

In 2011, 30 of these networks were located in Dublin, but were predominantly sectoral networks with a national remit and company membership. $25 \%$ of all Skillnets member companies and $33 \%$ of trainees were Dublin-based. Three networks were specific to the South East region (Carlow Kilkenny Skillnet, South Tipperary Skillnet and Waterford Chamber Skillnet). While Skillnets has a national impact, its influence is largely confined to SMEs which account for $94 \%$ of its 10000 member companies. Originally set up to cater exclusively for the employed, since 2010 Skillnets has a mandate to include the provision of training for jobseekers. This happens both in an integrated manner with jobseekers attending programmes with employees, and also by focusing exclusively on the needs of jobseekers through the provision of dedicated longer-term programmes (e.g. the Jobseeker Support Programme) which includes work placements. Skillnets launched a pilot training initiative, ManagementWorks, providing management training to the SME community with a key focus on owner-managers.

FIT Ltd is a not-for-profit, enterprise-led body that designs and oversees the delivery of training for unemployed people to provide skills in demand in high-growth sectors of the economy (principally IT but also office administration, customer care, logistics, and renewable energies). It is based on the realisation that "emerging sectors" require not just third level graduates but significant numbers of medium skilled workers and that these jobs are feasible for unemployed people. Its board comprises senior executives from blue chip companies who vouch for the relevance of the training provided. FIT can essentially be understood as a broker or supply chain manager. It designs the training, identifies the most capable providers (frequently a VEC or FÁS), selects trainees from referrals made by DSP, monitors the study period to ensure course quality and course completion, supports trainees in securing employment afterwards, and monitors both employer satisfaction and employee progress to the end of a three year cycle. Established in 1999, it is now responsible for the training of 2500 disadvantaged jobseekers a year.

Source: FIT (2013), FIT website, www.fit.ie, accessed June 2013; Skillnets (2011), Annual Report 2011; Skillnets website, www.skillnets.com, accessed June 2013.

\section{Work-based training and apprenticeships}

One of employers' biggest challenges is that people are not work ready, and young people in particular do not have sufficient work experience and employability skills. Secondary schools generally do not provide young people with work experience opportunities, although some use the transition year (an optional year at the age of 15) to 
allow students to gain workplace experience. Work based training is a feature of the most effective training courses (FÁS traineeships are often cited in this regard) and there is wide appreciation of the benefits of alternating classroom-based training with workplace periods. For young people in particular, there is a need for more traineeships and apprenticeships, but which are shorter and less costly than the standard Irish apprenticeship model (see Box 3.6).

Policy makers are considering how to reform the current national apprenticeship system which achieves high standards but has traditionally targeted a narrow range of largely construction-related trades. Reforms being considered include applying the core elements of the apprenticeship model to non-traditional sectors, such as health and other service sectors, looking at more flexible and shorter models that would attract wider employer involvement, and expanding work-based training opportunities, such as traineeships. During the OECD study visit, employer groups also expressed an understanding that training costs need to be more equitably distributed between the state and employers, as well as individuals. The successful extension of apprenticeships and traineeships will be particularly beneficial for young people who want to take a vocational route and for the small cohort who do not complete the senior cycle of secondary education.

\section{Box 3.6. Overview of Ireland's apprenticeship system}

Ireland's apprenticeship programme is the recognised vehicle through which to become a certified craftsperson. It is a modular, standards-based system that comprises alternating phases of classroom-based training and on-the-job work experience. It currently covers recognised technical or craft professions in areas including construction, engineering, electrical, motor, and printing and paper. Formal apprenticeships in Ireland last for four years and comprise seven phases regardless of sector/occupation. Three of the phases are off-the-job, and apprentices attend a FÁS Training Centre for the first phase and an Institute of Technology for the subsequent two phases over a total period of 40 weeks. The remaining four phases are spent in the workplace. Employers are given a list of activities to be developed on the job and the employer certifies that these have been performed satisfactorily. Successful completion of all phases leads to a national award of an Advanced Certificate at Further Education and Training Awards Council (FETAC) Level 6.

Apprenticeships are limited to a relatively narrow range of designated trades and tend to attract extremely low numbers of female participants. Formal apprenticeships in Ireland are only available in sectors with a strong craft tradition. In 2009, just two sectors construction and electrical trades - accounted for over $80 \%$ of all apprentices. This has had an impact on the gender profile of apprentices in Ireland. Only a very small number of apprentices are female. In 2004, of a total of 27935 apprentices, 119 were women (Gender in Irish Education, 2006).

Since the economic recession took hold, there has been a severe drop in the number of new registrants, particularly in construction-related trades, and a substantial number of live apprentices are redundant due to employers experiencing trade difficulties or ceasing to trade entirely. When the construction sector contracted after 2007, apprenticeship in Ireland effectively collapsed. From a peak of 8300 new registrations in 2005, new registrations fell to 1434 in 2012 and are expected to rise to 1596 in 2013.

Source: OECD (2014, forthcoming), "Local Youth Employment Strategies Review, Ireland", OECD Local Economic and Employment Development (LEED) Working Papers, OECD Publishing, Paris. 


\section{Matching people to jobs and facilitating progression}

\section{Career guidance and planning}

There is a strong sense that the availability and quality of career guidance can be improved and that its contribution to subsequent job tenure, productivity, earnings and employer satisfaction is undervalued. Successful job matching needs a strong regionallyspecific dimension but careers advice in Ireland tends to be based on national careers models.

The general consensus from local stakeholders during the OECD study visit was that careers advice for children and young people is insufficient and needs to be introduced into schools earlier. Schools receive a special allocation to fund career guidance and many school boards use it to appoint a dedicated career guidance counsellor. In 2012, the allocation was reduced and schools are either maintaining a dedicated counsellor at the expense of teaching hours elsewhere or trying to make it a general responsibility of the teaching staff. Even before the reduction in funding, there were strong concerns regarding the level of labour market knowledge of counsellors and the limited interaction between schools and employers. Career guidance is also chiefly given to students near the end of their school years. Outside school, young people can access career guidance through universities, VEC colleges, FÁS courses or Youthreach.

Adult career guidance and planning is provided by a wide range of agencies and organisations including VECs, FÁS, the Local Employment Service Network, higher education institutions, LDCs, and Citizen Information Services. Access to some form of career planning comes primarily when adults undertake a training course or become unemployed. The Adult Educational Guidance Initiative, for example, is a service for adults experiencing particular difficulties in accessing further education. Funded by the Department of Education and Skills, and provided through VECs, it advises people at the pre-entry, entry, on-going and pre-exit stages of further education, but coverage is patchy. The absence of an overall strategy for ensuring access for all adults to guidance, job search, and job matching is keenly felt.

\section{Mapping job profiles and strategies to address skills deficits}

Reports from the Expert Group on Future Skills Needs outline the skills and competencies required for jobs in specific sectors based on consultation and research at the national level. These are drawn on by training and other providers but are not sufficiently detailed to ground the mapping of profiles for local jobs. FÁs is implementing a new career-themed approach to training in its course provision and curriculum design and trainees will be made conscious of a range of jobs and industry sectors for which their training is equipping them. It has identified ten career clusters to inform its future training provision, including Health Care and Social Services, Built Environment and Transportation, Distribution and Logistics, Information Technology, Sales and Marketing, Financial Services, and Business Administration and Management. These clusters are based on the best labour market intelligence available on current and emerging employers' needs. There are some strategies in place to better match skills supply and demand and to address skills deficits, particularly in knowledge-intensive, fast growing sectors. For example, IBEC has national skills strategies for Information and Communications Technology, Chemicals and Pharmaceuticals, and Financial Services, and a Cloud Computing Strategy is under development. 


\section{Activation and job-matching}

In the first three months of an unemployment claim, an individual may participate in a group engagement session which provides information on services and entitlements, and this is a central part of the current activation process. A small number who have been profiled and assessed as being at particular risk of remaining jobless for a long time will get a one-to-one session. This will be widespread practice by the end of 2013 under the new Intreo activation system.

In working to fill vacancies, the PES formally relied principally on its National Contact Centre rather than on links between local offices and local employers. In practice, a large number of employers used neither the National Contact Centre nor their local employment office when recruiting, even for entry-level jobs, preferring to hire directly or via private jobs agencies. A recent business survey on recruitment of non-graduates showed that less than $10 \%$ of surveyed employers found the National Contact Centre to be fairly or very effective, while around 35\% described it as ineffective. Almost $60 \%$ of surveyed employers do not use this as a recruitment source in the first place. Findings for using the local employment office to source workers are similar (IBEC, 2013). In response to high profile local company closures or openings, a local employment office may have become proactive and collaborate directly with local employers to find alternative employments for a large group or in sourcing local candidates on behalf of a new company.

Intreo is introducing a new Employer Engagement Strategy that, along with its growing participation in local job fairs, will be a critical element of the new employment services' approach. A person will be appointed in each local office whose principal role will be to develop a databank of local employers and actively "market" local jobseekers to them. Intreo and Skillnets have also developed a working relationship in 2012 to forge local connections with networks at the local level, and have recently agreed to a protocol with the objective of increasing the quality and quantity of jobseeker referrals to Skillnets and raising awareness of what Skillnets can offer to clients of the Department of Social Protection frontline staff nationally.

\section{Facilitating progression for low skilled workers}

There is relatively little attention given to career pathways within companies, the evolution of people's earnings over time, or to the scale, causes and consequences of job mobility. Support for professional development and establishing career ladders for low skilled workers is evident but depends on the sector. The childcare sector is the focus of particular attention. The Department of Children and Youth Affairs has sought to establish minimum qualification requirements in the sector in order to improve the quality of childcare provided and the sector's capacity to develop and retain a qualified workforce. It was specified that only centres with pre-school leaders qualified to NFQ Level 5 (or equivalent) in early childhood care and education were able to receive payments for eligible children, with the result that providers had a strong incentive to send staff for training. In addition, a higher capitation fee was made payable where pre-school leaders were qualified to NFQ Level 7 (a bachelor degree in childhood/early education) and where pre-school assistants were qualified to Level 5. Likewise, Fáilte Ireland - the National Tourism Development Authority - pays close attention to career pathways within the hotel, catering and tourism industry but the bulk of training is now carried out at Level 6 on the NFQ (thus not targeting the low skilled). 


\section{Joined up approaches to skills}

\section{Attracting talent and co-ordinating action on skills}

There is a strong awareness of the need to attract and retain talent across Ireland. This is a major concern, communicated strongly by state development agencies to city and county authorities, and is embraced by the latter as crucial to the economic dynamism of their areas. However, there is no national skills strategy in Ireland.

Regional authorities, state development agencies, higher education institutions, and local authorities all acknowledge the importance of "branding" their region and promoting it internationally. In both regions, stakeholders are aware that good amenities, quality public services and a well-managed environment can make all the difference to the location decisions of high skilled workers and to the companies that employ them.

The retention and attraction of creative talent is emphasised in the Economic Development Action Plan for the Dublin City Region, 2009 - developed by the four local authorities in the Dublin region - and the Regional Planning Guidelines for the Greater Dublin Area 2010-2022, which received significant input from the seven Greater Dublin Area local authorities and Forfás. As highlighted earlier, the Dublin Creative Alliance develops, manages and promotes Dublin as the city of choice for internationally mobile, high skilled workers and professionals, in which Dublin City Council is an active participant alongside business representatives and academia.

Bringing skilled workers to the South East region is also something which local stakeholders have been concentrating on, although it can be difficult to compete with the stronger draw of the capital city. The local authorities in the South East and Forfás contributed to the development of the Regional Planning Guidelines for the South East 2010-2022, drawn up by the South East Regional Authority. The region's two Institutes of Technology in Waterford and Carlow link with local authorities and business to create, attract and retain creative talent. Indeed, in the South East the Institutes of Technology have had a demonstrable impact on the region's broader economic development. As previously highlighted, the Waterford Institute of Technology (WIT) is given a unique leadership role due to the scale of its impact on the region, and the high level of expectations which stakeholders in the region have for it.

\section{Theme 3: Targeting policy to local employment sectors and investing in quality jobs}

\section{Relevance of provision to important local employment sectors and global trends and challenges}

\section{Relevance of provision associated with internationally trading enterprises}

There is a developed awareness in each region of the skills needs of internationally trading enterprises, and resolute steps are generally taken quite quickly to address skills weaknesses impeding their growth. State development agencies and local economic development stakeholders are particularly forthcoming in working together when the local supply of skills (as well as infrastructural improvements) can be leveraged to attract new inward investment or underpin a company expansion and indeed this is where the strongest collaboration and consultation typically takes place between the key players including FÁs, city and county authorities, higher education institutions, and public employment services. 


\section{Figure 3.6. Dashboard results: Targeting policy to local employment sectors} and investing in quality jobs

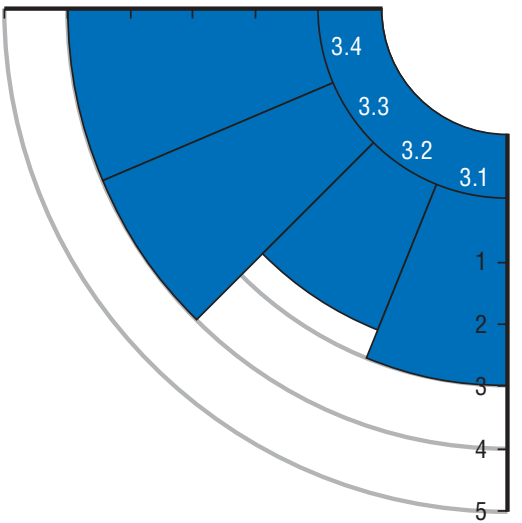

Sub-criteria

3.1. Relevance of provision to important local employment sectors and global trends and challenges

3.2. Work with employers on skills utilisation and productivity

3.3. Promotion of skills for entrepreneurship

3.4. Economic development promotes quality jobs for local people

Sectoral and thematic reports on the skills needs of internationally trading enterprises are produced by the Expert Group on Future Skills Needs in close collaboration with industry and skills providers. The EGFSN is a highly successful forum through which employers seeking high-level skills, and those producing skills at the highest levels, view the medium- and long-term together and plan accordingly. Despite its work, however, skills deficits exist and employers find that many graduates lack important workplace skills.

Immigration fills a large proportion of vacancies in some sectors (in particular, where extensive experience or languages are required) and, where necessary, the number of employment permits for high skilled workers from outside the EU/EEA is speedily increased. There is a tendency to regard international companies as offering high skill employment only and as being not always accessible to the lower skilled. The demand for mid-level skills and technicians in internationally trading enterprises has largely been met by FÁS to date, and there is concern at how quickly and effectively the Education and Training Boards will prove able to take on this role.

\section{Relevance of provision to local employment sectors}

Generally, the skills needs of companies serving the domestic market do not receive the same focus despite the fact that $57 \%$ of private sector employment in Ireland is in indigenous SMEs not engaged in exporting (Lawless, McCann and Calder, 2012). A number of domestic sectors are on a high growth trajectory, including Health Care, Education, and Energy. There is less comprehensive attention to their skills needs, and analysis of their contribution to regional competitiveness is much less frequent. For example, except for highlighting the importance of the retail sector in the local economy, The Dublin City Development Plan 2011-2017 is concerned primarily with the needs of internationallytrading businesses in its chapters on economic development. It is noteworthy, for example, that, even though a large proportion of the Dublin regional workforce is in the public sector, and wholesale and retail trade, the City of Dublin Vocational Education Committee, despite the potential of its activities for the region's workforce, is not prominent in the Creative Dublin Alliance - the principal network driving the city's economic development.

However, there are exceptions to this. In the Dublin region, two studies that appeared in 2010, Towards an Employment and Skills Strategy for the Dublin City Region and the Final 
Report of the Lord Mayor's Commission on Employment, both conducted extensive consultations with groups working at the small area level. The former report described domestic services as suffering from a poor economic image and too often regarded as "a poor relation to hightech sectors, manufacturing exports, and high value-added services that can be exported internationally" (WRC, 2010). It pointed out that domestic services cover a wide range of sectors - public and private, high skilled and low skilled - and underlined the importance of productivity in domestic services to regional economic dynamism.

Providers of employment services and training in both regions echoed the need for a stronger appraisal of the independent contribution of domestic sectors to local and regional economies. Much of their focus is on precisely the types of employment that arise in domestic services during cyclical upturns and in response to long-term societal trends. The trends most referred to include rising demand for social care arising from ageing, the pervasiveness of Information Technology and the rising threshold to digital literacy, growing internationalism and the premium attached to foreign language capabilities, the protection of the environment and value placed on green products and services, as well as the diversification of tourism.

Programme innovation and course development in vocational education has begun to reflect these trends. In general, most studies of opportunities in local employment sectors are carried out at the small area level by individual training centres, colleges or area-based partnerships as they track developments among local employers. These studies tend, however, to be ad-hoc and are seldom brought together at city/county or regional levels and rarely draw on comprehensive research carried out at higher levels. It is to be expected that SOLAS will strengthen the preparation of regional/local labour market profiles and extend their use to inform planning and provision by the new Education and Training Boards.

\section{Work with employers on skills utilisation and productivity}

\section{Skills utilisation and productivity}

Skills utilisation approaches look at how the workforce is structured and the relationship between an individual's skills and the needs of business. Skills utilisation approaches focus on how well employers are utilising the skills of their employees, which can improve productivity and profitability. Individuals also gain from the better utilisation of their skills through greater job satisfaction and autonomy. This approach avoids supplyside or "provider driven" training solutions, which may not address the breadth of an enterprise's organisational context. Instead, providers are encouraged to take on a workforce development role (Froy, Giguère and Meghnagi, 2012).

There is currently little focus within Ireland on skills utilisation approaches. Activities in the two case study areas are generally initiated and led by the private sector, although there is evidence of collaboration in certain sectoral networks with universities and Institutes of Technology on research and development, as well as by state development agencies. Former agencies with specific mandates to look at these issues have not survived, but a variety of bodies and programmes continue to address some of the issues involved including Enterprise Ireland, IBEC, the Irish Management Institute, and Skillnets Finuas programme.

As highlighted earlier, there has been a policy shift away from training those in employment to training for the long-term unemployed by FÁs, and subsidised training for workers occurs only on a small scale and in quite specific circumstances. A former public 
advisory body with a specific remit to address skills utilisation and work organisation in the public and private sectors - the National Centre for Partnership and Performance - has not survived. ${ }^{5}$ Public policy has been used in certain cases in Ireland to leverage up-skilling of the workforce. This was particularly pertinent in the manner in which a free pre-school year was introduced in 2012. As discussed earlier, only centres with pre-school leaders qualified to NFQ Level 5 (or equivalent) in early childhood care and education were able to receive payments for eligible children. This created a strong incentive for providers to send staff for training. As well, a higher capitation fee was available where pre-school leaders were qualified to NFQ Level 7 (a bachelor degree in childhood/early education) and where pre-school assistants were qualified to Level 5. Other notable examples of effective work in the public sector to raise the demand for skills include the SKILLVEC programme, in which Vocational Education Committees work with health services executives to up-skill their least qualified employees. Fáilte Ireland conducts workshops and short training days for the hotel, catering and accommodation industry. The Irish Agriculture and Food Development Authority (Teagasc) provides training to farmers and the food industry.

Educational institutes also play a role in optimising productivity mainly via research activities and leadership. The Dublin region's three universities and four Institutes of Technology have each developed a suite of research capabilities that includes links with local multinational employers. In addition, each works with Enterprise Ireland to generate new small enterprises on the basis of campus research - High Performance Start Ups.

Private employers and representative groups generally lead most of the work to identify and disseminate best practices in work organisation and productivity. There is a reluctance in the public sector to "lecture" the private sector about its business models and human resource management, and the general perception is that the private sector has more expertise in these areas. The main employers' representative body, IBEC, for example, has a number of sectoral networks (e.g. for the food and drink industry, financial services, ICT, pharmaceuticals and chemicals) and provides practical advice on best practices in the thematic areas of building employee capabilities, measuring and managing human capital, and optimising the use of human resources more generally.

It was repeatedly voiced by local stakeholders that creating a stronger policy focus on skills utilisation and productivity will, with the disbandment of the existing workforce development agency, depend on the priority SOLAS accords workforce development and on how well it and the Education and Training Boards in each region harness and apply local labour market intelligence. Employer bodies and enterprise agencies have called for SOLAS to be given a strong mandate for promoting in-work skills development of the existing workforce in the interests of up-skilling and utilising skills more effectively to raise productivity.

\section{Promotion of skills for entrepreneurship}

In Ireland, a strong emphasis has been placed on promoting skills for entrepreneurship. Modules and courses fostering entrepreneurship in training programmes and educational institutions are quite widespread (e.g. in university courses, FÁS training and VEC provision, and in voluntary initiatives undertaken by the private sector). There are a number of changes underway in the area of micro-enterprise supports locally as part of the broader local government reform process. Under the Action Plan for Jobs, Local Enterprise Offices will be set up in each local authority, replacing City/County Enterprise Boards and Business Support Units. 
A number of those interviewed for this study reported an element of "reluctant entrepreneurship" in Ireland as people pursued entrepreneurship due to the lack of other available employment options. Indeed, some claim that the entrepreneurial spirit in Ireland is subdued, citing the low percentage of people who aspire to be entrepreneurs. Difficulties in accessing finance, lack of knowledge of financial and legal issues, lack of confidence, and harsh bankruptcy laws have also been cited as hampering Ireland's entrepreneurial spirit (OECD, 2011a). Employers also expressed deep concern that the Irish education system fosters attitudes and aptitudes inimical to entrepreneurship (e.g. by emphasising rote learning, academic values and individual study) and spoke of a widespread cultural esteem for the professions, which has influenced parental choices for their children's education away from becoming self-starters.

\section{Entrepreneurship support in public employment programmes}

Comprehensive approaches are taken to encourage entrepreneurship via specifically designed employment programmes. Dating from the late 1980s, there has consistently been a programme for encouraging unemployed people to explore the option of selfemployment. Currently, two main national programmes exist which are implemented locally. The Back to Work Enterprise Allowance (BTWEA) is available for the long-term unemployed. It allows participants to keep a certain proportion of their social welfare payment (100\% in the first year of being self-employed, $75 \%$ in the second year) and people are helped in developing their business plan by either Local Development Company staff or by a specialist "facilitator" in the Department of Social Protection. Access to discretionary funding to help cover selected small start-up costs is also provided. The Short-Term Enterprise Allowance (STEA) is a similar programme but for people in the first year of unemployment who are still in receipt of an insurance-based payment, and it has lower take-up numbers. The numbers participating in both programmes have risen significantly during the economic crisis. Between 2009 and 2010, for example, there was a 73\% increase in the number of BTWEA recipients. ${ }^{6}$

Local area-based partnerships in the regions play a key role in providing these supports at the local level. Local Development Companies support many long-term unemployed and socially excluded individuals to establish their own enterprise by providing access to discretionary funds administered by the Department of Social Protection (e.g. the Technical Assistance Training Scheme, the Activation and Family Support Programme), which help cover selected training and start-up costs. Local Development Companies provide a range of supports including information and advice, pre-development supports, training, small grant/loan assistance, mentoring, networking, and follow-up support. Enterprise support is a significant and increasing element of Local Development Companies' work, and the ratio of those supported into work has increased from 2007 to 2011 (Pobal, 2013b). Many Local Development Companies reported that selfemployment plans by the unemployed have improved and that more micro-enterprises appear set to be successful as a result, and put one contributing factor as the higher educational level of many of the unemployed. However, despite the formal supports in place for entrepreneurship, it is difficult to prove whether they are effective. The Department for Social Protection has no central data on the types of self-employment that are supported nor on their levels of success, although Local Development Companies do collect data on the types of self-employment supported. ${ }^{7}$ 


\section{Entrepreneurship support in training programmes and universities}

It is common practice for vocational education students to be offered entrepreneurship training and this is integrated into courses. Practically all Vocational Education Committees offer modules, and some have dedicated courses on starting your own business. In universities, the extent of entrepreneurship teaching varies according to the discipline. In some degree courses with a high prospect of self-starting (e.g. business, engineering, commerce), modules on starting your own business are added.

\section{Economic development promotes quality jobs for local people}

Different types of national employment legislation ensure job quality overall - the national minimum wage, the regulation of temporary contracts, clarification of the rights of part-time workers, and steadily advancing health and safety requirements. There are concerns that the recession has increased the incentives for employers to offer, and jobseekers to accept, jobs that are precarious and of declining quality (Mandate, 2012).

\section{Focus on skills and job quality in inward investment strategies}

The national agency with responsibility for attracting inward investment (IDA Ireland) has developed extensive expertise in marketing regions/localities to inward investors, and ensuring that they receive the information they need and have full co-operation from local employment services and training providers. Information is provided on local education and training institutes and the skills of the local labour force, as well as on infrastructure, transport, amenities and other factors that affect location choice. FÁS, city and county authorities, higher education institutions, and the local employment office are routinely consulted.

There was an appreciation in both regions of the multiple benefits of hosting internationally trading enterprises. Consideration given to the quantity of jobs on offer to local residents when making planning decisions varies, and inward investment is welcomed independent of any analysis of the breakdown of employment between current residents and those who will be attracted into the area. It is standard practice to consider the quality of jobs. There is a strong acceptance that where the investment gives rise to high-skilled employment, whether for current residents or new arrivals, significant downstream benefits will accrue to local residents.

\section{New local developments, public procurement and job creation strategies}

Up to now, there has not been a major recourse to employment clauses in large building and regeneration projects or significant success in having large numbers of local residents employed in them. The structures and operating practices of the construction industry have typically proved to be major constraints. The procurement policy of local authorities is a potentially powerful tool for improving the quality of local jobs. Generally, tendering for public contracts in Ireland requires being fully compliant with existing employment legislation and tax law and no additional requirements are typically added. There is concern about centralising public procurement decisions at the national level. This will reduce the capacity of the public sector at the local level to have influence over its supply chain and local job creation.

There are strategies that support job creation in both the public and private sectors and a broad cross-sector strategy is in place for supporting local employment growth and 
job creation, incorporating employment, skills and economic development actors - the government's Action Plan for Jobs. The Action Plan has comprehensively reviewed all areas and levels of public policy action in 2012 and 2013 and identified for each year a large number of specific actions to be taken in support of job creation. It is the government's flagship strategy for economic recovery, and outlines actions that need to be taken across the whole-of-government to achieve an ambitious target of 100000 more people in work by 2016 and 2 million people in work by 2020. Many of the actions identified are to be taken at the city and county level and, in 2012, 12 specific measures designed to develop employment initiatives at the small area level were identified.

\section{Theme 4: Being inclusive}

Figure 3.7. Dashboard results: Being inclusive

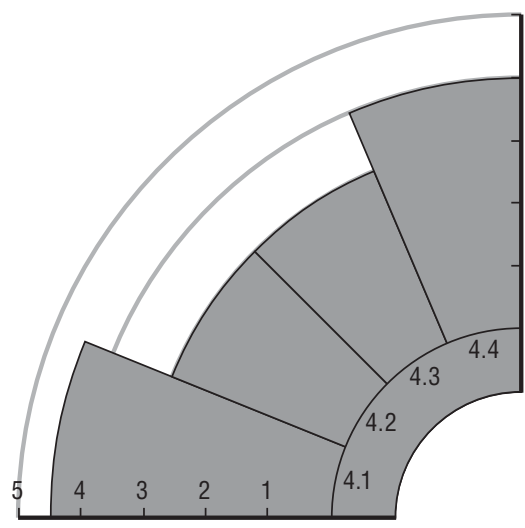

Sub-criteria

4.1. Employment and training programmes are geared to local "at-risk" groups

4.2. Childcare and family friendly

policies to support women's participation in employment

4.3. Tackling youth unemployment

4.4. Openness to immigration

\section{Employment and training programmes are geared to local "at-risk" groups}

Ireland's employment and training policies place a strong emphasis on the disadvantaged, the cohorts within which are determined at the national level. The country has a vibrant community and voluntary sector and its social inclusion and local development partnership model has been held up as international good practice (OECD, 2001). A broad range of employment and training programmes target "at risk" groups across Ireland and some progress has been made in reducing exclusion rates for these groups. Indeed, a significant response to the crisis has been a growing insistence at the national level that training providers should target the claimant unemployed (and the long-term unemployed in particular).

\section{Direct employment programmes}

The most common type of employment programme engaging with the disadvantaged is direct employment programmes. Contrasting with other OECD countries, a large proportion of active labour market programming spending is focused on direct job creation programmes. Ireland spends $0.26 \%$ of GDP on these types of active labour market programmes, compared to the OECD European average of 0.1\% (OECD, 2013e). These direct employment programmes provide work experience and skills training through job placement. They are nationally designed and administered, "drawn down" by public bodies and the community and voluntary sector at the local level. The programmes seek to simultaneously increase participants' preparedness for mainstream employment and 
produce outputs beneficial to their local community. In all regions, programme participants are overwhelmingly the long-term unemployed, lone parents, people with a disability, and the older unemployed. In recent years, there has been a greater insistence on strengthening their labour market credentials rather than community development credentials.

There are three main direct employment programmes, the largest of which by far is the Community Employment programme with an annual capacity of 22300 persons (the 2013 Budget announced funding for an additional 2000 places). Tús was introduced in 2011 and offers 5000 places. The Rural Social Scheme is the smallest with 2750 places and is a very narrowly targeted scheme - available only in rural areas and designed to provide parttime employment opportunities in the community for farmers and fishermen/women. ${ }^{8}$ Employment in all is part-time and there is a clear financial incentive to participate. ${ }^{9}$ Since 2006, Community Employment has included a specific training remit - participants are facilitated in adopting Individual Learning Plans - and a reduction in the sum available for this training element has not lessened its significance as a key enhancement of the programme. There are neither regional caps nor quotas restricting the numbers which can participate by region. There has been no analysis to date of take-up rates and outcomes by region of these main employment programmes. However, the data for doing so will be available within the Department of Social Protection in the future.

The Community Employment scheme has been the subject of most evaluations due to the high proportion of total active labour market programme spending for which it accounts (a budget of EUR 349 million in 2011, which equates to a cost of EUR 14934 per participant). Community and voluntary organisations sponsor local/community projects that satisfy two criteria - that they respond to an identified community need, and that they provide worthwhile work opportunities for participants. While places are widely distributed across the country, there are regional variations in the availability of places. The greatest concentration is in the West (with 62 places per 1000 unemployed) and lowest in the North East and Midlands (approximately 40 per 1000 ). Participants tend to be over 35 and to have low levels of education (almost 60\% of those starting in 2011 had qualifications below the Leaving Certificate). It is highly regarded at the local level for the services and opportunities provided to participants, and it reaches a relatively targeted, disadvantaged client group (DSP, 2012). However, a previous OECD study noted its limited effectiveness as a labour market programme, with many participants returning to longterm unemployment after long participation (OECD, 2011c). In the current conditions of high long-term unemployment, the capacity of the programme has been increased and attention is being focussed on the potential to steer it in a more "pro-market" direction and integrate it more into a wider activation strategy (DSP, 2012). There is also a new emphasis on increasing turnover on the scheme and the capacity of employment services to sanction individuals if they refuse to participate.

\section{Training programmes}

Specific training programmes are available for local at-risk groups. Vocational Education Committees in particular oversee sometimes large networks of colleges and schools through which most people can access some sort of learning. They frequently provide courses specifically for people in receipt of social welfare in order to encourage them to return to education via two nationally-designed access routes: the Back to Education Initiative (BTEI) and the Vocational Training Opportunities Scheme (VTOS). BTEI 
covers the tuition fees and protects the social welfare income of adult learners and early school-leavers who want to combine education with family, caring or work responsibilities. VTOS does the same for unemployed adults who want to study full-time. Training providers are also significant providers of English-language courses for non-native English speakers, including advanced courses for those who want to use their professional qualifications in Ireland.

FÁS provides bridging/foundation programmes for the unemployed who need presupports before they can access more mainstream training programmes. It also channels a large part of funding to the not-for-profit sector, some of which provides outreach courses in disadvantaged areas. Specialist Training Providers, Community Training Centres and Local Training Initiatives are operated by a wide range of local community organisations for those particularly marginalised for personal, social or geographical reasons and unable to access mainstream training (see Box 3.7). 28\% of FÁS's total training budget was allocated to these types of providers in 2012 but there is a large element of "roll over" in these budgets. While there is significant training provision available, its impact on participants cannot be assessed due to lack of evaluation.

\section{Box 3.7. Training delivered by the not-for-profit sector}

FÁS channels a large part of funding to the not-for-profit sector, some of which provides outreach courses in disadvantaged areas for those particularly marginalised for personal, social or geographical reasons and unable to access mainstream training.

- Specialist Training Providers (STPs) deliver training for people with disabilities. By far the largest is Rehab, an independent not-for-profit organisation that has expanded beyond Ireland. Its activities in Ireland include the operation of a National Learning Network through which tailored vocational programmes are available in practically every county. On completion of training, supports are provided to help gain employment or progress to further education. FÁS estimates that it will provide EUR 53.7 million in 2012 (11\% of its total budget) to Specialist Training Providers for the training of 3400 persons with disabilities.

- Community Training Centres (CTCs) are independent, community-based organisations providing training for early school leavers. There are 38 of them and FÁS estimates it will provide them with EUR 41.7 million in 2012 ( $9 \%$ of its overall budget) on behalf of some 3550 young people.

- Local Training Initiatives (LTIs) are operated by a wide range of local community organisations for unemployed people particularly marginalised for personal, social or geographical reasons and unable to access mainstream training. Target clients are typically people under 35 years of age, who did not complete the secondary school cycle or who have no formal qualifications. In a given year, some 170 LTIs may be funded and FÁS estimates it will provide EUR 33.4 million (7\% of its budget) for LTIs in 2012, from which 4800 people will benefit.

\section{Creating jobs/job placements for people not ready to enter formal employment}

The public employment service is equipped with several tools to direct employer interest to disadvantaged jobseekers. In a recent move, the existing Pay Related Social Insurance exemption and Revenue Tax Assist schemes are to be replaced by a simplified 
initiative known as JobsPlus. This aims to incentivise employers to take on additional employees from the Live Register, in particular, those who are long-term unemployed, via a mechanism which is easily understood and is operated in a user-friendly manner.

In addition, employers can hire people from the claimant count as interns at no cost under a recently established scheme known as JobBridge. This is mainly targeted at young people and graduates who are out of work, and the individuals in question continue to receive their social welfare payment plus a weekly bonus. The employer benefits from the contribution of the interns and can also "vet" a future employee, while exercising a degree of corporate social responsibility. When employers recruit a person with a disability, the employment office can support them financially and with other tailored services.

\section{Outreach and area-based approaches to tackle deprived areas}

A few training programmes are delivered directly through outreach into disadvantaged communities. Local Development Companies and not-for-profit organisations are frequently contracted by FÁS and Vocational Education Committees to provide courses in locations in disadvantaged urban and rural areas. Some of the smallest colleges of further education in Dublin are almost fully specialised in providing secondchance education for adults, foundation courses, and return to learning courses by virtue of their location in or near deprived neighbourhoods. Community Education Facilitators work within VECs to give support to local community groups. Public employment services generally provide outreach services via the Local Employment Service Network.

Local Development Companies and smaller community groups are active in supporting disadvantaged individuals. The sector has been strong at identifying local services that disadvantaged individuals can access, and which they help to provide on the basis of on-going subsidisation through a national programme. There is an expectation that the new Socio-Economic Committees (SECs) will provide a new space for co-ordinating the full range of social inclusion policies and improve on the weak integration achieved by the County Development Boards.

Social enterprise involvement in employment and training activities in Ireland remains under-developed, and there are very few social enterprises which can operate on a pure business model that can generate a surplus and be a source of subsidy for other valued social activities.

\section{Childcare and family friendly policies to support women's participation in employment}

The employment rate of women increased rapidly during the years of strong economic growth. Formal childcare can absorb a high proportion of earnings by international standards. As a result, many parents look for child minders. While those who are affluent can afford private childcare and the disadvantaged can participate in funded projects in deprived areas, for the vast majority of individuals the availability and accessibility of childcare is limited. Indeed, many mothers of young children find it does not pay to return to employment because of the high cost of childcare, thereby damaging their careers. A surge in the Irish birth rate in 2010 , to by far the highest in the EU, threatens to make this situation worse.

Significant progress has been made in targeting childcare and improving its quality, and in extending childcare provision. City and County Childcare Committees were 
acknowledged during the OECD study visit as having done a good job in influencing the allocation of funds for investment in childcare. The importance of protecting budgets to support learners in accessing childcare was emphasised. A period of formal childcare is now provided free for all children in the year preceding entry to the school system (Early Childhood Care and Education Programme) and has been highly successful. Taking in the children of parents in disadvantaged circumstances attracts a subsidy to the childcare providers under the Community Childcare Subvention Programme. In addition to the contributions it makes to children's and parents' lives, its role in local job creation is important - currently, it supports some 7000 jobs (Fitzgerald, 2013). Its extension to a second year would create a further 4000 to 5000 jobs in local communities (11 additional childcare places underpin one new job). Thus, in addition to making more parents, and women in particular, available to re-enter the labour market and thereby use their skills, the programme has an "investment" character and has contributed to job-creation.

Regarding long-term care, the Revenue Commissioners allow a person in employment to offset against tax the cost they incur in employing a person to look after an incapacitated or elderly relative. There is also a Carer's Allowance which is a payment to people on low incomes who themselves look after a person who needs support because of age, physical or learning disability or illness. There is, nevertheless, little subsidised support available for general care for the elderly. Care is usually provided by state agencies rather than community-led initiatives.

Employers are encouraged to adopt family friendly policies such as job rotation, flexible maternity and paternity leave, and part-time work, and the public sector in particular has adopted a wide range of practices that allow workers to balance home commitments with their work.

\section{Tackling youth unemployment}

Significant regional and local variations in youth joblessness are evident, declining in some regions but increasing in others. The problem has also had to fight for space as a policy priority alongside larger numbers of unemployed and heavily indebted adults. "Silver linings" to this bleak picture have been a rise in school completion rates and a greater demand for higher and further education and training places as many young people seek to "sit out" the jobs crisis in the classroom. Ireland has one of the highest levels of young people not in employment, education or training (NEET) in the EU (21\%). Despite the high levels of youth joblessness, youth unemployment has been given less of priority in Ireland than in many other OECD countries. A significant contributing factor is that the absolute increase in the numbers of youth unemployed has been much smaller than that of those aged over $25 .{ }^{10}$ In addition, a large proportion of young people are not registered as unemployed as they live at home and are disqualified from receiving social welfare due to parental income. ${ }^{11}$

\section{Policies and programmes to support NEETs and early school leavers}

There are two main national programmes for early school leavers and young people who are not working, studying or training. Poor school performance and absenteeism are particularly likely among young males in urban disadvantaged areas, and their transition to employment after they have turned 18 is a major challenge for the new activation strategies of Intreo.

1. Youthreach is a programme that offers 15 to 20 year olds who have left school the opportunity of full-time education/training that is tailored to their needs. Funded by the 
Department of Education and Skills, it is provided either in centres managed by Vocational Education Committees or in FÁS-funded, independently managed Community Training Centres (CTCs). Participation is for one to two years. It is a nationwide programme and participants may progress straight to employment (a diminishing likelihood with the rise in joblessness), to mainstream training or return to school. There are 21 Vocational Education Committee Youthreach facilities and 17 CTCs in the Dublin Region, with nine Vocational Education Committee Youthreach facilities and six CTCs operating in the South East.

2. The School Completion Programme (SCP) was introduced in 2002. It supports schoolbased Local Management Committees (incorporating community, statutory and voluntary interests) to put together supports that target the needs of local young people at risk of early school leaving. The supports may be provided in school, after-school or during holiday time. There were 124 local SCP projects nationwide in 2010 and they are the responsibility of the National Education and Welfare Board.

A significant number of NEETs, however, do not benefit from national measures in the absence of a more comprehensive and systematic approach and slip through the cracks in the system. Different youth services go some way to filling these gaps and they access funds through a variety of channels to engage in actions to work with young people. The youth work model is widespread in Ireland and some NGOs working with youth have exceptional national coverage and engage young people in educational, community and recreational activities of a high standard. For example, Ireland's largest youth club, Foroige, has also set up a youth entrepreneurship programme, affiliated to the United States nonprofit Network for Teaching Entrepreneurship. It seeks to increase school completion and college attendance in low income communities, and runs an entrepreneurship curriculum in which students set up their own business (see Box 3.8). However, work in the youth sector is essentially voluntary and funding is limited.

A parallel OECD LEED review on local youth employment strategies in Ireland has found that there are no clear access routes into vocational education and training, and that many young people and their families are confused by the vocational options on offer and are getting lost in the system (OECD, 2014, forthcoming). There is no national youth employment strategy or regional/local youth employment strategies and no operational structures at the sub-national level whereby such strategies might be developed in the short-term.

\section{Policy focus on higher skilled youth}

There are unprecedented numbers of third level graduates on the Live Register - by the end of 2012, they accounted for $16 \%$ of the long-term unemployed (CSO, online database). This has prompted several new measures to help them acquire work experience, "convert" their skills or acquire new ones to meet skills deficits through "conversion courses". These include the National Internship Programme (JobBridge) and a joint government-industry ICT Action Plan. Under this, higher education providers partner with industry to provide conversion programmes for graduates to acquire ICT skills at Level 8 on the National Framework of Qualifications. Springboard courses are a more general initiative providing part-time higher education courses to address skill needs in a range of emerging sectors. 


\section{Box 3.8. Strengthening entrepreneurial skills among disadvantaged youth, NFTE}

Foróige ("development for youth" in Irish) is Ireland's largest youth organisation. First established in rural Ireland in 1952, it is now present nationwide including in disadvantaged urban settings through an extensive network of youth clubs and a diverse set of youth projects. It relies strongly on volunteers to deliver its youth programmes. More than 5000 volunteers, supported by a staff of over 300, engage in activities with around 60000 young people each year. It has perfected several youth leadership programmes of its own and adapted others from overseas.

In 2004, it affiliated to the non-profit, US-based Network for Teaching Entrepreneurship (NFTE) and introduced the latter's radical programme for awakening and strengthening entrepreneurial skills among school-going young people living in low income communities. The main objectives of NFTE Ireland are to increase school completion and attendance rates, promote self-belief and motivation, build communication skills, and develop interest in business. It aims to impact on the lives of some 8000 young people aged between 12 and 18 years. In 2012/2013, 1500 young people participated in the NFTE Programme setting up a total of 750 businesses in ten counties throughout Ireland.

An NFTE University (NFTE U), or "train the trainers" programme, has equipped 70 teachers and youth workers to deliver a 40 hour entrepreneurship curriculum either in school or out of school settings during the academic school year. Students are required to develop a business during the year, to meet local entrepreneurs and partake in wholesale and sales events. A seed capital grant is available and the students become active participants across the network with awards being made to inspire and highlight success.

Participation from the business community is encouraged through NFTE's Business Volunteer Programme, in which business volunteers from small, medium and large organisations link up with a school/youth centre and commit to mentoring young people during the year. Business volunteers get involved in a range of activities which support young people such as guest speaking, workshops, assisting with business plans, hosting site visits, and judging at business plan competitions. Almost 200 business mentors volunteered their time in 2012/2013 from organisations such as Accenture, Citi, SMBC Aviation Capital, Grant Thornton \& Associates, Bank of Ireland, AIB, Kraft Foods, IKEA, and Johnson \& Johnson.

In a new initiative, Sligo Institute of Technology will provide entrepreneurship scholarships to past NFTE participants beginning in September 2013. This is jointly funded by Sligo IT, NFTE, and Accelerating Campus Entrepreneurship. In the North Dublin area, in the academic year 2012/2013, seven schools and one Youthreach Centre participated in the NFTE programme with a total of 408 young people. The NFTE programme has had a strong impact in the Coolock area in particular. Bonnybrook Youthreach, Chanel College, and Colaiste Dhulaigh collectively ran nine NFTE classes with approximately 150 participating young people. Bonnybrook Youthreach's participant was awarded the title Youth Entrepreneur of the Year in 2011 with his woodwork business.

Source: Foróige (2013), Youth Entrepreneurship, www.foroige.ie/our-work/youth-entrepreneurship, accessed July 2013.

\section{Openness to immigration}

Generally, regions in Ireland have absorbed a large inflow of migrants over quite a short period of time (the share of Ireland's foreign-born population increased from $10 \%$ in 2002 to $17 \%$ in 2009) and with considerable success (OECD, 2010c). The bulk of this 
increased immigration has come from the central and eastern European states that joined the EU in 2004 and 2007. Non-Irish workers in Ireland are better educated than Irish workers overall $-28 \%$ had an upper secondary education as their highest attainment and $45 \%$ a third level qualification against $26 \%$ and $32 \%$ respectively in 2011 . However, this is largely due to their being younger on average (McGinnity et al., 2011). This has made labour market integration easier, but many have nonetheless faced language difficulties and had limited prior cultural contacts with Ireland. Migrants are generally employed in sectors particularly vulnerable to the recession and many have lost jobs and remain unemployed in larger numbers than Irish nationals.

\section{Recognition of qualifications, skills and competences from abroad and language training}

For recognition of qualifications acquired abroad, migrants are referred to national schemes by local staff in the public employment services and vocational education and training systems. Qualifications and Quality Ireland (QQI) offers a comprehensive online service for holders of foreign qualifications and employers. Certain foreign qualifications are listed and it provides advice regarding the comparability of the qualifications to those that can be gained in Ireland. If they are not online it can take a long time to get qualifications recognised, with individual applications having to be made to the Qualifications and Quality Ireland. The expertise and competence required to identify and assess the variety of qualifications that migrants in Ireland present is formidable, and it will be some time before the QQI will have the capacity.

Local assistance is given to recognising informal and non-professional skills/ competences acquired overseas, but this is frequently piecemeal and does not cover demand. The Recognition of Prior Learning (RPL) and its accreditation are in place - any training provider can be accredited in this - and there is increasing demand as they seek to accommodate larger proportions of mature and non-standard entry students on their programmes. EU/EEA nationals in Ireland are formally in a position to benefit from these developments in the same way as Irish nationals, but it is frequently more difficult to establish and assess their prior learning. If third country nationals are in a position to legally apply for a training programme, which will normally be at their own expense, whatever Recognition of Prior Learning arrangements are in place will apply to them.

Vocational Education Committees have been particularly active in providing ESOL and EFL courses (English for Speakers of Other Languages and English as a Foreign Language). In 2010, an estimated 11500 immigrants completed a course free of charge (subsidised by the Department of Education and Skills). The courses operate at beginner and advanced levels and some are offered in conjunction with modules that prepare immigrants to seek work in a specific occupation (e.g. ICT, media studies, and business studies). For example, the City of Dublin Vocational Education Committee provides English as a Second Language programmes at various levels in its colleges and in the community and has a central coordination team to guide provision, support teachers and tutors, develop programmes, and advise on policy. However, there is no statutory obligation to provide English language training and the Vocational Education Committees have responded to demand in the absence of a national policy. A number of concerns exist. It is thought that there is insufficiently co-ordinated and not enough provision (e.g. during the summer months when VECs close), insufficient supply of specialist teachers, inadequate contact hours for students, and that the high number of migrants are not coming forward because of 
working hours and/or the inability to pay for courses. There is significant support within the general population for the idea that no one living in Ireland should be at risk of social exclusion because of a poor command of English, and "bottom-up" initiatives have emerged, supplementing formal provision. For example, an initiative encouraging older people to volunteer time to teach conversational English to a migrant, Fáilte Isteach, ("Welcome In" in Gaelic) had 45 branches in 18 counties in 2011 and 1150 migrants a week participated.

\section{Tackling discrimination in the labour market outside of national legislation}

There are some actions in place to tackle and reduce discrimination in the public, private, and not-for-profit sectors, but these are ad hoc. Local authorities have Social Inclusion Committees which frequently collaborate with voluntary groups representing Ireland's "new communities" to monitor how immigrants are integrating and the extent to which publicly funded local services are effective in reaching them. There are several NGOs with a national reach that advocate for immigrants and their families and provide services at the local level. Ireland's public employment service, through its EURES division, has created a network (called DIALOG) of service providers bringing some key NGOs and consular/diplomatic missions together to develop a greater understanding of the issues facing migrant workers in Ireland. There is on-going work taking place to develop a greater understanding of issues facing migrant workers in Ireland in general and to develop solutions to these issues. A national research institute - the ESRI - is currently working on a detailed annual report monitoring the integration of migrants which should prove a useful resource.

\section{Notes}

1. Dublin City Council has subsequently restructured and the Economic Development Unit is now the Office of Economy and International Relations.

2. The SLMRU also makes maximum use of disaggregated data from the national Labour Force Survey, the Live Register, vacancies advertised in the national media and other sources.

3. By travel to work areas we mean the local labour market area within which people commute daily to work.

4. The National Framework of Qualifications (NFQ) was launched in 2003. All the major national awarding bodies, including the Further Education and Training Awards Council (which since November 2012 is part of the new Quality and Qualifications Ireland), reference their awards with respect to it. Many professional bodies and UK awarding bodies have their awards included in the NFQ.

5. The National Centre for Partnership \& Performance (NCPP) was established by the Irish government in 2001 to promote and facilitate partnership-led change and innovation in Ireland's workplaces. In January 2007, the NCPP was integrated into the National Economic and Social Development Office and was dissolved in April 2010.

6. In the Dublin region in 2010, nearly 8000 people availed of the BTWEA and 445 of the STEA. In the South East there were 1000 in receipt of the BTWEA and 148 of the STEA.

7. Pobal is currently conducting a research project on enterprise supports provided by the Local and Community Development Programme, to be published shortly (Pobal, 2013b).

8. A fourth programme, the Job Initiative Programme, was closed to new recruits in late 2004 and has a legacy stock of 1300 . It is not considered here.

9. The financial incentive was much reduced after the decision in Budget 2012 that participants could not continue to receive a full social welfare payment, however an incentive remains and is independent of how participants use the rest of their working week. 
10. In 2012, in each region, an additional eight to nine people aged over 25 were on the Live Register for each one unemployed young person compared to 2008.

11. Young people living at home can be disqualified from receiving social welfare when parental income is taken into account (the "benefit and privilege" rule deducts $34 \%$ of parental income).

\section{References}

DECLG (2012a), "Putting People First: Action Programme for Effective Local Government", www.environ.ie/en/PublicationsDocuments/FileDownLoad,31309,en.pdf.

Department of Jobs, Enterprise and Innovation (2012), Action Plan for Jobs.

Department of Social and Family Affairs (2006), Proposal for Supporting Lone Parents - Government Discussion Paper.

Department of Social Protection (2012), A Review of Department of Social Protection Employment Support Schemes.

Dublin City Council (2010), Dublin City Development Plan, 2011-2017.

Dublin City Council (2009), "Economic Development Action Plan for the Dublin City Region", www.dublincity.ie/Press/PressReleases/PR2009/Press_Releases_July_2009/Documents/Dublin_ Region_Economic_Action_Plan_-_Lo_Res[1].pdf.

Dublin Regional Authority (2010), "Regional Planning Guidelines for the Greater Dublin Area 2010-2022", www.dra.ie.

eCollege Learning Portal (2013), eCollege Learning Portal website, www.ecollege.ie, accessed June 2013.

Eurofound (2012), NEETs - Young People not in Employment, Education or Training: Characteristics, Costs and Policy Responses in Europe, Publications Office of the European Union, Luxembourg.

Expert Group on Future Skills Needs (EGFSN) (2007), Tomorrow's Skills: Towards a National Skills Strategy, 5th Report, www.skillsstrategy.ie/pdfs/egfsn070306_skills_strategy_report_webopt.pdf.

FÁS (2013), Service Plan for FÁS Training Provision 2013.

FÁS (2012), "Momentum programme offers 6500 training and education places for jobseekers", 18/12/12, www.fas.ie/en/About+Us/News/momentumskills.htm.

FÁS (2012), Service Plan for FÁS Training Provision 2012.

FIT (2013), FIT website, www.fit.ie, accessed July 2013.

Fitzgerald, F. (2013), “Early Years Strategy and the Economic Benefits of Early Intervention", Statement to Seanad Éireann by Frances Fitzgerald, TD, Minister for Children and Youth Affairs.

Forfás (2012), Guidelines for the Alignment of Further Education Programmes with the Skill Needs of Enterprise.

Foróige (2013), Youth Entrepreneurship website, www.foroige.ie/our-work/youth-entrepreneurship, accessed July 2013

Froy, F. and S. Giguère (2010), "Putting in Place Jobs that Last: A Guide to Rebuilding Quality Employment at Local Level", OECD Local Economic and Employment Development (LEED) Working Papers, No. 2010/13, OECD Publishing, doi: 10.1787/5km7jf7qtk9p-en.

Froy, F., S. Giguère and M. Meghnagi (2012), "Skills for Competitiveness: A Synthesis Report", OECD Local Economic and Employment Development (LEED) Working Papers, No. 2012/09, OECD Publishing. doi: 10.1787/5k98xwskmur6-en.

Giguère, S. and F. Froy (2009), "A New Framework for Labour Market Policy in a Global Economy", in Flexible Policy for More and Better Jobs, OECD Publishing, doi: 10.1787/9789264059528-3-en.

IBEC (2013), “IBEC Business Sentiment Survey Q2 2013 - Non-graduate recruitment”, Irish Business and Employers Confederation.

Institute of Guidance Counsellor (2012), Results of National Survey: Phase 1 and Phase 2, LifeCare Psychological Services, October/November 2012.

Kis, V. (2010), OECD Reviews of Vocational Education and Training: A Learning for Jobs Review of Ireland 2010, OECD Reviews of Vocational Education and Training, OECD Publishing, doi: 10.1787/9789264113848-en.

Lawless, M., F. McCann and T.M. Calder (2012), "SMEs in Ireland: Stylised facts from the real economy and credit market", Conference draft paper, Central Bank of Ireland conference, 2 March 2012. 
Lord Mayor's Office (2010), Final Report of the Lord Mayor's Commission on Employment, Mansion House, Dublin.

Mandate (2012), Decent Work? The Impact of the Recession on Low Paid Workers, a Report for Mandate Trade Union, Research: Camille Loftus; Survey: Behaviour \& Attitudes, http://issuu.com/mandate/docs/ mandate_decent_work_report_2012.

McGinnity, F. (2011), Annual Monitoring Report on Integration 2011, Economic and Social Research Institute, Dublin.

OECD (2014, forthcoming), "Delivering Local Development: Ireland", OECD Local Economic and Employment Development (LEED) Working Papers, OECD Publishing, Paris.

OECD (2014, forthcoming), "Local Youth Employment Strategies Review, Ireland”, OECD Local Economic and Employment Development (LEED) Working Papers, OECD Publishing, Paris.

OECD (2013), OECD Economic Surveys: Ireland 2013, OECD Publishing, doi: 10.1787/eco_surveys-irl-2013-en.

OECD (2011a), "Building Quality Jobs in the Recovery: Conference Proceedings: Summary and Recommendations", Dublin conference October 2011, Local Economic and Employment Development, www.oecd.org/cfe/leed/50261929.pdf.

OECD (2011b), OECD Economic Surveys: Ireland 2011, OECD Publishing, doi: 10.1787/eco_surveys-irl-2011-en.

OECD (2010), International Migration Outlook 2010, OECD Publishing, doi: 10.1787/migr_outlook-2010-en.

OECD (2008), OECD Public Management Reviews: Ireland 2008: Towards an Integrated Public Service, OECD Publishing, doi: 10.1787/9789264043268-en.

OECD (2001), Local Partnerships for Better Governance, OECD Publishing, doi: 10.1787/9789264189461-en.

Pobal (2013a), The Pobal HP Deprivation Index, Haase and Pratschke, www.pobal.ie/Pages/NewMeasures.aspx, accessed May 2013.

Pobal (2013b), “LCDP Enterprise Research Proposal”, e-mail correspondence, unpublished.

Skillnets (2011), Annual Report 2011, Dublin.

South-East Regional Authority (2010), Regional Planning Guidelines for the South-East Region 2010-2022, www.sera.ie.

WRC Social and Economic Consultants (2010), Towards an Employment and Skills Strategy for the Dublin City Region. 



\section{Chapter 4}

\section{Towards an action plan for jobs in Ireland: Recommendations and best practices}

Stimulating job creation at the local level requires integrated actions across employment, training, and economic development portfolios. Co-ordinated placebased policies can help workers find suitable jobs, while also contributing to demand by stimulating productivity. This requires flexible policy management frameworks, information, and integrated partnerships which leverage the efforts of local stakeholders. This chapter outlines the key recommendations emerging from the review of local job creation policies in Ireland. 


\section{Better aligning programmes and policies to local economic development}

Recommendation: The reform process underway should be seized as an opportunity to give local employment offices greater flexibility to adapt programmes and policies to local labour market conditions, in particular in selecting target groups and designing programmes.

With the establishment of Intreo, public employment offices will acquire a greater employment activation function, which will be important for connecting workers to jobs. This reform provides an opportunity to inject more flexibility into how national employment programmes and policies are designed and managed at the local level. There is a clear need for locally sensitive services and this could be done within a nationally articulated accountability framework, which would ensure minimum service provisions. This would enable local employment offices to more fully contribute to local economic growth and social inclusion objectives.

Research by the OECD LEED Programme has found greater local flexibility to be associated with an increase in employment rates in some OECD countries (Eberts and Giguère, 2009). Granting local flexibility in employment offices does not mean that governments need to decentralise labour market policy (Froy and Giguère, 2010). Additional flexibility can be achieved through a range of measures. These include giving local offices more input into designing policies and programmes. Allowing room for subnational goals which can be adapted locally and setting targets in negotiation with local offices can also be beneficial. Flexibility can be provided by allowing local offices to identify and prioritise special target groups within their locality for targeted activation measures and granting more flexible funding streams. For example, divisional and local Intreo offices could be allocated special funds to support locally/regionally adapted programmes targeted at specific groups. This is the case in Denmark where municipal job centres focus on national target groups but also have scope to select their own target groups. They can also receive additional funds (about 10\% of their budget) for developing initiatives to meet regional "bottleneck" areas in the labour market (see Box 4.1), an approach which could be considered in Ireland. The imminent roll-out of Socio-Economic Committees in each city and county offers a vehicle for input into this prioritisation process by other government agencies and social partners.

When considering whether to award greater flexibility, policy makers should ensure that the level of governance is right. It is important that local employment agencies are working at the level of homogenous travel to work areas or local labour markets. Larger cities, for example, often have the skills and capacities to effectively implement labour market policies and strategies, but this is not recognised within "one size fits all" management strategies taken forward by national governments, and in some countries it may make sense to establish particular flexibility in the management of labour market policies for cities. For example, in the Netherlands, it was decided to allocate greater strategic and operational responsibilities at the level of the 30 largest municipalities. 


\section{Box 4.1. Denmark - flexible labour market policy at the local level}

The Danish system for the management of labour market policy has undertaken an important transition in recent years, with responsibility being progressively awarded to municipalities, while maintaining a strong system of control from the National Labour Market Authority, facilitated by the four employment regions. Municipalities are well placed to play a significant role in combining an approach which meets both individual and community needs. They have the potential to work across policy silos and take broad community issues into account when planning employment policies and programmes. The local employment councils also ensure that the system includes a degree of local horizontal accountability, through the involvement of the local social partners.

At the same time, the role of the National Labour Market Authority and the employment regions is essential in setting targets, ensuring minimum standards are met, sharing good practice and research findings, and measuring whether the sum of local actions allows Denmark to meet national employment policy objectives. The Danish employment system achieves a balance between accountability and flexibility within the management system through a number of different instruments; legislation, financing, performance-based and dialogue-based management, IT tools, methodology requirements, and organisational requirements. The system appears to underpin both high accountability with regard to national goals and focus areas, and moderate to high local flexibility, meaning that local players and stakeholders can co-operate on targeting employment measures to local challenges and needs.

\section{Programme design and strategy setting}

In Denmark, national labour market regulations by law set down minimum measures for the municipalities, the frequency of contact, and the right of citizens to receive employability enhancement programmes. Legislation also stipulates general tools to be applied. For example, job centres are typically required to provide jobseekers with a CV/ contact interview every three months as a minimum, access to an employability enhancement programme after a certain period of unemployment, and a job plan. However, within the legal minimum requirements, municipalities and job centres can determine the content of employability enhancement schemes and develop their own measures. The municipality may structure and develop its own programmes/municipal projects for specific target groups, compose programmes based on local challenges, needs and economic situation, and decide how to plan co-operation with enterprises.

\section{Budget management}

In Denmark, all expenditures for active and passive labour market measures are guaranteed to municipalities by the national government through a block fund with no earmarking for specific policy areas. The financial management system gives each municipality considerable flexibility with regard to deciding budget levels and resource allocations, allowing municipalities to prioritise and enhance active measures according to local needs. Generally, the municipalities obtain a financial benefit every time a citizen becomes employed; spending on public benefits is reduced and tax revenues are increased. There are also a number of financial incentives for meeting timelines and putting in place active measures through a system of refunds, and good results that can generate revenue for the municipalities. 


\section{Box 4.1. Denmark - flexible labour market policy at the local level (cont.)}

\section{Target setting}

The minister for employment sets three to four national goals and targets through an annual planning process to be incorporated into local employment plans, and approved by the municipal council. These goals are designed to be the central focus of the dialogue which the four employment regions have with each municipality and to raise ambitions in the employment area. If a ministerial goal is not thought to be particularly relevant to the locality (e.g. reducing the number of non-Danes on public assistance in an area with few non-natives), it is not given much focus in the performance follow-up and dialogue with the employment region. Outside of the four principal targets, municipal job centres can locally identify and prioritise special target groups for measures and freely organise enterprise-directed measures. Decisions on prioritising target groups locally are usually a political choice, dealt with by the political committee and local employment council.

To support the job centres' work, the four Danish employment regions regularly prepare analyses of target groups for employment measures for use by the job centres, supplemented by information available on municipal/job centre databases and an online portal (jobindsats.dk). These resources can assist in identifying barriers facing target groups, options available in legislation, as well as examples of previously demonstrated successful outcomes.

\section{Performance management}

Local offices also determine which performance requirements are to be included in the employment plan, whether supplementary local targets and performance requirements are to be laid down, and the strategies to be launched. Each year, municipalities are expected to undertake a performance audit (a short status report on the results of employment measures) and prepare an income statement (a comparison between municipalities). Full transparency of local, regional, and national outcomes is offered through an internet portal which allows municipalities to benchmark their own measures and performance against clusters of comparable municipalities. All of this data is available without charge. The primary goal of the regional and local employment councils is to monitor trends in performance results and the impact of local employment measures. Using this available data, they then discuss approaches for improvements with the appropriate managers.

Source: Froy, F. et al. (2011), "Building Flexibility and Accountability Into Local Employment Services: Synthesis of OECD Studies in Belgium, Canada, Denmark and the Netherlands", OECD Local Economic and Employment Development (LEED) Working Papers, No. 2011/10, OECD Publishing, doi: 10.1787/5kg3mkv3tr21-en.

Similarly, in the United Kingdom, greater discretion and management flexibility in the implementation of employment policies was awarded to larger towns and cities participating in the 2007-11 City Strategy Initiative (Froy et al., 2011).

\section{Recommendation: Ensure that capacity is adequately supported in the new national and local bodies, including potential outsourced employment agencies.}

The creation of the two new national bodies (Intreo and SOLAS) is clearly an ambitious transformation at a difficult time for the labour market and involves amalgamating five separate agencies. This will take time, commitment, and leadership to ensure institutional memory is not lost and that adequate knowledge transfer takes place. The administration of benefit and the design and supervision of active labour market programmes in the 
public employment service are being merged in order to create a more integrated one-stop shop model. If poorly managed, staff in their new roles will not have the right skills to take on their new job function (e.g. case managers who previously processed unemployment payments may be placed in an activation function without the required knowledge of labour market and training opportunities). It is vital that sufficient staff training is undertaken to ensure local staff have the skills they need to carry out their jobs competently and provide good services to clients.

Local capacity needs to also be considered when granting additional flexibility to local employment offices. A "chicken and egg" situation often appears to exist in relation to capacities at the local level internationally. National governments fear that local capacities are low and are reluctant to offer new responsibility and hence new resources. However, without gaining responsibility and a degree of control over policy implementation, local actors often have little opportunity to build their competences (Froy and Giguère, 2010). In Ontario, Canada, a Change Management Office was set up to oversee the transfer of staff from the federal to provincial government and it helped to bridge different organisational cultures and work processes (see Box 4.2). A similar organisation could be considered for Ireland to ensure a smooth transition phase. OECD research has identified some key areas where additional capacities can be built within local public and community organisations, including creativity and problem solving skills, analytical skills, strategic skills, leadership skills, and partnership skills (Froy and Giguère, 2010).

\section{Box 4.2. Change Management Office, Ontario, Canada}

In 2005, Canada and Ontario reached a Labour Market Development Agreement which resulted in the transfer of a large number of staff (about 600 individuals), funding and programme responsibilities to the provincial government. To manage this transfer, the Ontario Ministry of Training, Colleges, and Universities established a Change Management Office. The Change Management Office ensured the successful transfer of knowledge, work processes, and programme implementation practices and also helped to bridge the different organisational cultures that existed.

The Office organised workshops and staff training sessions where current and former employees of divisions affected by the organisational change could exchange information on the job functions and develop processes for working together on issues that may arise for staff members who are new to the subject matter.

Source: OECD (2014, forthcoming), OECD Reviews on Local Job Creation - Canada, OECD Publishing, Paris.

When considering the role of private sector providers, it will be important to complement the capacity and expertise that is already in place and ensure local services are well integrated. Collaboration between all relevant stakeholders is critical for coherent policy measures which are cognisant of local contexts. When outsourcing to for-profit providers, it is critical that local employment offices are involved in setting the framework for how private agencies operate, and they can oversee how contracts are being carried out to ensure a local focus is retained. Divisional/local Intreo offices should be consulted on how outsourcing is to be carried out in order to ensure that all activation methods are adapted to local contexts. Any terms of reference should be informed by discussions at the sub-national level and local stakeholders should be given the opportunity to feed back into 
the decision making process. Setting outcome targets rather than input or output targets in outsourced contracts can be an effective way in allowing governments to retain control over results while allowing private entities to determine the best way to administer services, including experimenting with innovative approaches.

\section{Recommendation: Policy co-ordination and integration needs to be significantly strengthened between actors at all levels. This can be achieved through stronger partnerships and local platforms for collaboration.}

There is a need to build stronger mechanisms for joint working to better co-ordinate actions on skills initiatives. Co-operation between local actors in the case study areas is developing in accordance with new needs but the co-ordination mechanisms need to be strengthened, as current platforms are generally non-statutory and disproportionately dependent on individuals and the stimulus of a specific, often short-term project. In order to strengthen communication and joint working between the tripartite bodies of vocational education, employment services, and local economic development, there is a need for a forum which could bring these stakeholders together.

There are a number of opportunities within the new structures to improve policy co-ordination and integration. Firstly, the establishment of Intreo and SOLAS should improve how employment services and vocational education providers collaborate and communicate with each other. The merging of FÁS Training and Vocational Education Committees into 16 Education and Training Boards can also be expected to improve collaboration within the vocational education and training system. It will also more closely align it with public employment services through closer working between the Education and Training Boards and local Intreo offices. At the national level, the legislation establishing SOLAS requires it to develop a strong relationship with Intreo. Secondly, there is considerable potential in the local government reforms underway to strengthen voices that speak with authority for the needs of regional and local economies. The newly drawn up "super regions" could provide a greater impetus for stronger regional thinking on skills and serve as more effective co-ordination units for preparing local skills strategies for high, medium, and low skilled workers. It is critical that they are properly resourced, have the necessary capacities, and are given the authority required in order to prevent them from becoming a limited governance structure.

The Regional Spatial and Economic Strategies could be a particularly effective coordination mechanism as they better reflect functional economic areas rather than administrative boundaries. The preparation of these strategies will be the principal function of the three new regional assemblies, which will be obliged to collaborate with a broad range of stakeholders in this process. They will have a role in monitoring how the strategies are implemented and must adhere to them in their on-going functions (DECLG, 2012a). There is room to broaden the organisations involved in preparing the regional strategies and membership should be opened to a wider range of educational and skills related institutions as well as employers.

More broadly, the reforms provide local authorities with a stronger mandate to be more proactive in supporting the emergence of strategic leadership in economic development. At the local authority level, the new Socio-Economic Committees offer the prospect of improved collaboration between the key local players and, indeed, they are intended to become the prime co-ordination mechanism at this level on social issues. The new Strategic Policy Committees for economic development to be set up in all local 
authorities, and dedicated Directorates for Services to Economic Development in large urban areas, also offer the prospect of a more consistent and competent role being played by local government in identifying and working with key stakeholders.

OECD LEED research has identified a number of local governance mechanisms for strengthening partnerships and institutional collaboration, which could be considered in the Irish context. Brokers can be used to act as intermediaries to engage horizontally with a broad set of policy areas to solve problems. In Australia, the government has recently introduced Local Employment Coordinators, whose specific function is bringing together local stakeholders to develop locally based solutions to labour market challenges, including organising local job fairs to connect the unemployed with employers (see Box 4.3). The Coordinators are provided with a flexible pool of funds that can be used to support partnership initiatives. This brokerage function is critical to connect local actors, stimulate initiatives, as well as to increase effectiveness and efficiency in the use of resources.

\section{Box 4.3. Local Employment Coordinators in vulnerable areas, Australia}

Australia's Keep Australia Working strategy has made the co-ordination of employment policies at the local level a priority. One of the measures included the identification of Priority Employment Areas - areas most vulnerable to the expected downturn and future unemployment - to ensure that these areas received their appropriate share of additional funding and support. In each Priority Employment Area, Local Employment Coordinators (LECs) were appointed and advisory committees were established comprising local stakeholders from employment, vocational education and training, as well as economic development backgrounds. LECs assist in driving local responses to local labour market problem areas. The Local Employment Coordinator is an agent of the federal government and their main role is to:

- identify the needs of the area and match them with employment, education and training opportunities;

- target business and industries to identify emerging employment opportunities;

- develop and maintain a relationship with the Advisory Committee;

- identify skills and labour shortages, and structural barriers that compromise job matching; and

- identify projects or activities which may be funded through allocated federal funding - the Flexible Funding Pool - and which will deliver employment and skills development outcomes.

Another key role played by the LEC is to organise a Jobs and Skills Expo. The Expo is a "one-stop jobs and skills marketplace", bringing employers, employment service providers, labour and recruitment agencies, and registered training providers all under one roof on one day. For example, the latest Jobs and Skills Expo in Ballarat, Victoria in April 2012 was attended by about 2000 persons. It provided a good opportunity for businesses to connect with the community at large, and with jobseekers in particular, and to disseminate information about their skill needs. Job seekers got an overview of the variety of jobs and training opportunities that were available and could meet potential employers face-to-face.

Source: OECD (2014, forthcoming), OECD Reviews on Local Job Creation - Australia, OECD Publishing, Paris. 
Operational and strategic platforms can also be a way to create a more networked approach to employment policy and to bring together different actors. For example, in the aftermath of the downturn, the Dutch government established a series of work squares (werkpleinen) and mobility centres which united public employment services and municipalities to provide a one-stop-shop service. In Flanders, Belgium, tripartite consultation platforms were set up to address employment issues. They did not provide services themselves but acted as a "strategic advisor" in their work area. Oversight bodies at the sub-national level can prove useful in monitoring trends in performance results and the impact of local employment measures. In Denmark, local employment councils take on this role and statutory provisions on their establishment in municipalities mean that there is a permanent institutional framework for involving social partners and other stakeholders in employment measures (Froy et al., 2011). Finally, rewarding officials for collaboration (and specifically for the additional outcomes achieved through this) and providing additional funding to cover the costs involved can be helpful.

Another tool which is important in bringing local stakeholders together is information and evidence. Often, this can be the "glue" that enables local stakeholders to identify common issues facing their community. An example of this is the Workforce Intelligence Network in Michigan, United States, where a set of data and metrics have brought together employment services, vocational education institutes, and employers (see Box 4.4).

\section{Box 4.4. The Workforce Intelligence Network, Michigan, US}

The Workforce Intelligence Network (WIN) provides opportunities for co-ordination and innovation across partners by delivering actionable marketplace intelligence to support more efficient solutions for employers. This information helps consortium members, particularly community colleges, make better "real time" decisions regarding skill gaps. One of the tools used by WIN is a methodology to search the internet for job openings and resumés. This information, combined with data from the state's labour market information and special surveys, is incorporated in strategic plans and operational decisions. For example, SEMCA (the local Workforce Investment Board that manages employment services) has been able to act upon this information and is currently working to create a talent pool for Computerized Numerical Control and Welding. SEMCA also relies on WIN for detailed analysis of specific industries and occupations. Each year it completes a "Region Top Jobs" report, which includes the availability of current and projected opportunities by occupation, with the number of openings, and the rates of pay.

Within the advanced manufacturing sector, WIN connects with various organisations and associations and is leading important initiatives to better align the talent system with talent needs. WIN serves as project lead and fiscal agent for InnoState - a new coalition among WIN, the Detroit Regional Chamber's Connection Point, the Michigan Manufacturing Technology Center, the National Center for Manufacturing Sciences, the Business Accelerators of Southeast Michigan, and the Society of Manufacturing Engineers. Backed by funding from the Michigan Economic Development Corporation and various federal government agencies, InnoState is focused on expanding the New Product Contract Manufacturing Cluster of firms to increase their business and compete globally. WIN also convenes the skilled trades taskforce, which addresses employer talent needs through ongoing dialogue between the talent system and employers looking for skilled trades talent. 


\section{Box 4.4. The Workforce Intelligence Network, Michigan, US (cont.)}

In the area of IT, which includes some of the fastest growing firms in the region, WIN's cluster strategy includes the convening of an employer-led, multi-industry council, which has come to be known as the Tech Council of Southeast Michigan. The Council is convened to raise awareness of and shape community responses to regional talent needs. This group meets routinely and has two primary foci: talent attraction and development; and marketing and branding Southeast Michigan as a technology hub.

The Council is comprised of more than 30 employers who have a significant need for information technology talent and is open to any additional company who may be interested in participating. WIN is directly involved with company-led training initiatives like "IT in the D" and serves as a communication conduit for the region's various talent partners. WIN is also working closely with the Michigan Economic Development Corporation, the State of Michigan, business accelerators, and many others to collaborate and help drive their efforts and programmes aimed at closing the IT talent gap in Southeast Michigan.

Source: Workforce Intelligence Network (2013), win-semich.org, accessed June 2013.

\section{Recommendation: Increase the availability of data at the sub-national level and use it more effectively in policy making, planning, and evaluation to build a stronger evaluation culture.}

In order to build a strategic approach that is relevant to local conditions, it is essential to have a strong evidence base. Authoritative and updated skills profiles of local labour markets are important in framing providers' strategies and strengthening accountability and can also galvanise local actors into a common agenda for action when used well. While the collation of data at the sub-national level has improved in Ireland, there is a need to improve its interpretation and use in policy-making and programme planning. There should be a greater focus on evaluating policies and programmes, and feeding findings from robust evaluations into the policy development cycle so that activities and their impacts can be continuously improved. The quality and use of data for evaluation purposes is poor and relatively few courses, programmes and providers can demonstrate where they take their learners/participants. Developing longitudinal tracking of individuals after course or programme completion was raised by participants during project meetings as a priority. This is not easy to achieve however, with few OECD countries having a successful tracking system in place, and could be set as a longer tem goal. Collecting good quality data and using this effectively when designing, implementing and evaluating policies is a critical first step.

Increasing the resources of the Skills and Labour Market Research Unit, which prepares all the major national publications on skills supply and demand, could be a way to enable it to provide more tailored services for local economies. Pobal is developing the Irish Reporting and Information System for the local development sector in this regard but there is still work to be done to improve its core indicators and to advance from recording activities to identify outcomes. In the case of direct employment programmes, there is a need for greater monitoring and evaluation of their impact locally. Currently, there is no analysis of whether they are used more intensively and/or with more success in some regions than in others but for the first time, however, a single department (the Department of Social Protection) is in a position to acquire the necessary data for such an analysis. 
The lack of a clear fit between the administrative boundaries of various public services (e.g. the Department of Social Protection, Education and Training Boards, and local authorities), which often does not match with the travel to work areas, has made data collection and analysis more challenging. Data analysis at the level of the new regional assemblies, particularly under the regional economic strategies, might go some way towards alleviating the disjointed data gathering, aligning it with broader travel to work areas. The Socio-Economic Committees could provide a forum in which local stakeholders can share data and use it to inform the drawing up of County/City Local and Community Plans, thereby ensuring horizontal accountability.

\section{Adding value through skills}

Recommendation: Increase the engagement of employers in employment and training services through stronger partnerships and by giving them greater input into the design and delivery of programmes, including potential new apprenticeship and traineeship models.

In regards to public employment services, Intreo's new employer engagement strategy, along with its growing participation in local job fairs, will be a critical element of the new employment services' success. There is a need for the public employment services to become more pro-active in their engagement with employers and for this to occur locally. In Australia, employment service providers often have "reverse marketers" who actively market job seekers to potential employers where vacancies have not been advertised. This can stimulate demand by anticipating employers' hiring needs before a vacancy is created (see Box 4.5). Some imaginative ways are being piloted to speed up innovation and implementation by providers in Ireland - the new approach to funding adopted for the MOMENTUM Fund (and its predecessor, the Labour Market Activation Fund) suggests that the need for greater employer contribution to employment programmes has been recognised and built into programming.

\section{Box 4.5. Reverse Marketers to stimulate demand, Australia}

The term reverse marketing has been in use for some time to describe a marketer who helps consumers to achieve their goals without trying to sell them anything. It works by making the consumer come to you, not you to them. The term, reverse marketing, is now commonly used in the Australian employment services industry. It refers to the practice of providers actively marketing job seekers to potential employers where vacancies have not been advertised, and referring and placing job seekers into those jobs. Reverse marketing provides a mechanism to stimulate demand for labour by pre-empting employers' labour needs before they create a vacancy. Effective reverse marketing can play an important role in the wider employment services framework by providing job ready job seekers with access to vacancies that may not otherwise exist.

In Australia, reverse marketers target specific employers with whom the job seeker is likely to be able to find sustainable employment. This means understanding the skills, attributes and desire of the job seeker to work in a specific industry and matching these to local employers who are most likely to need additional labour, and having a strategy to "sell" the job seeker to these employers. It is in the best interests of both providers and job seekers that providers target their reverse marketing activities according to the needs of their local labour market.

Source: OECD (2014, forthcoming), OECD Reviews on Local Job Creation - Australia, OECD Publishing, Paris. 
Vocational education and training in Ireland is widely accessible and is generally adaptable to individual needs through the use of online learning, after-hours training, modular and part-time courses. There is also a lot of flexibility in the vocational education system to create "bottom up" training initiatives which respond to local needs. It is critical that this is maintained or strengthened in the on-going realignment of services - Education and Training Boards should be granted sufficient freedom to innovate.

Employers are asking for a more active role in designing and delivering training programmes to ensure that programmes provide the skills they need in their workforce, and this applies to SMEs in particular. Employers in the domestic sector are key contributors to regional competitiveness and dynamism but more needs to be done to respond to their hiring needs. A more responsive vocational education and training system would more fully involve employers in the design and delivery of training. This is the practice in the United States where community colleges can rapidly develop courses because they use industry representatives as trainers. Because these trainers are from industry, it also helps to ensure a good relationship with employers. In some cases, community colleges have created a separate branch of their institution from the part of the college which offers more traditional academic courses, in order to be agile to local needs, and this dual institutional structure is particularly evident in California (OECD, 2013d). Employers will be represented directly on Education and Training Boards, which is a welcome development and will assist in helping the boards to provide training providers with detailed and authoritative information on local employers' needs. It should be ensured that employers can fully contribute, and also that new Socio-Economic Committees have sufficient private sector representation.

During the study visit, the OECD team heard that employers find that one of their biggest challenges is that people are not work ready, and that young people in particular do not have sufficient work experience and employability skills. When established, SOLAS should focus on providing more education and training programmes based on the dual model of classroom-based instruction and on-the-job training which has been proven to be effective in fostering skills acquisition and promoting smooth school to work transitions (OECD, 2012). The review of the apprenticeship model is welcomed and it will be necessary for the government to look to expand apprenticeship beyond the traditional trades to service-based occupations and sectors. However, it is also important to stress that making people more prepared for the labour market and ensuring they have the right skills is not about quick fixes and needs to begin from early years education and care.

The government should also keep in mind that, in many cases, employers' needs can be short-term, therefore it is critical that other partners, such as unions and the non-profit sector, are also involved in training and that there is sufficient emphasis on equipping individuals with generic skills which will enable them to be more adaptable and resilient. Demand for generic skills is increasing in today's knowledge-based economy and it is not just those at the top of the employment ladder who need these skills. OECD research has shown that, increasingly, those involved in "routine-work" (e.g. salespeople) can bring benefits to employers by being able to solve problems and feedback information from their communication with customers (Froy and Giguère, 2010). It is important to build on good bottom up collaboration and networks that already exist. There are some good examples in Ireland of employer-led organisations which are filling skills gaps in firms, and SMEs in particular (e.g. Skillnets and FIT Ltd). Northern Ireland has recently introduced an Employer Engagement Plan which seeks to simplify its demand side advisory structure (see Box 4.6). 


\section{Box 4.6. Northern Ireland Employer Engagement Plan}

Northern Ireland has recently introduced an Employer Engagement Plan which seeks to simplify its demand side advisory structure. This entails ensuring that employers are able to articulate their skill needs to education and training providers, to input into curriculum development, standards and qualifications and to provide feedback on improvements to the delivery system. They will also advise on government spending and policy in relation to longer term skill needs.

The need for the Plan arose from the complexity of the previous arrangements which engaged employers in a number of different ways, including a local Workforce Development Forum in each major employment district across Northern Ireland. Initially, these fora, which brought together the Employment Service, employers and other local stakeholders, worked well but over time their role became confused as government engaged with employers on a number of different fronts.

The Plan, which was driven by the Minister for Employment \& Learning (DEL) supported by the Northern Ireland Adviser on Employment \& Skills, is firmly embedded in the Northern Ireland Skills Strategy, with its targets of raising the level of skills and qualifications in the Northern Ireland Workforce. Some of the key features of the plan are as follows:

- Skills Solution Service - this consists of a small team of trained "skills advisers" who work with SMEs to provide them with advice on existing skills provision and will assist in designing and brokering customised solutions for skills problems faced by employers.

- Assured Skills - this is a joint initiative between DEL and Invest Northern Ireland that works with new or existing inward investment companies to ensure that their future skills and training needs are being met.

- Employer Engagement Unit - a small specialist unit has been established within the public Employment Service to work with employers at strategic level and to support Employment Service staff to better meet the needs of employers and those seeking work.

An important underpinning element of the plan is the enhancing of management and leadership training for private sector and social economy enterprises. This enhanced provision is targeted particularly at the micro enterprises (those employing less than ten people) that make up the majority of the business base. For larger firms the plan proposes to work with companies to improve skills utilisation within the company and to recognise and accredit existing in-house training programmes. A further innovative element is the introduction of a Skills Collaboration Fund which will support employers who wish to coinvest to address critical skill shortages in their sector.

The plan sets out a number of quantified and time based targets which will be monitored and the whole plan will be evaluated at the end of the current planning period in 2015. It has been widely welcomed by employer organisations who report that the department has become more responsive to their needs since it was introduced.

Source: Department of Education and Learning Northern Ireland (DELNI) (2012), Success through Skills Transforming Futures: Employer Engagement Plan.

Recommendation: Ensure adequate career guidance and information on pathways is available for both youth and adults, informed by local labour market intelligence.

Career guidance in Ireland generally does not have a regional and local labour market emphasis and there is limited direct contact between schools and the world of work. 
Career guidance is also chiefly given to students near the end of their school years, meaning that young people do not always receive the most accurate or well informed jobs information.

Schools need to work more closely with the public employment service and vocational education system to create clearer, simpler and more recognised pathways into vocational education and training. Career pathway approaches can be used to support young people moving into more vocationally specific careers and set out how this can be done by articulating the knowledge, skills and competencies to better connect education with work in an occupation. In Ireland, there is scope to better trace career pathways into employment-intensive domestic sectors that have high-growth potential and in establishing career clusters. In the Action Plan for Jobs, the Irish Government has highlighted a number of sectors which have the potential to support job creation. This is important, as there needs to be greater recognition that higher productivity in domestic sectors, such as health and social care, retail, catering and accommodation, plays a vital role in local, regional and national job creation and that adequate training needs to be put in place to meet skill needs.

The new employment and training services must ensure that career guidance can match labour market entrants and unemployed people to lasting jobs. As part of Intreo's new integrated provision, a Personal Progression Plan (PPP) will be drawn up for each individual unemployed for longer than six months, sourcing available further education and training which reflects emerging labour market trends. It is important that the referrals contained within PPPs are informed by a quality career guidance service, with accurate and timely knowledge of local, regional, and national labour market trends. FÁS training has been developing a new career-themed approach in its course provision and curriculum design which is a welcome development.

Jobseekers and career guidance staff in Ireland would benefit from greater breadth, quality and accessibility of national and sub-national data on existing and emerging jobs available. This is done, for example, in the United States in the occupational outlook handbook maintained for the United States Department of Labour by its Bureau of Labour Statistics. Barcelona Activa, Barcelona's Local Development Agency, has also created an online service for professional guidance which allows users to identify their work interests and match their own profile with job profiles (see Box 4.7).

\section{Box 4.7. Career planning information, US and Barcelona, Spain}

\section{US Occupational Handbook}

This provides information on 341 occupational profiles covering $85 \%$ of the jobs in the US economy. It is updated every two years by economists in its Employment Projections programme. The information covers what workers in each occupation do and their working conditions; the education, training, and other qualifications typical of those who enter the occupation; pay - median and hourly earnings for the country, for individual states, and for metropolitan and nonmetropolitan areas; the employment outlook for the nation as a whole, though almost all states undertake one of their own; emerging occupations; and similar occupations to which it is linked. 


\section{Box 4.7. Career planning information, US and Barcelona, Spain (cont.)}

\section{Porta 22}

Porta 22, maintained by Barcelona's Local Development Agency - Barcelona Activa - has created an online service for professional guidance. With a bank of almost 1000 professional profile descriptions, it allows users to identify their work interests and match their own profile with job profiles. The key skills dictionary allows users to better understand the importance of key competencies in the current labour market. Providing clear, up-to-date information on local employment sectors, and the skills required to enter these sectors, means that job-seekers can assess which career paths are open to them, and it also helps to ensure greater transparency in career pathways.

Source: United States Department of Labor (2013), Occupational Outlook Handbook website, Bureau of Labor Statistics, www.bls.gov/ooh/, accessed May 2013; Clark, G., J. Huxley and D. Mountford (2010), Organising Local Economic Development: The Role of Development Agencies and Companies, Local Economic and Employment Development (LEED), OECD Publishing, doi: 10.1787/9789264083530-en.

\section{Targeting policy to local employment sectors and investing in quality jobs}

\section{Recommendation: Encourage policies targeted to better utilise skills and examine the role that the Education and Training Boards can play in this area.}

A key pillar of job quality is better utilising the skills of those already at work. This requires not only considering how skills are provided by the education and training system, but the extent to which employers develop and utilise skills in the production process. OECD research has shown that local public agencies can contribute to improving how skills are put to use by using a number of different policy instruments, such as incentives for employers to invest in new technology and the promotion of more effective forms of work organisation (Froy and Giguère, 2010). In many countries, it can be difficult for the public sector to advise business on productivity issues, as there is a "credibility" gap which needs to be filled before policy makers can successfully get involved in this area. To overcome this, it can help to work with intermediaries. In South East Lincolnshire, for example, a local university campus led the development of a new Food Industry Technical Training Partnership which has been instrumental in up-skilling local workers and raising local productivity through sharing innovation and promoting technology transfer. While the partnership provides formal training to people working within local industry, it was the informal exchange of experience and knowledge which has been most useful in encouraging employers to "raise their game" and increase their productivity (Froy and Giguère, 2010). Initiatives in Canada and Italy provide interesting examples of the role that vocational education institutes can play in this area (see Box 4.8).

In Ireland, there is a developed awareness of the importance of organisational structures and human resources policies in shaping the demand for and the utilisation of skills, but actions on this are generally led by the private sector. Ireland had been active on in-work skills upgrading and skills utilisation in the past but this focus has been lost in recent years, and subsidised training is targeted mainly at the unemployed rather than developing the skills of those in employment.

The public sector can be more pro-active in approaching small employers and advising them on how to train staff and manage human resources arrangements. This can include promoting knowledge sharing networks, and aiding incremental innovation. Public bodies 


\section{Box 4.8. Better skills utilisation in action - Canada and Italy}

\section{Skills utilisation approaches in Niagara, Ontario, Canada}

Local educational institutions in the Niagara region of Canada are actively engaged in stimulating productivity and increasing the utilisation of skills by employers. The local community college, Niagara College, for example, has a tradition of working with local firms on R\&D and innovation projects and has recently received funding from the Federal Economic Development Agency for Southern Ontario (FedDev Ontario) to increase its capacity to support the innovation goals of regional SMEs.

The research arm of the college (Niagara Research) collaborates with firms in areas that include product and process applied research; engineering design; technology development; product testing; proof of concept; piloting; and problem solving. The most recent federally funded year-long programme includes partnering with 165 SMEs to develop basic business tools within the following sectors: information and communication technology, advanced manufacturing, greenhouse/viticulture/horticulture, renewable energy, and environmental technologies. The local Brock University has also developed a newly-built Cairns Family Health and Bioscience Research Centre which includes, alongside scientific and technical research, a business incubator to encourage spin-offs and ensure that products can be taken to market.

\section{Improving skills supply and utilisation in Rivera Del Brenta, Italy}

In the Rivera del Brenta industrial district in Northern Italy, a cluster of firms in the footwear sector have collaborated to pool investment in training provision while also collectively upgrading product market strategies in order to engage in high quality international markets. The region traditionally hosted cottage-based shoe making industries which mainly employed low-skilled blue collar workers. However the area has now become a global centre for the production of high quality ladies footwear (supplying to Giorgio Armani, Louis Vuitton, Chanel, Prada, Christian Dior), through the development of an international brand by the local employers association, ACRIB.

An important role has been played in the economic development of the district by the privately-run local polytechnic, Politecnico Calzaturiero, which employs firm managers to train local workers and job seekers after hours, while also offering management training, and investing in research, innovation and technology transfer. The polytechnic therefore invests in skills supply whilst also optimising skills utilisation through new product development and improved human resource management. The fact that firms are members of ACRIB means that they are less worried about pooling training, technology and new innovations - investment in local human capital will not only improve prospects for individual firms but also for the global brand as a whole.

Source: Eddington, N. and P. Toner (2012), "Skills Formation Strategies in Queensland: A Skills Shortage?", OECD Local Economic and Employment Development (LEED) Working Papers, No. 2012/07, OECD Publishing, doi: 10.1787/ 5k9b9mjdj4xr-en; Froy, F., S. Giguère and M. Meghnagi (2012), "Skills for Competitiveness: A Synthesis Report", OECD Local Economic and Employment Development (LEED) Working Papers, No. 2012/09, OECD Publishing, doi: 10.1787/5k98xwskmur6-en.

can also encourage participation in training for both managers and workers, as better trained managers are likely to create more productive working environments for their staff. In parallel, companies need to be encouraged to make training and other skills development opportunities available to their employees. Advising on how to develop a quality-driven supply chain can also be useful to help local firms think longer term and therefore invest in increased productivity. This can include, for example, longer 
contracting periods. In addition, government contracts can require a certain level of working conditions, and a certain level of commitment to training.

The Department of Jobs, Enterprise and Innovation and the Department of Education and Skills should consider jointly how they can best work with employers on skills utilisation and productivity in an integrated manner. SOLAS could be given a mandate for promoting in-work skills development of the existing workforce in partnership with Enterprise Ireland, the Higher Education Authority and Intreo - particularly as it implements its Employer Engagement Strategy and develops stronger links with firms. The new Education and Training Boards are well placed to implement this on the ground through their training centres, in partnership with employers and the Local Enterprise Offices. State development agencies can also apply their expertise, particularly the IDA. There should be sufficient capacity building so that the existing expertise on workforce development is applied across Education and Training Boards.

Recommendation: Support professional development by putting in place career ladders for lower skilled people to make it easier to move into higher skilled positions.

There is support for professional development and establishing career ladders for low skilled workers in Ireland but it tends to be ad hoc and is generally undertaken by individual colleges and only in certain sectors. It is vital not only to get the high numbers of unemployed into work but to ensure continuous in-work training and career ladders for those with lower skills so that they can raise their skills levels, progress in work, access better jobs with better pay, and develop transferable skills. This will also reduce the chances of low skilled workers being made redundant in any future downturns. Raising the skill levels of low skilled workers can also raise overall productivity, as the productivity of the most skilled workers often depends on the skills levels of those around them. Employers should be encouraged to provide more up-skilling opportunities to their staff and target them specifically at lower-skilled workers, as it is higher skilled workers who tend to participate in these training opportunities. Employers and workers have a joint role to play in this by supporting a culture of workplace learning.

Ensuring employment progression is a key aspect of job quality. OECD research has shown that low-skilled adults are generally less likely to access training and this situation is often exacerbated for individuals who lack contact with local labour markets through long-term, and sometimes multigenerational unemployment. Many communities are faced with the need to respond to a "stagnation of participation" in education and training amongst the lower skilled. Lower-skilled people are increasingly employed on a temporary basis, with it being unusual now for such workers to gain a "career for life", and it can be difficult to see how one job may lead to another higher up within the job hierarchy. Putting in place the right policy mechanisms for employment progression can support low-skilled employees in particular to advance in a given occupation or sector.

Education and Training Boards under direction from SOLAS can play a role in promoting workforce development in domestic sectors which are more likely to employ lower-skilled workers. They should prioritise not only supporting the growth of these jobs but ensure in-work progression for individuals in them through further developing the career pathways and ladders already established. Whatever individuals' starting points, economic development should deliver quality jobs for local residents. Tracing pathways through the education and training system into such companies and their supply chains, 
ensuring they can access more of the direct and indirect employment being created and that there is mobility from entry level positions upwards within a company or sector is critical.

The city of Breda in the southern Netherlands identified retail as a sector with high concentrations of low-quality, low-income and low-productivity work. As it became more difficult to fill job vacancies and reduce labour market churn, a service unit for the sector was set up to better manage labour market transitions, train staff, and improve work organisation and productivity, as well as the sector's image as a place to work (see Box 4.9).

\section{Box 4.9. Raising job quality in the retail sector, Breda, the Netherlands}

Retail is an important part of the local economy of Breda in the south of the Netherlands. The sector has 2200 establishments in the area, and is currently relatively stable. However, in the context of population ageing it is expected that it will become more difficult to fill vacancies in the future. It is also acknowledged that more has to be done to increase the quality of employment in the sector and the productivity and competitiveness of local enterprises, particularly SMEs. Several organisations such as the national board for retail trade, the Breda retail platform, the association of enterprises, the Chamber of Commerce and Werkplein Breda (a service to help people to access jobs which combines the PES and the municipal social service department) established a service unit for the retail sector (Servicepunt Detailhandel) in 2009. The objective of this service unit is threefold:

1. Improving the inflow and outflow of workers and better managing labour market transitions within the sector: For example, by improving the match between demand for labour and supply of labour through investments in skills;

2. Training of staff: Implementing an external information and advice service on human resource management for SMEs to improve work organisation, productivity and the quality of local job opportunities; and

3. Improving the image of the sector: Organising promotional work with regard to working in the retail sector, improving customer satisfaction.

The strength of the service unit is that the approach is demand driven and based on oneon-one relationships with local retailers. If action is needed this takes place immediately through individual company visits and visits to the members of the association of retailers. Local work coaches (who place local people into work) also receive training from the national board for the retail trade.

In early 2010, a similar service point was established for the care and welfare sectors, with plans to develop one for technical professions. A consulted business representative felt that through this collaboration they have come a long way in a short period of time.

Source: Dorenbos, R. and F. Froy (2011), "Building Flexibility and Accountability Into Local Employment Services: Country Report for the Netherlands”, OECD Local Economic and Employment Development (LEED) Working Papers, No. 2011/13, OECD Publishing, doi: 10.1787/5kg3mktqnn34-en.

\section{Being inclusive}

Recommendation: Youth need to become a greater policy priority. A national youth employment strategy should be created and conditions should be put in place to support the emergence of integrated place-specific strategies for youth employment.

A strong, co-ordinated policy framework is required at the national level, bringing together key government departments: the Department of Social Protection, Department 
of Children and Youth Affairs, Department of Jobs, Enterprise and Innovation and Department of Education and Skills. This policy framework should set out the role of regions and local stakeholders in addressing youth unemployment and could be linked into the Action Plan for Jobs which is already providing significant momentum on driving forward integrated decision making by government.

The policy delivery frameworks of each department should allow for and favour policy integration at the local level to support the emergence of place-specific strategies for youth employment with a strong involvement of employers. Young people need effective pathways between education and employment, but good individual programmes and bodies remain isolated and are denied the synergies that would arise from a clear, overarching strategy and stronger local co-ordination. Joint working is needed to ensure that young people have accurate careers guidance for opportunities in the local economy, and career ladders to support employment progression. Moreover, co-ordinated responses can support better skills utilisation in the workplace, leading to higher productivity and greater opportunities for entering and progressing within firms. Putting in place integrated services can allow participants to access a number of different, follow-on programmes, thereby aiding continuous learning and development. Such an integrated approach is also required for the success of the eventual youth guarantee.

The province of Upper Austria, Austria, is an example of a region taking charge of developing its own youth employment strategy and setting its own priorities in collaboration with the main stakeholders. The province developed its own Masterplan for Youth to improve employment outcomes for young people and raise their skills levels (OECD, 2013a). Ontario, Canada, has also recently announced a new Youth Jobs Strategy (see Box 4.10). The government expects the initiative to help up to 30000 young people in the province find employment, and is part recognition of the fact that Ontario's youth have not shared in the province's recovery since the 2008 recession.

Improving employability skills is also a priority. Investment should be made in early years education as generic skills are learnt early in life and not all children benefit equally from pre-school and school-age education. What is more, a growing evidence-base correlates the provision of quality early years services with longer term benefits for children from low-income and migrant groups, those most likely to be later classified as not in employment, education or training (NEET). Ireland has already made progress on this by introducing the free pre-school year in early childhood care and education.

While overall Ireland's youth is better educated than ever before, and many young people invest in their skills when employment opportunities are not in sight, the lack of practical skills and job experience is flagged as a significant barrier by employers. The Irish apprenticeship system is the recognised vehicle through which to become a certified craftsperson but apprenticeships are limited to a relatively narrow range of designated trades and tend to have very low female participation rates. Since the recession struck, there has been a severe drop in the number of new registrants. An Apprenticeship Review Group has recently been set up with the express aim of examining the future of apprenticeship training in Ireland, looking at ways to ensure a greater focus on work-based learning and a closer alignment of the current needs of the Irish labour market.

More could be done to promote entrepreneurship as a viable career option for youth. There is evidence that young people are enthusiastic about starting businesses (including non-profit) but they face greater barriers when starting a business due to lower levels of 


\section{Box 4.10. A Youth Employment Strategy, Ontario, Canada}

In Canada, the Ontario government has recently announced a new Youth Employment Strategy in its 2013 Budget. This strategy is designed to help more young people find jobs, while also ensuring the employers can hire the skilled workers they need in today's economy. The entire strategy is supported by a total investment of CDN 295 million over two years, and is estimated to create 30000 new job opportunities. The strategy focuses on jobs, entrepreneurship and innovation for youth in Ontario and includes the following new programmes:

- Ontario Youth Employment Fund - this fund will provide hiring incentives to employers to offer young people in all regions of the province an entry point into long-term employment. Youth who participate in the programme would learn life and work skills while earning income. It would also help employers better tap into the youth talent available in the province.

- Ontario Youth Entrepreneurship Fund - supports the next generation of entrepreneurs through mentorship, start-up capital and outreach supports.

- Ontario Youth Innovation Fund - supports youth to lead and manage industrial research, development and commercialisation. It would also support young entrepreneurs at universities and colleges.

- Business-Labour Connectivity and Training Fund to bring together business, labour, educators and youth to better prepare young people to develop the skills they need to succeed.

Source: OECD (2014, forthcoming), OECD Reviews on Local Job Creation - Canada, OECD Publishing, Paris.

skills, less experience, more difficulty accessing financing, and less developed business networks. More should be done to support the acquisition of entrepreneurship skills by youth by embedding entrepreneurship teaching throughout the education system, providing information, advice, coaching and mentoring, facilitating access to financing, and offering support infrastructure for business start-up.

Recommendation: Retain a focus on targeting the most disadvantaged at the local level to prevent long-term unemployment from becoming structural and inter-generational. There is also scope to make greater use of public procurement and social enterprise models to support this.

Ireland's employment and training policies place a strong emphasis on the disadvantaged and its social inclusion and local development partnership model has been held up as international good practice, albeit a practice which emerged in the absence of strong local government (OECD, 2001). There is a wide range of programmes currently in place which work with "at risk" groups, either as national direct employment programmes or smaller scale programmes delivered directly into disadvantaged communities. Ireland's strong community collective is evident in the large number of not-for-profit organisations which receive funding to deliver training to the disadvantaged. Local Development Companies and other community groups are active in encouraging disadvantaged individuals to access support, which can generate employment. The sector has been strong at identifying local services that disadvantaged individuals can access on the basis of ongoing subsidisation through a national programme.

There is room for the national training and employment services and area partnerships to strengthen horizontal collaboration, and to identify the effectiveness of 
activation and training and best practices at the local level. The alignment of the local development sector with the local government system will have an impact and whatever the final structures may be, it is important that policy silos are reduced through horizontal governance arrangements. The knowledge, competences and networks which community and voluntary groups have built up should be fully utilised and promoted in the new institutional arrangements. The new Socio-Economic Committees to be set up in each local authority area can create additional synergies by providing a new space for co-ordinating the full range of social inclusion policies. The committees should be provided with the capacity they require to function effectively and to underpin their authority to influence decisions about funding, and should have sufficient employer engagement to ensure social policies are interlinked with broader economic development. There also needs to be strong co-ordination between new Education and Training Boards, supported and directed by SOLAS, the Intreo "one stop shops", broader economic development sectors, and the notfor-profit sector to ensure a continued focus on those who are most at risk of staying outside the labour market. It should be identified which skilling and employment measures for the disadvantaged are working well and are promoted across the networks of providers.

The use of public procurement as a means of local economic development and to promote job quality should be more fully explored nationally and locally. It is important to remember that the public sector can play an important role in helping to shape skills demand and utilisation locally, not only as a policy maker but also as a purchaser of services (Froy, Giguère and Meghnagi, 2012). National governments should ensure that the public sector at the local level has the necessary capacity to influence its local supply chain. This includes being able to require training, apprenticeship and employment opportunities for local people when putting construction, regeneration and other development activities out to tender. Public procurement can be used as a strategic tool to meet wider objectives and can ensure that more public expenditure is focused on having a positive impact. The potential to use public procurement for inclusion, as well as wider social and economic goals, is being increasingly used in Wales, UK, through their "Community Benefits" approach (see Box 4.11).

\section{Box 4.11. Using public procurement for economic, environmental and social benefits, Wales, UK}

The Welsh Assembly Government has placed a strong focus on using public procurement processes to meet economic, social and environmental goals. By embedding sustainable development into public procurement, the Welsh government has recognised the role public procurement can play not only in meeting social goals, such as reducing poverty and social exclusion, but also the way in which it can be used to build strong, more economically successful local communities. The Community Benefits approach has been used to ensure that public contracts support SMEs and the social economy's involvement in public procurement processes, tackle long-term unemployment, promote equality, provide training, and ensure work meets minimum requirements. 


\section{Box 4.11. Using public procurement for economic, environmental and social benefits, Wales, UK (cont.)}

An example of the positive impact of the Community Benefits approach can be found in the construction sector in Wales. Six (now completed) contracts worth GBP 146 million led to GBP 56 million in salaries to Welsh people and GBP 68 million spent in Welsh based businesses, some $82 \%$ of which were SMEs. Training and work experience were also provided to apprentices and disadvantaged individuals. The Welsh government has suggested that the very small fall in employment in the construction sector $(0.4 \%)$ compared to other parts of the UK (up to $15 \%$ ) is an outcome of the Community Benefits approach.

Source: Ministry of Business and Budget Wales (2010), Community Benefits: Delivering Maximum Value for the Welsh Pound, Cardiff; Ministry of Business and Budget Wales (2012), "Making Procurement Work for the Welsh Economy and Communities", Welsh Government.

In addition, there is an opportunity for a more explicit focus on, and appropriate policy supports for, social enterprises as they can stimulate economic activity which can be used for social and community gain. Social enterprise activity in employment and training activities in Ireland remains under-developed, and there are very few social enterprises which can operate on a pure business model. Social enterprises can be used more effectively by engaging them to deliver employment programmes and thereby ensuring that more money remains within the local economy. It is encouraging that the government has identified the potential for social enterprises to create more jobs in the Action Plan for Jobs.

\section{References}

Barr, J. et al. (2012), "Local Job Creation: How Employment and Training Agencies Can Help - The Labour Agency of the Autonomous Province of Trento, Italy", OECD Local Economic and Employment Development (LEED) Working Papers, No. 2012/17, OECD Publishing, doi: 10.1787/5k919d0trlf6-en.

Department of Education and Learning Northern Ireland (DELNI) (2012), Success through Skills Transforming Futures: Employer Engagement Plan.

Department of Jobs, Enterprise and Innovation (2012), Action Plan for Jobs, Dublin.

Dorenbos, R. and F. Froy (2011), "Building Flexibility and Accountability Into Local Employment Services: Country Report for the Netherlands", OECD Local Economic and Employment Development (LEED) Working Papers, No. 2011/13, OECD Publishing, doi: 10.1787/5kg3mktqnn34-en.

Eddington, N. and P. Toner (2012), "Skills Formation Strategies in Queensland: A Skills Shortage?", OECD Local Economic and Employment Development (LEED) Working Papers, No. 2012/07, OECD Publishing, doi: 10.1787/5k9b9mjdj4xr-en.

Froy, F., S. Giguère and M. Meghnagi (2012), “Skills for Competitiveness: A Synthesis Report”, OECD Local Economic and Employment Development (LEED) Working Papers, No. 2012/09, OECD Publishing, doi: 10.1787/5k98xwskmur6-en.

Froy, F. and L. Pyne (2011), "Ensuring Labour Market Success for Ethnic Minority and Immigrant Youth", OECD Local Economic and Employment Development (LEED) Working Papers, No. 2011/09, OECD Publishing, doi: 10.1787/5kg8g2l0547b-en.

Froy, F., et al. (2011), "Building Flexibility and Accountability Into Local Employment Services: Synthesis of OECD Studies in Belgium, Canada, Denmark and the Netherlands", OECD Local Economic and Employment Development (LEED) Working Papers, No. 2011/10, OECD Publishing, doi: $10.1787 / 5 \mathrm{~kg} 3 \mathrm{mku} 3 \mathrm{tr} 21-\mathrm{en}$. 
Froy, F. and S. Giguère (2010), "Putting in Place Jobs that Last: A Guide to Rebuilding Quality Employment at Local Level”, OECD Local Economic and Employment Development (LEED) Working Papers, No. 2010/13, OECD Publishing, doi: 10.1787/5km7jf7qtk9p-en.

Froy, F., S. Giguère and A. Hofer (eds.) (2009), “Designing Local Skills Strategies”, Local Economic and Employment Development (LEED), OECD Publishing, doi: 10.1787/9789264066649-en.

Giguère, S. and R. Eberts (2009), "Effects of Decentralisation and Flexibility of Active Labour Market Policy on Country-Level Employment Rates", in Flexible Policy for More and Better Jobs, OECD Publishing, doi: 10.1787/9789264059528-5-en.

Giguère, S. (ed.) (2008), "More Than Just Jobs: Workforce Development in a Skills-Based Economy”, Local Economic and Employment Development (LEED), OECD Publishing, doi: 10.1787/9789264043282-en.

Hamilton, V. (2012), “Career Pathway and Cluster Skill Development: Promising Models from the United States”, OECD Local Economic and Employment Development (LEED) Working Papers, No. 2012/14, OECD Publishing, doi: 10.1787/5k94g1s6f7td-en.

Ministry of Business and Budget Wales (2010), Community Benefits: Delivering Maximum Value for the Welsh Pound, Cardiff.

Ministry of Business and Budget Wales (2012), "Making Procurement Work for the Welsh Economy and Communities", Welsh Government.

Mploy (2011), "Building Flexibility and Accountability Into Local Employment Services: Country Report for Denmark", OECD Local Economic and Employment Development (LEED) Working Papers, No. 2011/12, OECD Publishing, doi: 10.1787/5kg3mktsn4tf-en.

OECD (2014, forthcoming), OECD Reviews on Local Job Creation - Australia, OECD Publishing, Paris.

OECD (2014, forthcoming), OECD Reviews on Local Job Creation - Canada, OECD Publishing, Paris.

OECD (2014, forthcoming), OECD Reviews on Local Job Creation - United States, OECD Publishing, Paris.

OECD (2014, forthcoming), “Local Youth Employment Strategies Review, Ireland”, OECD Local Economic and Employment Development (LEED) Working Papers, OECD Publishing, Paris.

OECD (2012), OECD Note on “Quality Apprenticeships”, G20 Task Force on Employment, 26 September 2012, www.oecd.org/els/emp/OECD\%20Apprenticeship\%20Note\%2026\%20Sept.pdf.

OECD (2011), Doing Better for Families, OECD Publishing, doi: 10.1787/9789264098732-en.

OECD (2001), Local Partnerships for Better Governance, OECD Publishing, doi: 10.1787/9789264189461-en.

Scarpetta, S., A. Sonnet and T. Manfredi (2010), "Rising Youth Unemployment During The Crisis: How to Prevent Negative Long-term Consequences on a Generation?", OECD Social, Employment and Migration Working Papers, No. 106, OECD Publishing, doi: 10.1787/5kmh79zb2mmv-en.

United States Department of Labor (2013), Occupational Outlook Handbook website, Bureau of Labor Statistics, www.bls.gov/ooh/, accessed May 2013.

Workforce Intelligence Network (2013), win-semich.org, accessed June 2013. 


\section{ANNEX A \\ Information on interviews and roundtables in Ireland}

\section{Interviews and roundtables held for the Local Job Creation project, Ireland Interviews}

A series of face-to-face interviews were carried out by the national expert in order to gather information for this report. These interviews took place from June 2012 to September 2012. All interviews, which were strictly confidential, covered the four main thematic areas of the report and were guided by the questions contained within the methodology. The national expert met with:

- Department of Education and Skills

- Department of Environment, Communities and Local Government

- Department of Social Protection

- Dublin City Council

- FÁS: Dublin, South East Region, Head Office

- Fastrack to IT (FIT Ltd.)

- Forfás

- Irish Business and Employers Confederation (IBEC)

- Irish National Organisation of the Unemployed (INOU)

- Intreo

- Pobal

- Skillnets Ltd.

- VECs: City of Dublin, City of Waterford, County Waterford

- Waterford Institute of Technology

Many other organisations and individuals made valued inputs in telephone conversations and through e-mail.

\section{Programme of OECD Secretariat visits and roundtables}

Visits to Ireland by the OECD Secretariat took place in June and September 2012, and were co-ordinated and hosted by Pobal. In addition, three roundtable meetings were held in December 2012, with one in each of the case study areas and a national roundtable. Staff from the OECD Secretariat were joined by a number of international consultants (acting as independent agents). See below for the participating bodies in each: 
Wednesday 5 December, South East region roundtable, Waterford

- Chamber of Commerce, South East

- Department of Social Protection

- Dunhill Ecopark

- Enterprise Ireland

- FÁS

- ITs: Carlow, Waterford

- Teagasc, Carlow

- VECs: Carlow, Waterford

- Waterford Area Partnership

- Wexford Local Development

Thursday 6 December, Dublin region roundtable, Dublin

- Ballymun Whitehall Area Partnership

- Department of Environment, Communities and Local Government

- Department of Social Protection

- Dublin Chamber of Commerce

- Dublin City Council

- Dublin City University, Ryan Academy

- FÁS

- Foroige

- Irish Business and Employers Confederation (IBEC)

- Speedpak

- VECs: Dublin

Friday 7 December, National roundtable, Dublin

- County and City Manager's Association (CCMA)

- Chambers Ireland

- Congress Centres for the Unemployed

- Department of Children and Youth Affairs

- Department of Environment, Communities and Local Government

- Department of Education and Skills

- Department of Social Protection

- FÁS

- Fastrack to IT (FIT)

- FORFAS

- Irish Business and Employers Confederation (IBEC)

- Institutes of Technology Ireland

- Irish National Organisation of the Unemployed (INOU)

- Irish Rural Link 
- Irish Vocational Education Association

- National Traveller Monitoring and Advisory Committee

- Pobal

- Skillnets

- SOLAS/FÁS

- South Dublin City Council 


\section{ANNEX B}

\section{Spatial distribution of skills supply and demand in Ireland}

Figure B.1. \% of population with post-secondary education, South East region,

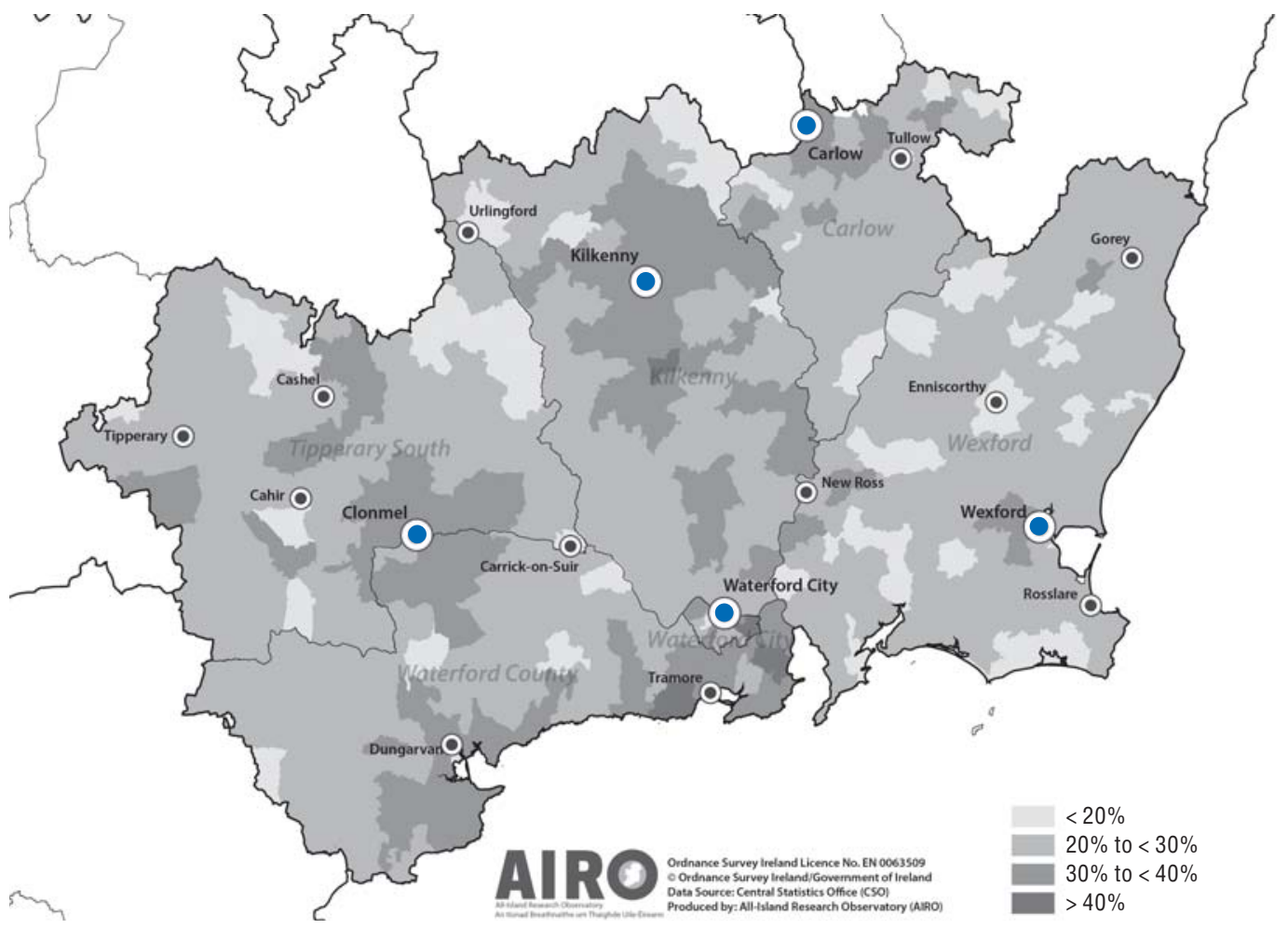

Note: Based on non-Degree and Degree level. Source: All-Island Research Observatory, 2013. 
Figure B.2. \% of population with post-secondary education, Dublin region, 2011

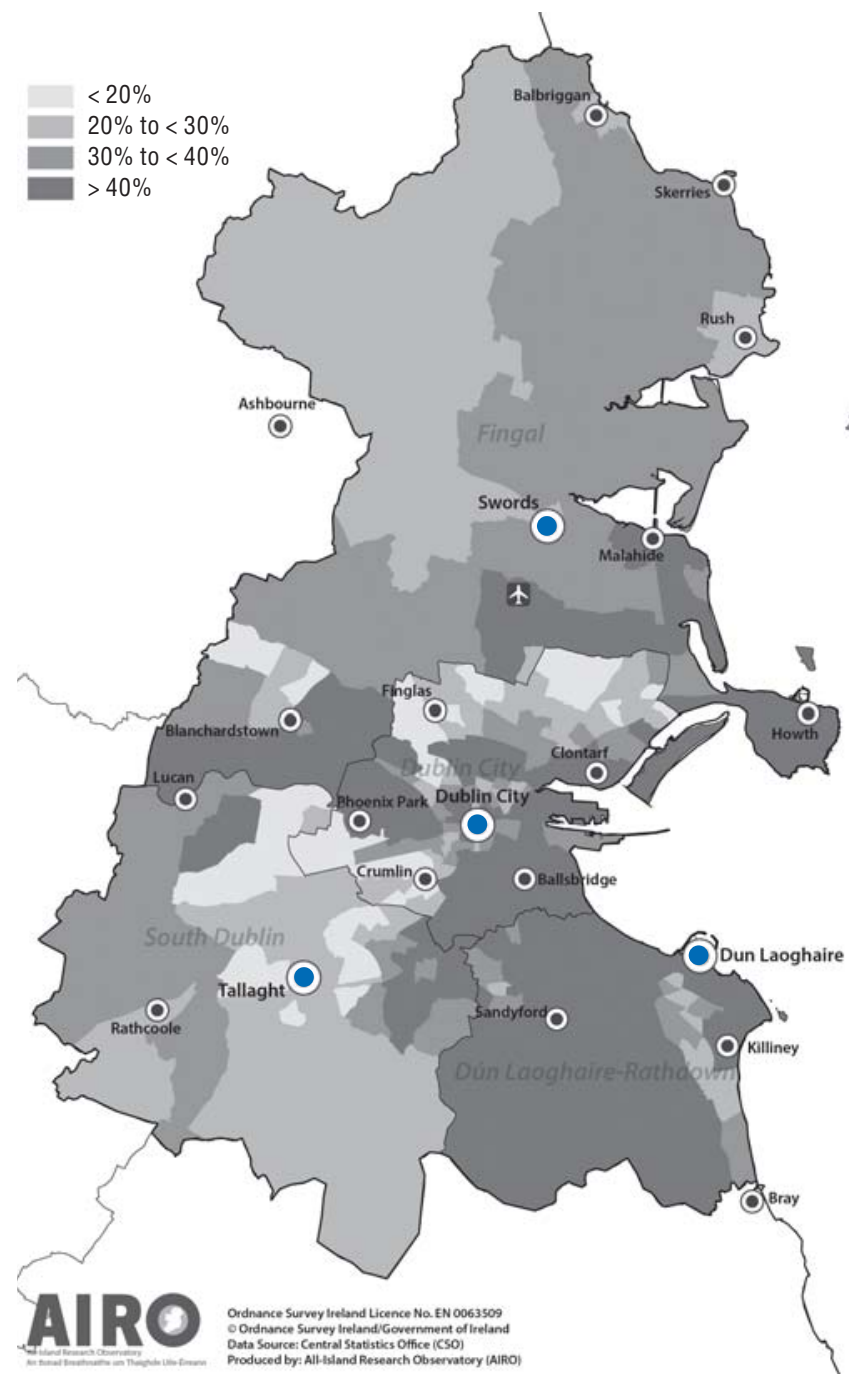

Note: Based on non-Degree and Degree level.

Source: All-Island Research Observatory, 2013. 
Figure B.3. High-medium skill occupations, South East region, 2011

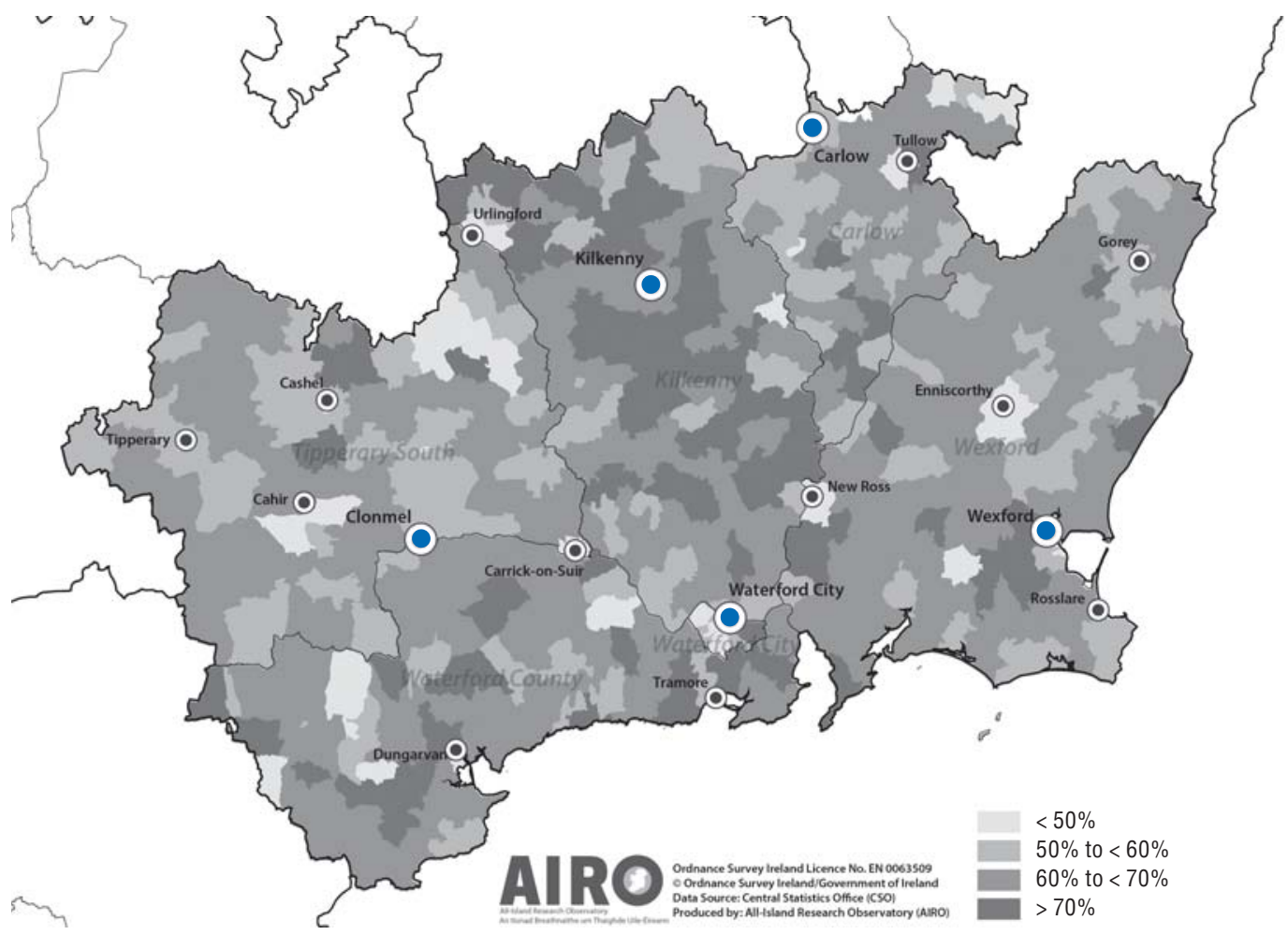

Note: This has been classified using four occupations: Managers, Directors and Senior Officials; Professional Occupations; Associate Professional and Technical Occupations; Skilled Trades Occupations.

Source: All-Island Research Observatory, 2013. 
Figure B.4. High-medium skill occupations, Dublin region, 2011

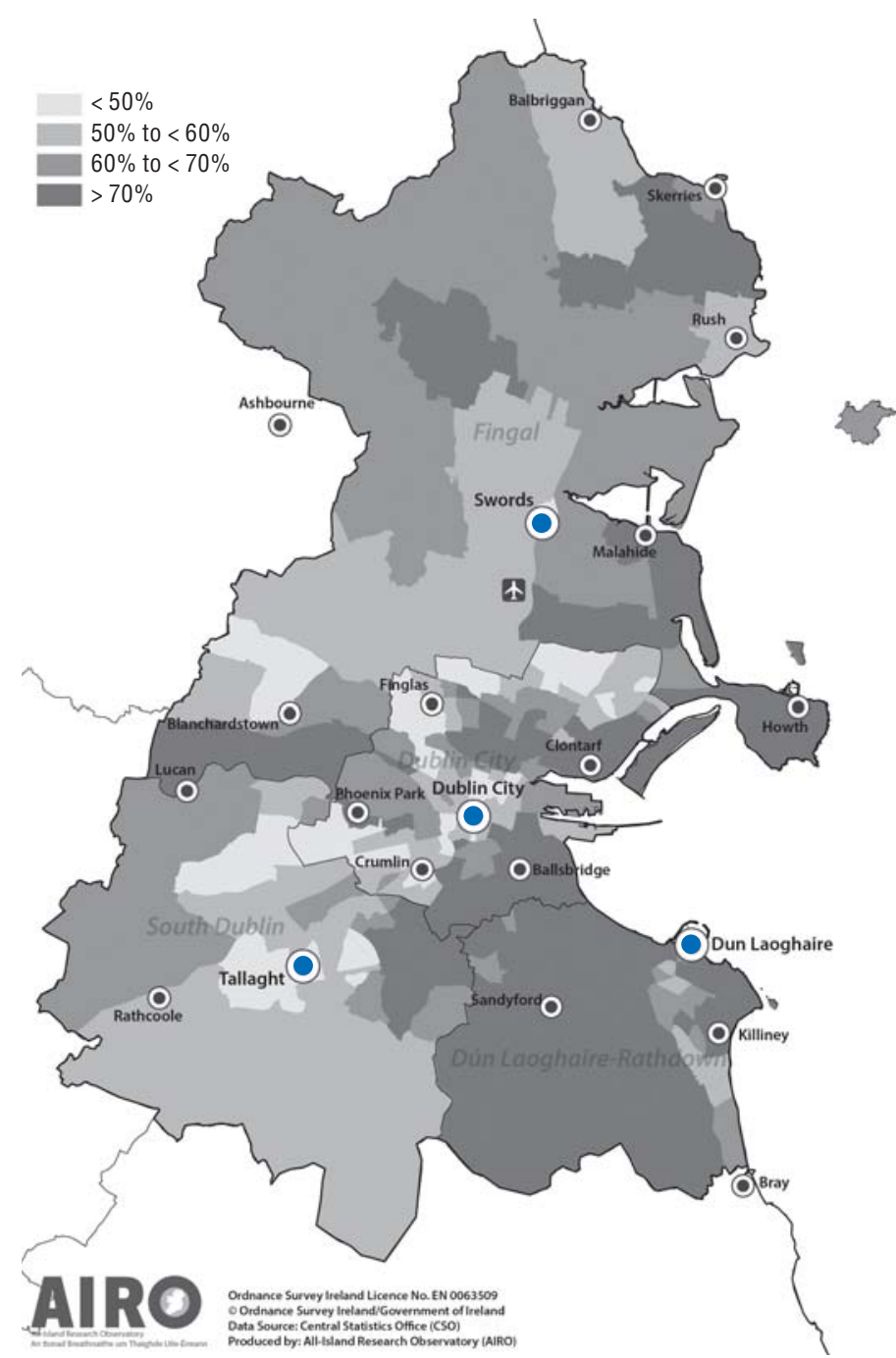

Note: This has been classified using four occupations: Managers, Directors and Senior Officials; Professional Occupations; Associate Professional and Technical Occupations; Skilled Trades Occupations. Source: All-Island Research Observatory, 2013. 


\section{ORGANISATION FOR ECONOMIC CO-OPERATION AND DEVELOPMENT}

The OECD is a unique forum where governments work together to address the economic, social and environmental challenges of globalisation. The OECD is also at the forefront of efforts to understand and to help governments respond to new developments and concerns, such as corporate governance, the information economy and the challenges of an ageing population. The Organisation provides a setting where governments can compare policy experiences, seek answers to common problems, identify good practice and work to co-ordinate domestic and international policies.

The OECD member countries are: Australia, Austria, Belgium, Canada, Chile, the Czech Republic, Denmark, Estonia, Finland, France, Germany, Greece, Hungary, Iceland, Ireland, Israel, Italy, Japan, Korea, Luxembourg, Mexico, the Netherlands, New Zealand, Norway, Poland, Portugal, the Slovak Republic, Slovenia, Spain, Sweden, Switzerland, Turkey, the United Kingdom and the United States. The European Union takes part in the work of the OECD.

OECD Publishing disseminates widely the results of the Organisation's statistics gathering and research on economic, social and environmental issues, as well as the conventions, guidelines and standards agreed by its members.

\section{LOCAL ECONOMIC AND EMPLOYMENT DEVELOPMENT (LEED)}

The OECD Programme on Local Economic and Employment Development (LEED) has advised governments and communities since 1982 on how to respond to economic change and tackle complex problems in a fast-changing world. Its mission is to contribute to the creation of more and better quality jobs through more effective policy implementation, innovative practices, stronger capacities and integrated strategies at the local level. LEED draws on a comparative analysis of experience from the five continents in fostering economic growth, employment and inclusion. For more information on the LEED Programme, please visit www.oecd.org/cfe/leed. 


\section{OECD Reviews on Local Job Creation Employment and Skills Strategies in Ireland}

The Local Job Creation series focuses on the role of employment and training agencies in contributing to job creation and productivity. It explores how OECD countries are implementing labour market and skills policy and putting measures in place at the local level to stimulate quality employment, inclusion and growth.

\section{Contents}

Executive summary

Reader's guide

Chapter 1. Policy context for employment and skills in Ireland

Chapter 2. Overview of the Irish case study areas

Chapter 3. Local job creation dashboard findings in Ireland

Chapter 4. Towards an action plan for jobs in Ireland: Recommendations and best practices

Annex $A$. Information on interviews and roundtables in Ireland

Annex B. Spatial distribution of skills supply and demand in Ireland

Consult this publication on line at $h t t p: / / d x . d o i . o r g / 10.1787 / 9789264207912-e n$.

This work is published on the OECD iLibrary, which gathers all OECD books, periodicals and statistical databases. Visit www.oecd-ilibrary.org for more information. 